\title{
A Study Of Vertical Gas Jets in a Bubbling FLUIDIZED BED
}

WORK PERFORMED UNDER AGREEMENT

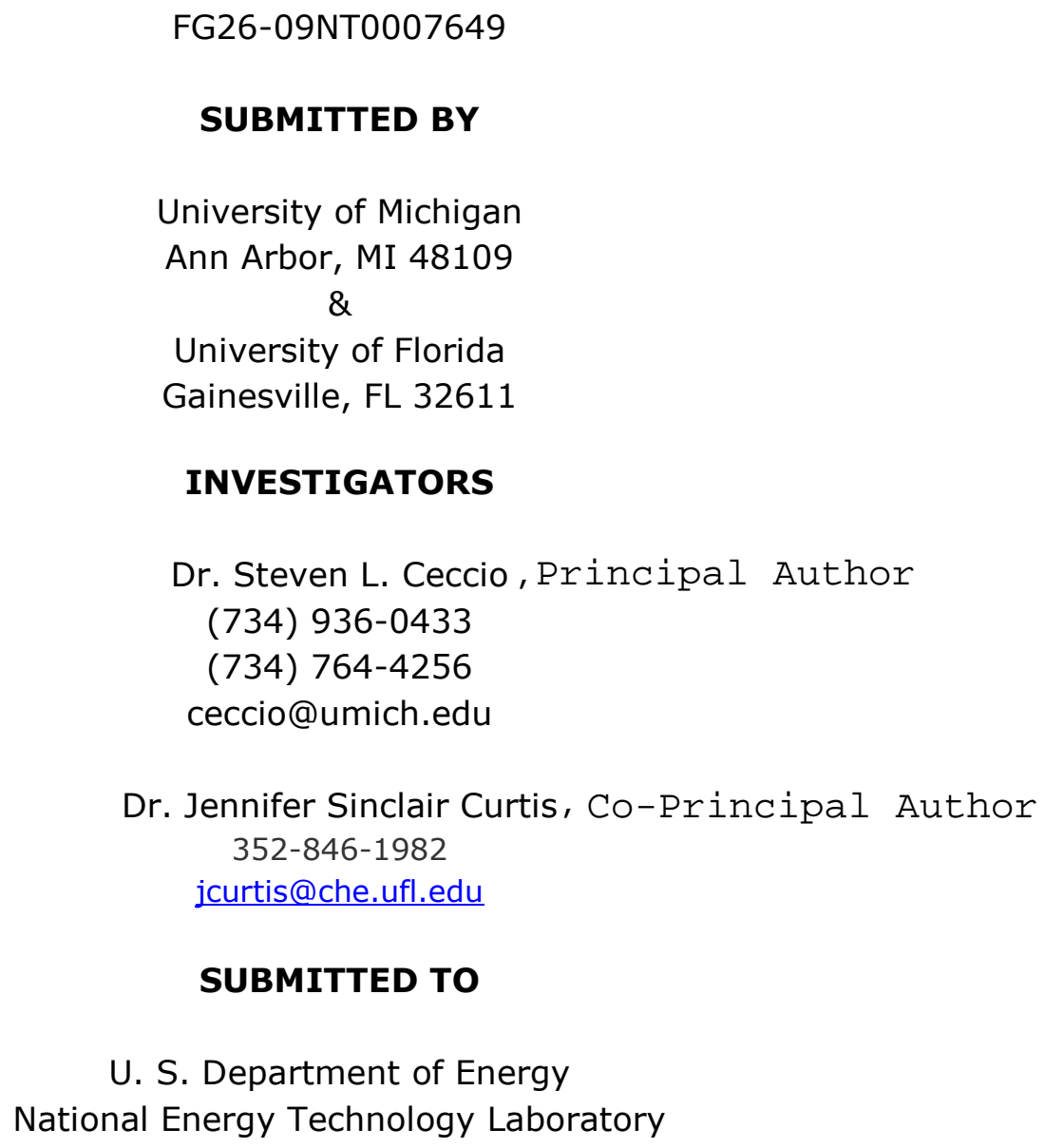

Final Report: 1/19/2009 - 1/18/2011 


\section{ABSTRACT}

A detailed experimental study of a vertical gas jet impinging a fluidized bed of particles has been conducted with the help of Laser Doppler Velocimetry measurements. Mean and fluctuating velocity profiles of the two phases have been presented and analyzed for different fluidization states of the emulsion. The results of this work would be greatly helpful in understanding the complex two-phase mixing phenomenon that occurs in bubbling beds, such as in coal and biomass gasification, and also in building more fundamental gas-solid Eulerian/Lagrangian models which can be incorporated into existing CFD codes.

Relevant simulations to supplement the experimental findings have also been conducted using the Department of Energy's open source code MFIX. The goal of these simulations was twofold. One was to check the two-dimensional nature of the experimental results. The other was an attempt to improve the existing dense phase Eulerian framework through validation with the experimental results. In particular the sensitivity of existing frictional models in predicting the flow was investigated. The simulation results provide insight on wall-bounded turbulent jets and the effect frictional models have on gas-solid bubbling flows.

Additionally, some empirical minimum fluidization correlations were validated for non-spherical particles with the idea of extending the present study to non-spherical particles which are more common in industries.

Disclaimer: "This report was prepared as an account of work
sponsored by an agency of the United States Government. Neither
the United States Government nor any agency thereof, nor any of
their employees, makes any warranty, express or implied, or
assumes any legal liability or responsibility for the accuracy,
completeness, or usefulness of any information, apparatus,
product, or process disclosed, or represents that its use would
not infringe privately owned rights. Reference herein to any
specific commercial product, process, or service by trade name,
trademark, manufacturer, or otherwise does not necessarily
constitute or imply its endorsement, recommendation, or favoring
by the United states Government or any
agency thereof. The views and opinions of authors expressed
herein do not necessarily state or reflect those of the United
States Government or any agency thereof."




\section{Table of Contents}

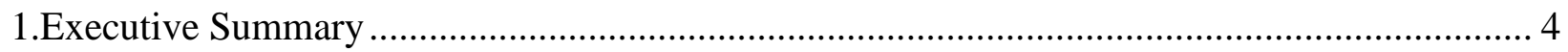

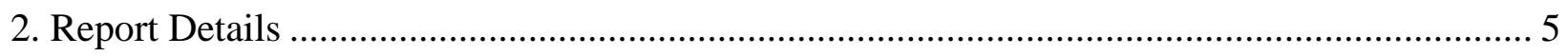

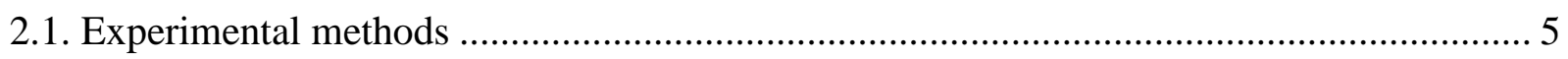

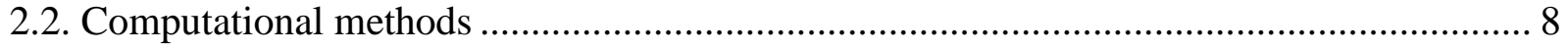

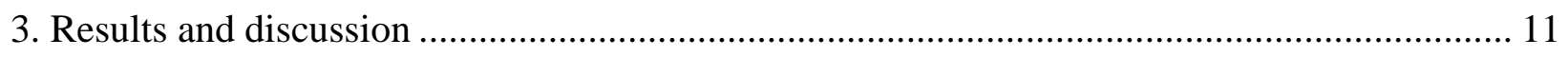

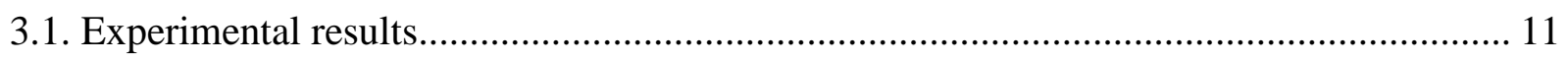

3.1.1. Empty bed mean velocity profiles and analysis.......................................................... 11

3.1.2. Bubbling bed mean velocity profiles and analysis .................................................... 14

3.1.3. Effect of fluidization on mean dynamics and analysis ............................................. 22

3.1.4. Effect of fluidization on fluctuating velocities and analysis ...................................... 30

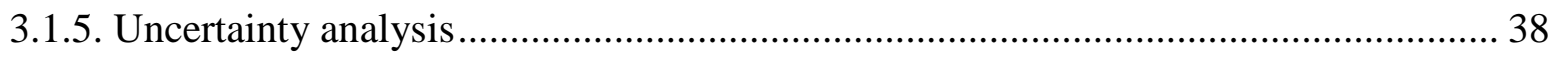

3.1.6. Validating non-spherical minimum fluidization correlations ...................................... 43

3.2. Computational results ………………......................................................................... 45

3.2.1. CFD study on spanwise confinement ..................................................................... 45

3.2.2. CFD study on the sensitivity of frictional models in predicting minimum fluidization

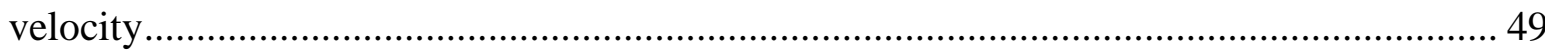

3.2.3. CFD study on the sensitivity of frictional models in predicting flow caused by jet

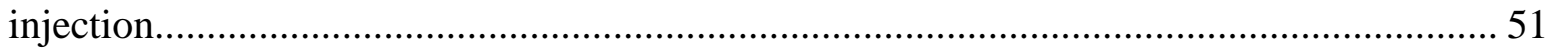

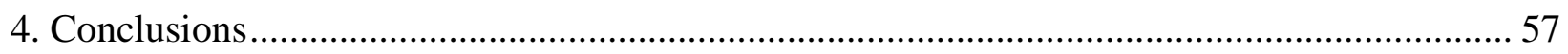

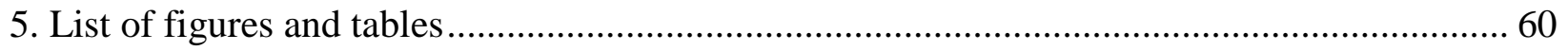

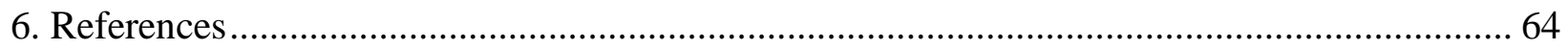

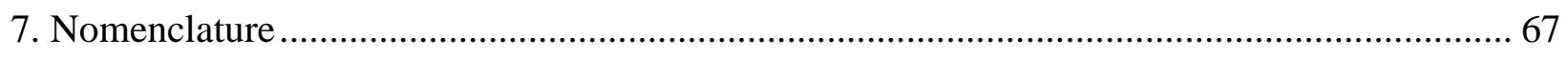

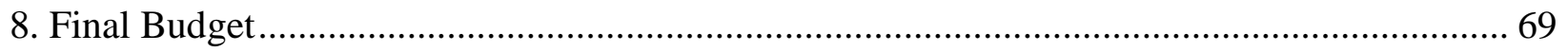

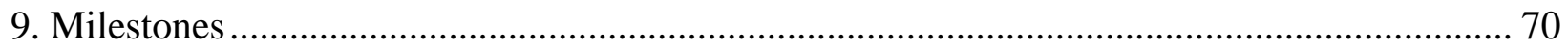

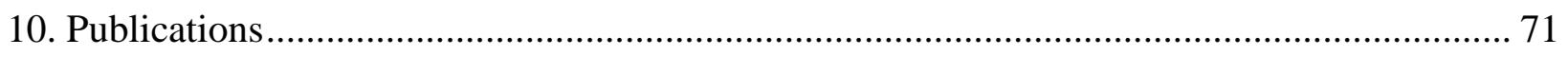

11. Acknowledgement and Disclaimer...................71 


\section{Executive Summary}

The work done in the eight quarters are summarized below.

\begin{tabular}{|c|c|}
\hline Quarter & Work highlight \\
\hline 1 & Eliminated spurious peaks which contaminate the LDV signals \\
\hline 2 & $\begin{array}{l}\text { - Developed a robust LDV measurement technique: ice crystals as tracer } \\
\text { particles, intensity subranging to separate gas and particle signals } \\
\text { - Got familiar with MFIX code and capabilities }\end{array}$ \\
\hline 3 & $\begin{array}{l}\text { Measured gas and particle mean velocities in a bubbling bed using the robust } \\
\text { technique developed in the previous quarter }\end{array}$ \\
\hline 4 & $\begin{array}{l}\text { - Analyzed velocity profiles by checking for self-similar behavior } \\
\text { - Validated the gas-solid equations in MFIX with experimental data from a } \\
\text { bubble injection experiment performed by Kuipers (1990). }\end{array}$ \\
\hline 5 & $\begin{array}{l}\text { Measured mean velocity profiles by varying the fluidized state of the } \\
\text { emulsion using the LDV technique. } \\
\text { - Performed MFIX validation studies - minimum fluidization prediction, } \\
\text { single-phase laminar and turbulent jets. }\end{array}$ \\
\hline 6 & $\begin{array}{l}\text { - Further analyzed experimental results through calculation of void fraction, } \\
\text { mass and momentum rates. } \\
\text { - Studied performance of empirical non-spherical minimum fluidization } \\
\text { velocities. } \\
\text { - Simulated a single-phase turbulent jet using MFIX and compared with } \\
\text { experimental data. }\end{array}$ \\
\hline 7 & $\begin{array}{l}\text { Extended experimental data obtained for means to extract fluctuating } \\
\text { profiles and analyzed the same. } \\
\text { - Made simulations to characterize the effect of bounding walls on the } \\
\text { experimental results. }\end{array}$ \\
\hline 8 & $\begin{array}{l}\text { - Studied the sensitivity of frictional models on predicting flow in bubbling } \\
\text { beds. } \\
\text { - Made further studies on spanwise confinement using MFIX }\end{array}$ \\
\hline
\end{tabular}




\section{Report Details}

\subsection{Experimental methods}

Experiments were carried out in a thin, practically two-dimensional, rectangular column. The column measured $457 \mathrm{~mm}$ in width, $1 \mathrm{~m}$ in height and $12.7 \mathrm{~mm}$ in thickness. The walls were made of transparent acrylic. The coordinate system chosen is shown in Figure 1 . A vertical round jet inlet, flush with the distributor surface and having a diameter, $D_{j}=9.2 \mathrm{~mm}$, was placed at the origin. A quartz viewing window measuring $102 \mathrm{~mm}$ by $153 \mathrm{~mm}$ by $5 \mathrm{~mm}$ was inserted at a height $y=50 \mathrm{~mm}$, within which all velocity measurements were made. The gas used was atmospheric air which was cooled to a temperature $T_{j}=-5^{\circ} \mathrm{C}$ to produce ice crystals which enabled optical tracing of the gas. The bed particles used were high density polyethylene spheres with a Sauter mean diameter, $d_{p}$, of $838 \mu \mathrm{m}$ and density, $\rho_{p}$, of $900 \mathrm{~kg} / \mathrm{m}^{3}$. These particles fall into the Geldart B classification of powders, which bubble immediately upon reaching minimum fluidization. For fluidization studies, the distributor velocity was varied while keeping other parameters, such as the inlet jet velocity $\left(V_{j}\right)$ and the initial bed height $(H)$, a constant at $92 \mathrm{~m} / \mathrm{s}$ and $38 \mathrm{~cm}$ respectively. The fluidization air was first turned on followed by the jet air. All measurements were made once a visually stable plume was formed, which took less than a second after turning on the jet inlet.
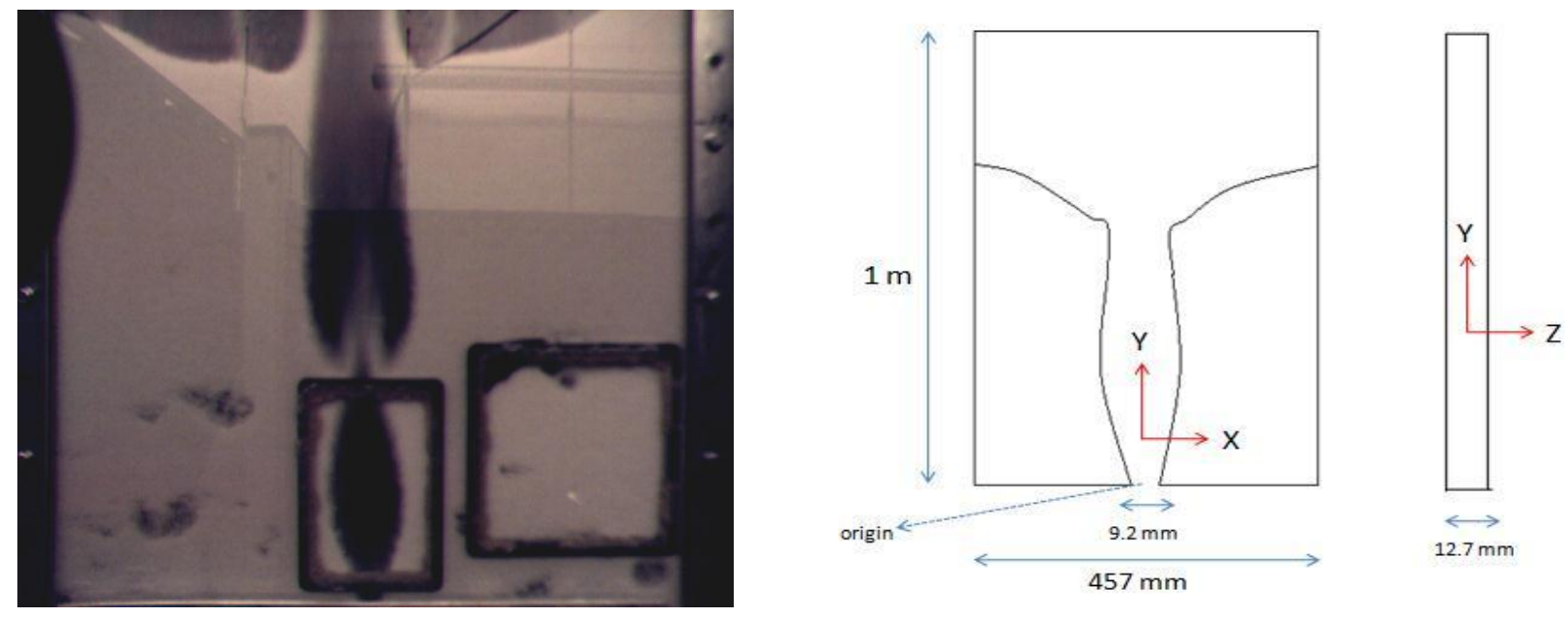

Figure 1: Vertical gas jet in the laboratory 2D bubbling fluidized bed and corresponding sketch

One of the major achievements in this project was in the development of a laser Doppler Velocimetry (LDV) technique to simultaneously measure the gas and particulate phase velocities in the high-speed jet plume of the bubbling fluidized bed. The laser, optics, and signal processing filters were configured to eliminate problematic laser-beam intensity fluctuations, which can contaminate Doppler signals in optically dense flows (Mychkovsky et al. 2009). In order to avoid damaging the optical access windows, the high-speed gas jet was seeded with small ice crystals. LDV bursts from the bed particles and gas tracer ice crystals were 
simultaneously recorded. The Doppler signals from the tracer ice crystals and bed particles were differentiated based on their burst intensity and coincidence (Figure 2) to yield the particulate and gas phase velocities at a given location within the jet plume. Further details on the LDV technique employed can be found in the paper submitted to Powder Technology (Mychkovsky et al. 2010).
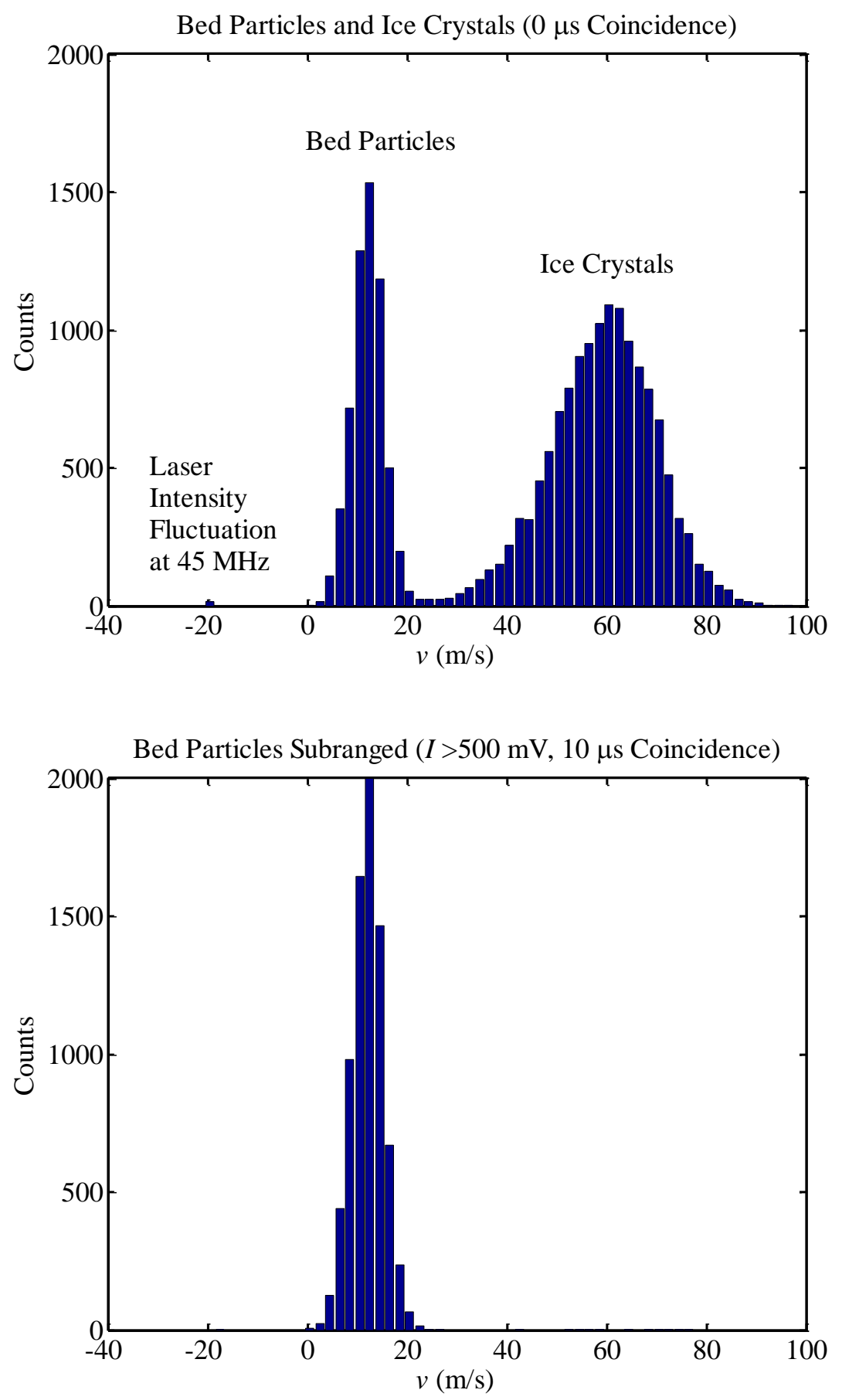


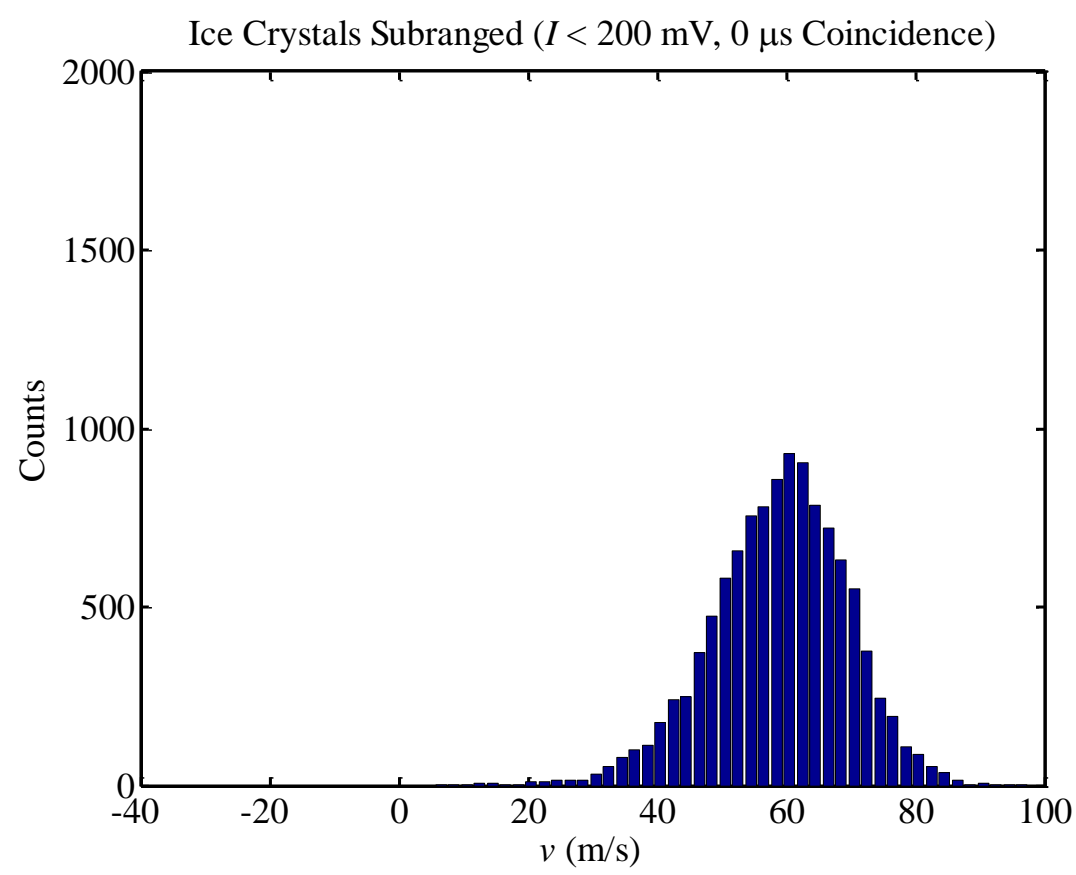

Figure 2: Velocity histogram for bed particles and gas tracer ice crystals measured in a jet plume before and after subranging

This same technique was also extended to yield fluctuating velocity measurements. The details of the LDV settings are summarized in Table 1.

\begin{tabular}{|l|c|c|}
\hline & Ch 1 & Ch 2 \\
\hline Laser Power per Beam $(\mathrm{mW})$ & 90 & 55 \\
\hline Beam Diameter (microns) & 90 & 85 \\
\hline PMT Gain $(\mathrm{mV})$ & 450 & 450 \\
\hline Burst Threshold $(\mathrm{mV})$ & 250 & 150 \\
\hline Frequency Downmixing $(\mathrm{MHz})$ & 0 & 0 \\
\hline Band Pass Filter $(\mathrm{MHz})$ & $5-50$ & $20-65$ \\
\hline Bragg Shift Frequency $(\mathrm{MHz})$ & 40 & 40 \\
\hline Fringe Spacing $($ microns) & 3.74 & 3.55 \\
\hline Velocity Range $(\mathrm{m} / \mathrm{s})$ & 131 to -37 & 71 to -89 \\
\hline Coincidence Interval $(\mu \mathrm{s})$ & 10 & 10 \\
\hline
\end{tabular}

Table 1: LDV parameters. The system was optimized for maximum laser beam power and minimal laser beam intensity fluctuation complications. The large dynamic velocity range enables simultaneous gas and particulate phase velocity measurements. 


\subsection{Computational methods}

Simulations to enable comparisons with the experiment data in the project were carried out by solving an Eulerian-Eulerian model for gas-solid flows as first proposed by Anderson and Jackson (1967) and coded in the Department of Energy's open source code MFIX. An outline of the equations solved is given in Table 2. Figure 3 shows a sketch of the simulation domain employed.

$$
\begin{gathered}
\varepsilon \rho_{g}\left[\frac{\partial \underline{V_{g}}}{\partial t}+\underline{V_{g}} \cdot \nabla \underline{V_{g}}\right]=\varepsilon\left[-\nabla p_{g}-\nabla \cdot \underline{\underline{\tau_{g}}}\right]+\varepsilon \rho_{g} \underline{g}-\underline{F_{D}} \\
v \rho_{s}\left[\frac{\partial \underline{V_{s}}}{\partial t}+\underline{V_{s}} \cdot \underline{\nabla V_{s}}\right]=v\left[-\nabla p_{g}-\nabla \cdot \underline{\underline{\tau_{g}}}\right]+\underline{F_{D}}+v \rho_{s} \underline{g}-\nabla \cdot \underline{\underline{\sigma_{s}}} \\
\underline{\underline{\sigma_{s}}}=\underline{\underline{\sigma_{k}}}+\underline{\underline{\sigma_{f}}} \\
\underline{\underline{\tau_{g}}}=\underline{\underline{\tau_{V I S}}}+\underline{\underline{\tau_{T U R}}}
\end{gathered}
$$

\begin{tabular}{|c|c|c|}
\hline Term & Name & Model \\
\hline$\underline{F_{D}}$ & Drag & Syamlal, et al. (1993) \\
\hline$\underline{\underline{\sigma_{k}}}$ & Collisional solid stress & Lun, et al. (1984) \\
\hline$\underline{\underline{\underline{\tau_{T U R}}}}$ & Gas turbulence model & Standard k-epsilon \\
\hline
\end{tabular}

Table 2: Summary of the continuum approach employed (www.mfix.netl.doe.gov)

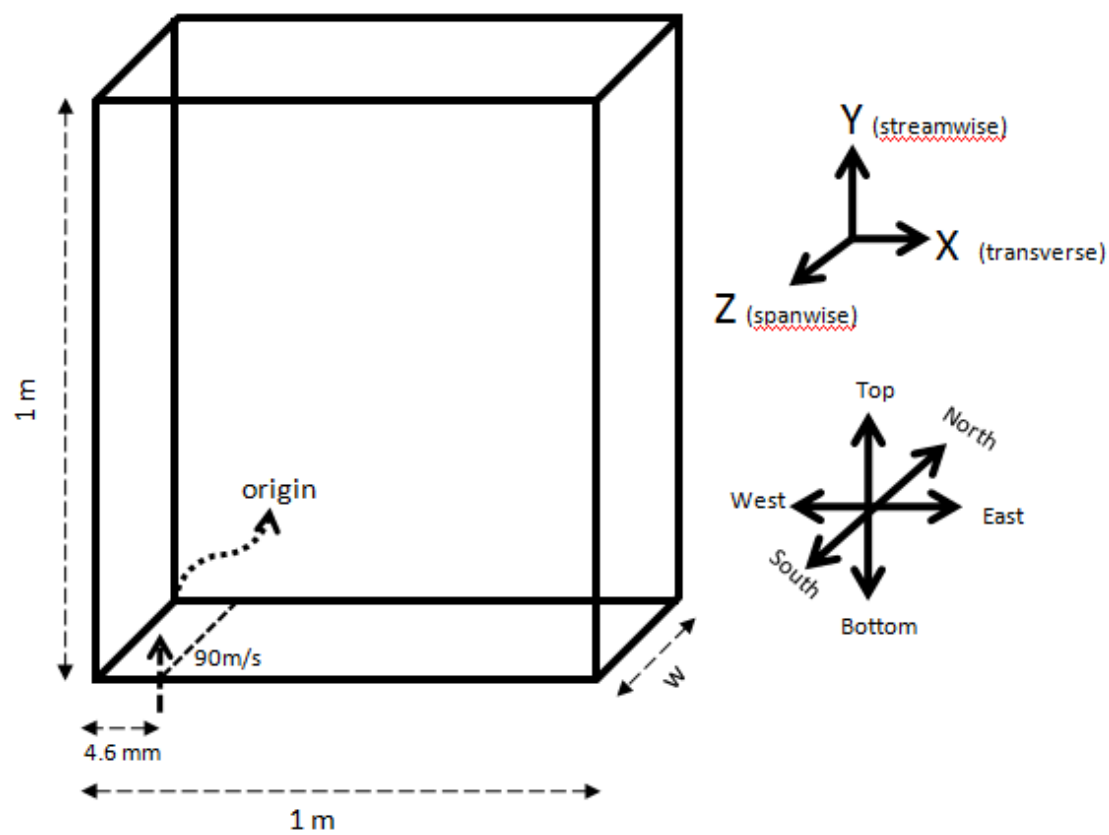

Figure 3: The simulation domain 
The simulations were carried out only in one half of the actual domain due to the advantage of symmetry and to get rid of the "jet-locking" phenomenon which was observed with twodimensional k-epsilon model (see Figure 4) as previously observed by Akhtar (2010).

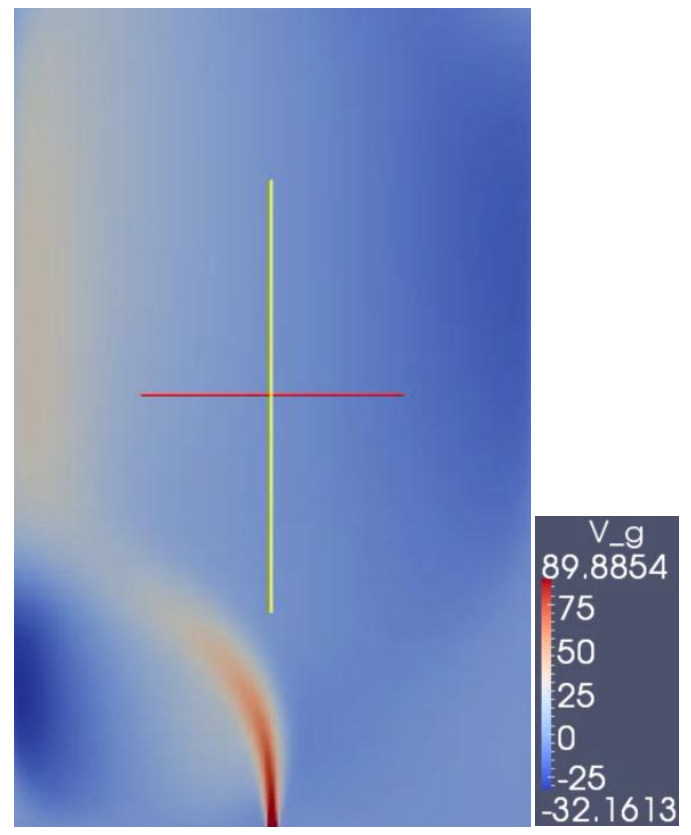

Figure 4: An example of the unphysical behavior observed when doing a 2D single-phase jet simulation using kepsilon model. The jet locks to one side of the domain.

It must be noted that the MFIX code had to be modified to allow free-slip walls to be enforced when using the k-epsilon model, a feature it lacks by default. The boundary conditions employed were free-slip along the west face, constant pressure outlet in the north and standard wall functions along all other faces. Though the usage of wall function in the east and bottom faces made no difference, it was important in the north and south faces to successfully capture the wall-bounded flow associated with the k-epsilon model. The Johnson and Jackson (1986) boundary conditions were employed at walls for solids. The column had the same dimensions as that of the experimental setup - width $(l) 228.5 \mathrm{~mm}$, height $(h) 1 \mathrm{~m}$ and the thickness $(w) 12.7$ $\mathrm{mm}$. The jet width $\left(D_{j} / 2\right)$ was $4.6 \mathrm{~mm}$ and the jet inlet velocity $\left(V_{j}\right)$ was $92 \mathrm{~m} / \mathrm{s}$. It must be noted that the round jet opening in the experiment was approximated by a rectangular opening in the simulations. The air was at temperature $\left(T_{g}\right)=-5^{\circ} \mathrm{C}$ with a dynamic viscosity $\left(\mu_{g}\right) 1.65 \mathrm{E}-5$ $\mathrm{kg} /(\mathrm{ms})$. The particles specified had properties similar to the particles used in the experiments with size $\left(D_{p}\right) 838 \mu \mathrm{m}$ and density $\left(\rho_{p}\right) 900 \mathrm{~kg} / \mathrm{m}^{3}$. The coefficient of restitution between the particles (polyethylene-polyethylene) and particle-wall were taken as $(e) 0.9$ and $\left(e_{w}\right) \quad 0.5$ (polyethylene-acrylic) respectively. For simulations with frictional model included, the specularity coefficient $(\varphi)$ was taken to be 0.002 and the angle of internal friction $(\delta) 27^{\circ}$. All simulations reported have been ensured to be grid insensitive. 
The effect of the spanwise walls on a single-phase jet was conducted by varying the thickness $(w)$ and at an extended width $(l=1 \mathrm{~m})$. Additional validations of the gas-solid equations used by MFIX were made by comparisons with the experimental data of Tsuji et al. (1983) for vertical risers and Kuipers (1990) for bubble injection, and were found to match favorably. These are, however, not included in this report. 


\section{Results and discussion}

\subsection{Experimental results}

\subsubsection{Empty bed mean velocity profiles and analysis}

Before attempting to quantify and analyze two-phase measurements in the bubbling bed jet plume, the behavior of the single-phase gas jet in the empty 2D bed was examined. The jet crosssectional velocity profiles taken at axial locations of $y=70 \mathrm{~mm}, 100 \mathrm{~mm}$, and $130 \mathrm{~mm}$ are shown in Figure 5.

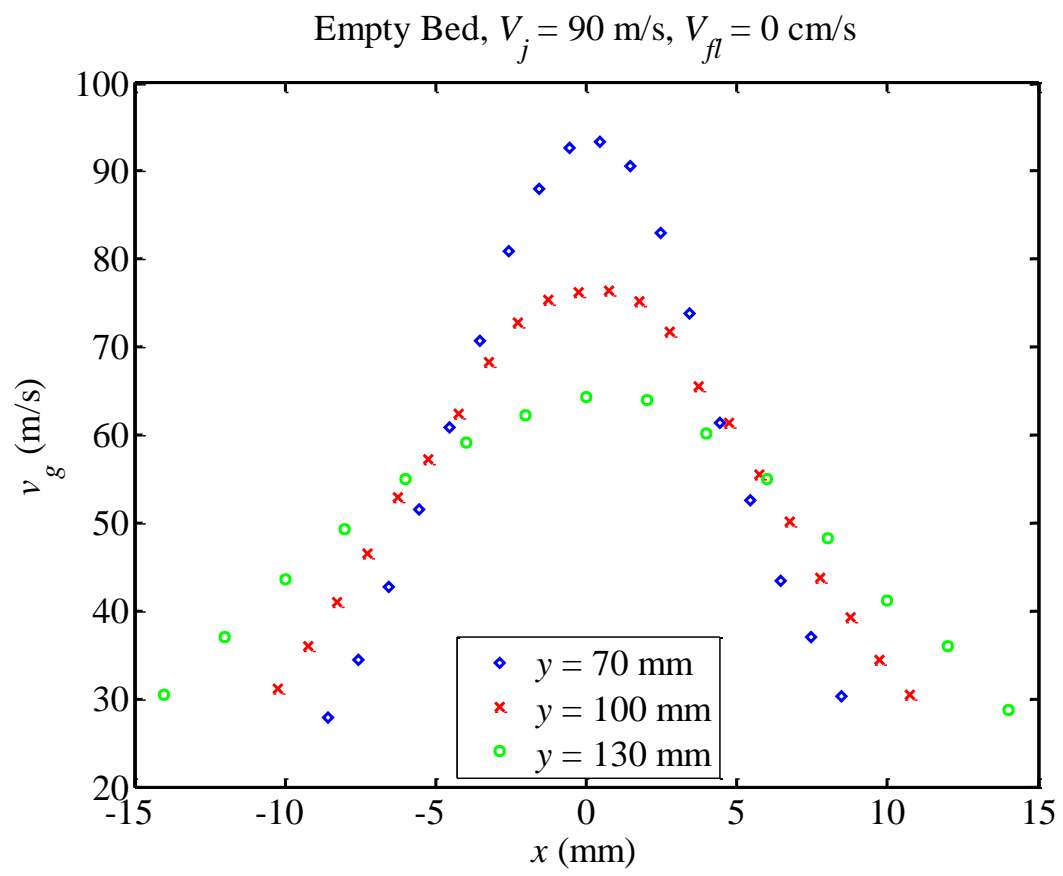

Figure 5: Gas phase velocity profile

The velocity profiles at each axial location are normalized with respect to the maximum value and plotted versus the similarity variable $x /\left(y-y_{o}\right)$ in Figure 6 in order to determine if a selfsimilar shape exists. 


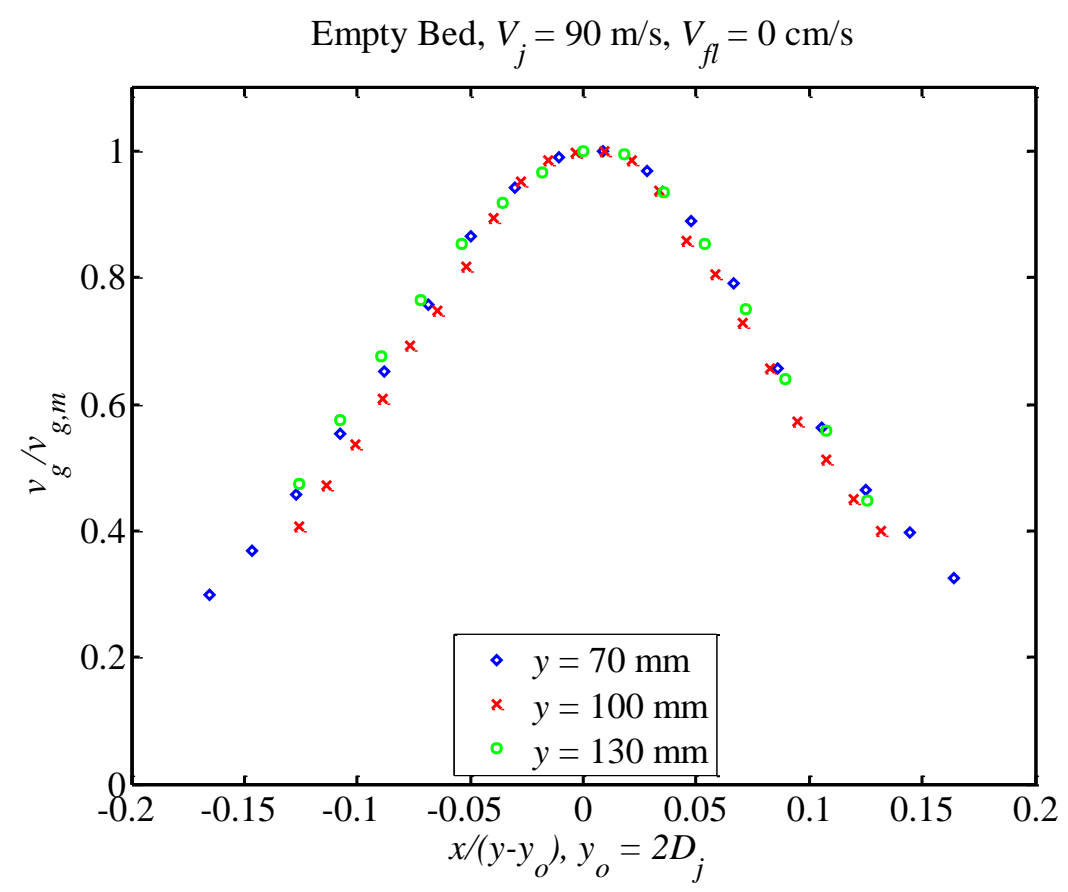

Figure 6: Gas velocity profile normalized by $x /\left(y-y_{o}\right)$

The illustration indicates that the self-similar behavior of jets occurs with respect to the virtual (or apparent) origin, located at $y_{0}$. The apparent origin is a hypothetical point source of momentum, whose location is related to the decay of the potential core, which usually occurs at a distance of a few jet orifice diameters (White, 2006). However, there are several ways to describe the bell-curve like shape of the velocity profile at a given axial location. For the sake of computational ease, a Gaussian profile has been used (Ounnar, et al., 2009) as shown in Figure 7 and given by the following equation

$$
\frac{v_{g}}{v_{g, m}}=\exp \left[-\ln (2) \xi_{g}^{2}\right]
$$

where the similarity variable is scaled with the half-velocity point

$$
\xi_{g}=\frac{x}{x_{g, 1 / 2}}
$$




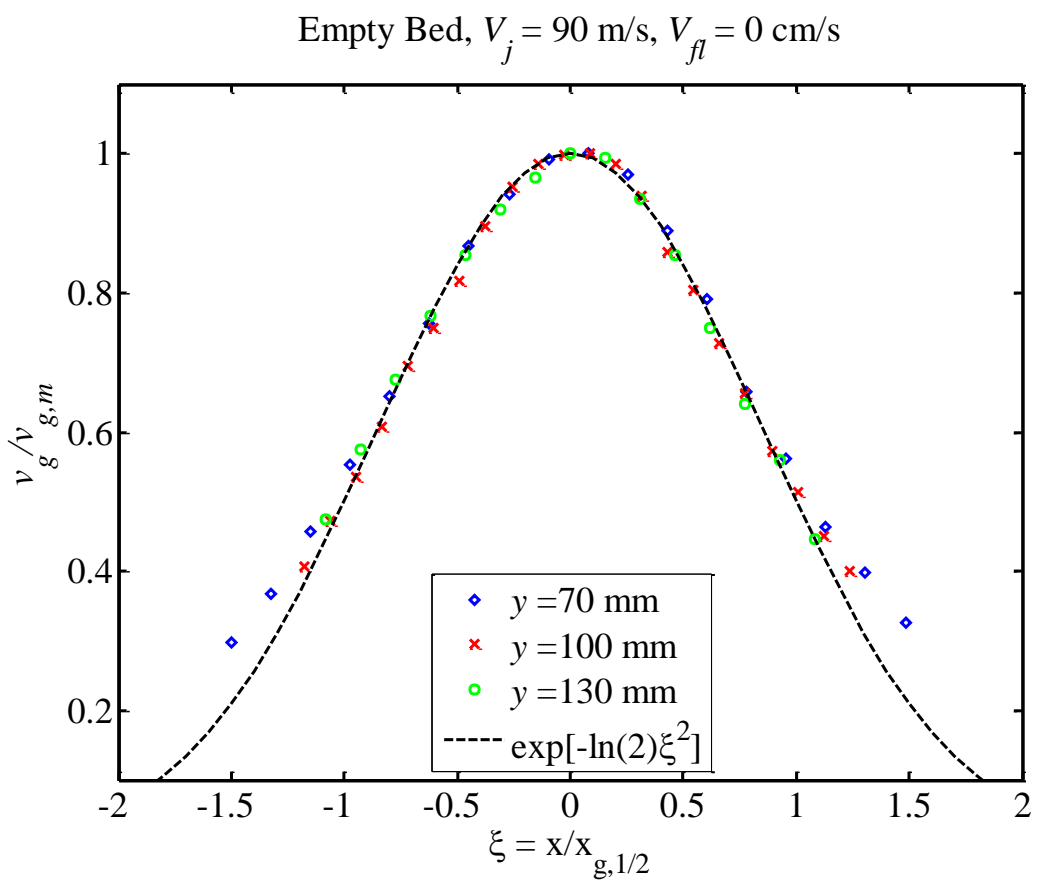

Figure 7: Normalized gas phase velocity profiles scaled with respect to the half-velocity points and compared to the Gaussian profile

One of the defining characteristics of a free jet is that its axial momentum is conserved. The vertical jet gas momentum flux can be measured at an axial location by integrating measured velocity profiles. Momentum rates calculated by numerically integrating the LDV data points are reported (

Table 3). The momentum rates calculated for the downstream locations of $70 \mathrm{~mm}, 100 \mathrm{~mm}$, and $130 \mathrm{~mm}$ are all consistent, indicating that the jet does not lose significant momentum to friction with the bounding walls.

\begin{tabular}{|c|c|}
\hline Physical Location, $y(\mathrm{~mm})$ & $J_{g}\left(\mathrm{~kg} \cdot \mathrm{m} / \mathrm{s}^{2}\right)$ \\
\hline 0 & 0.722 \\
\hline 70 & 0.701 \\
\hline 100 & 0.715 \\
\hline 130 & 0.754 \\
\hline
\end{tabular}

Table 3: Momentum rates in the jet plume determined from the Gaussian profiles. 


\subsubsection{Bubbling bed mean velocity profiles and analysis}

Once the vertical jet in the empty bed had been fully characterized, the bed was filled with high density polyethylene (HDPE) microspheres. These particles are considered Geldart Group B particles, which bubble immediately beyond minimum fluidization. Gas and particulate phase velocity profiles are presented and analyzed. The analysis includes similarity profile scaling as well as void fraction, mass flow, momentum rate and particle drag calculations. The velocity profiles of both the gas and particulate phases taken at axial locations of $y=60 \mathrm{~mm}, 70 \mathrm{~mm}, 100$ $\mathrm{mm}$, and $130 \mathrm{~mm}$ are shown in Figure 8 and Figure 9. The slip velocity, defined as

$$
v_{s}=v_{g}-v_{p}
$$

is plotted in Figure 10. Next, the particle Reynolds number in the jet plume, defined as

$$
\operatorname{Re}_{p}=\frac{\rho_{g}\left(v_{g}-v_{p}\right) d_{p}}{\mu_{g}}
$$

is plotted in Figure 11.

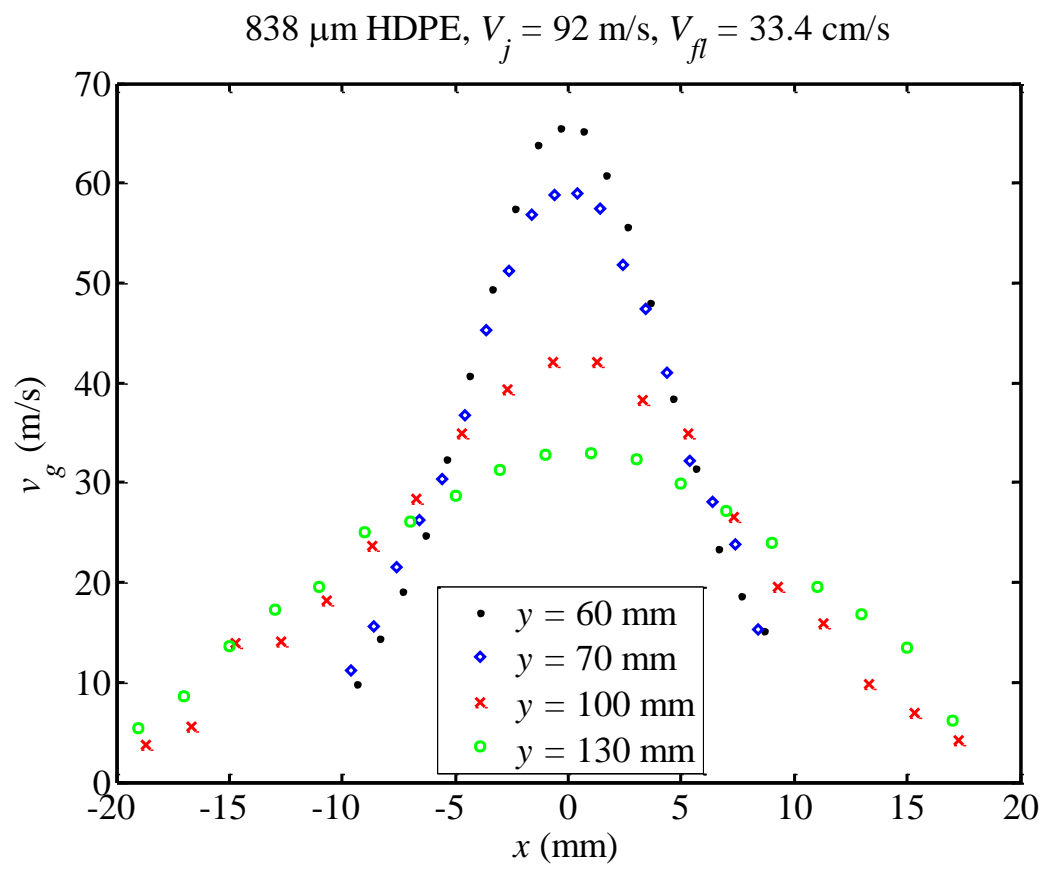

Figure 8: Gas phase velocity profiles 


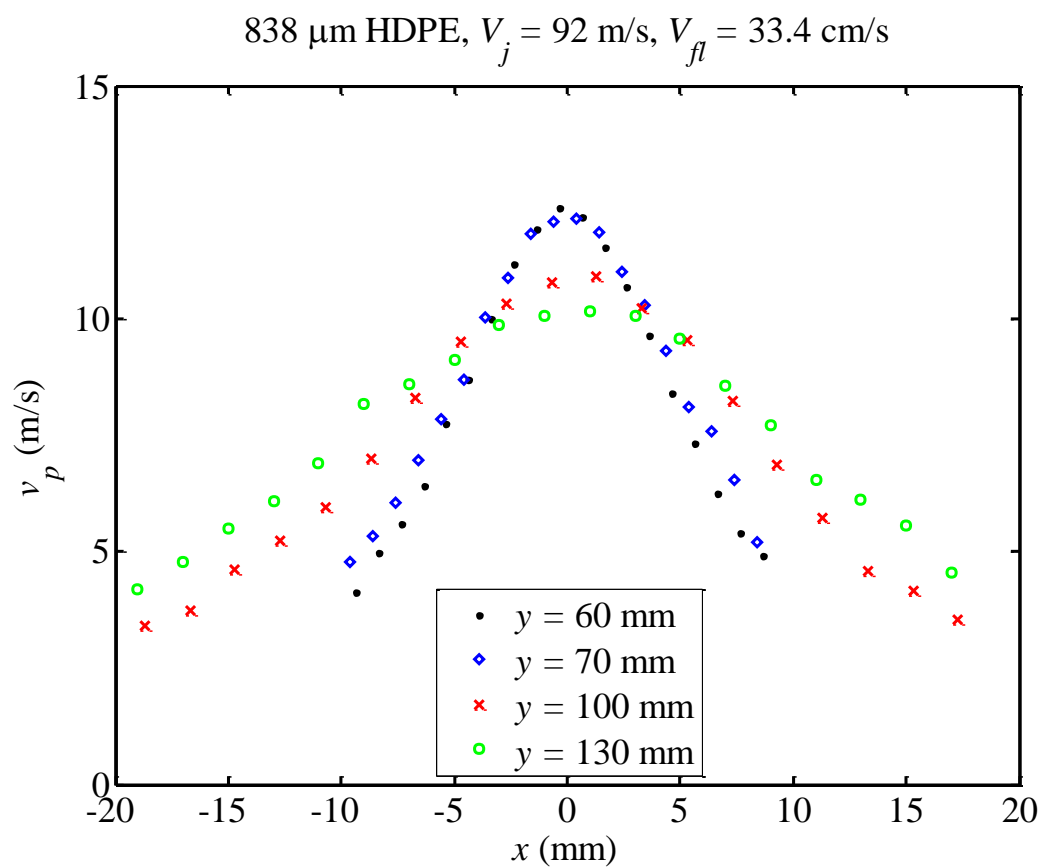

Figure 9: Particulate phase velocity profiles

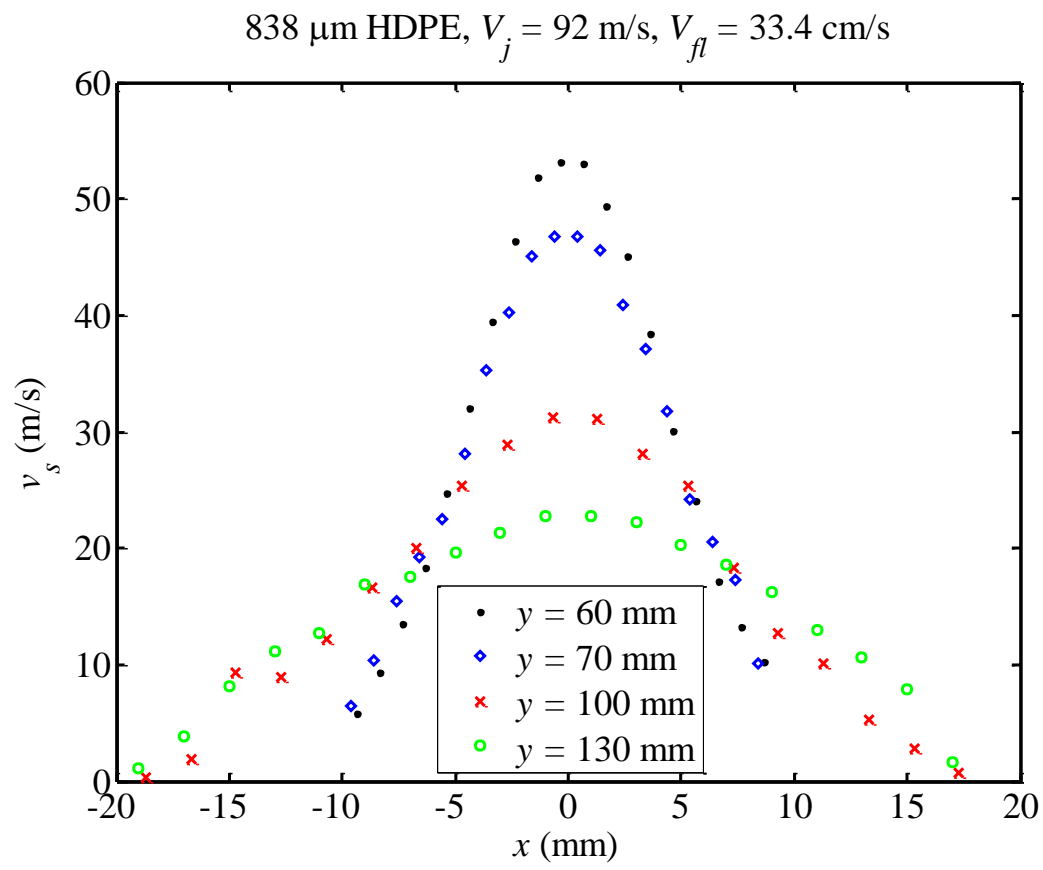

Figure 10: Slip velocity profiles 


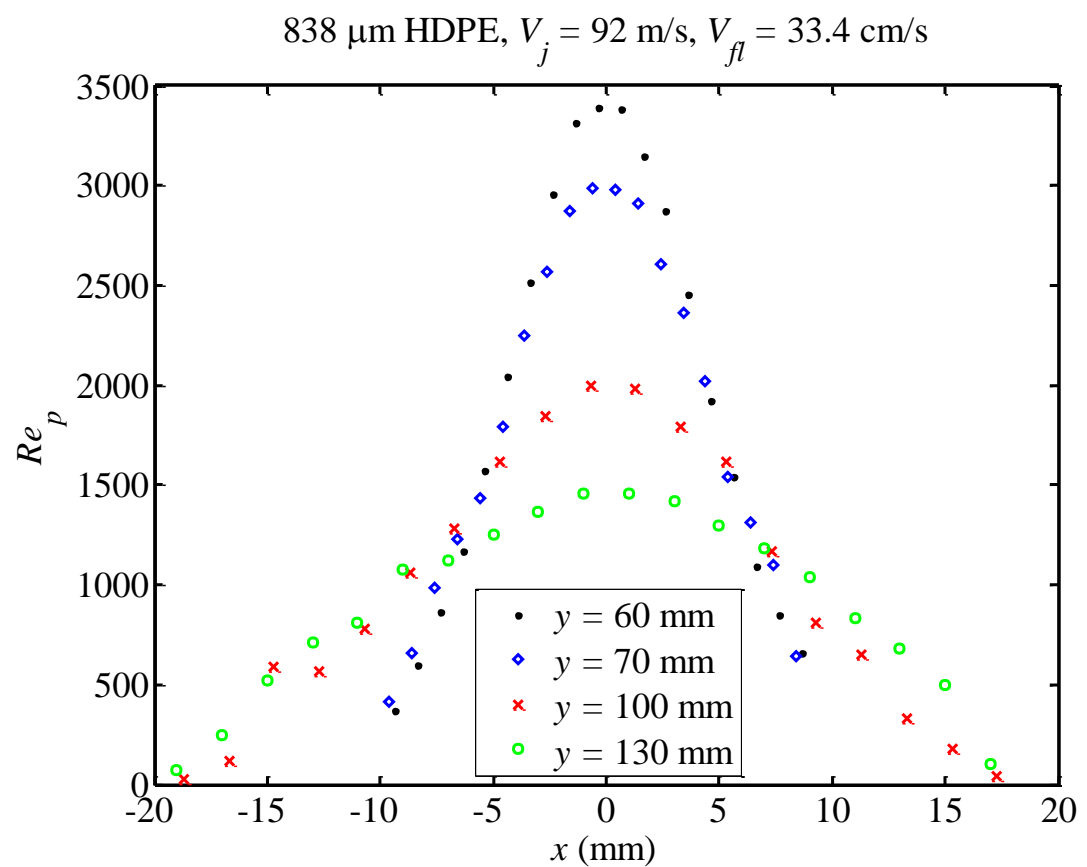

Figure 11: Particle Reynolds number profiles

The normalized velocity profiles are scaled with their respective half-velocity points and compared with the Gaussian profile. The gas and particulate profiles appear to be self-similar when scaled in this manner (Figure 12 and Figure 13).

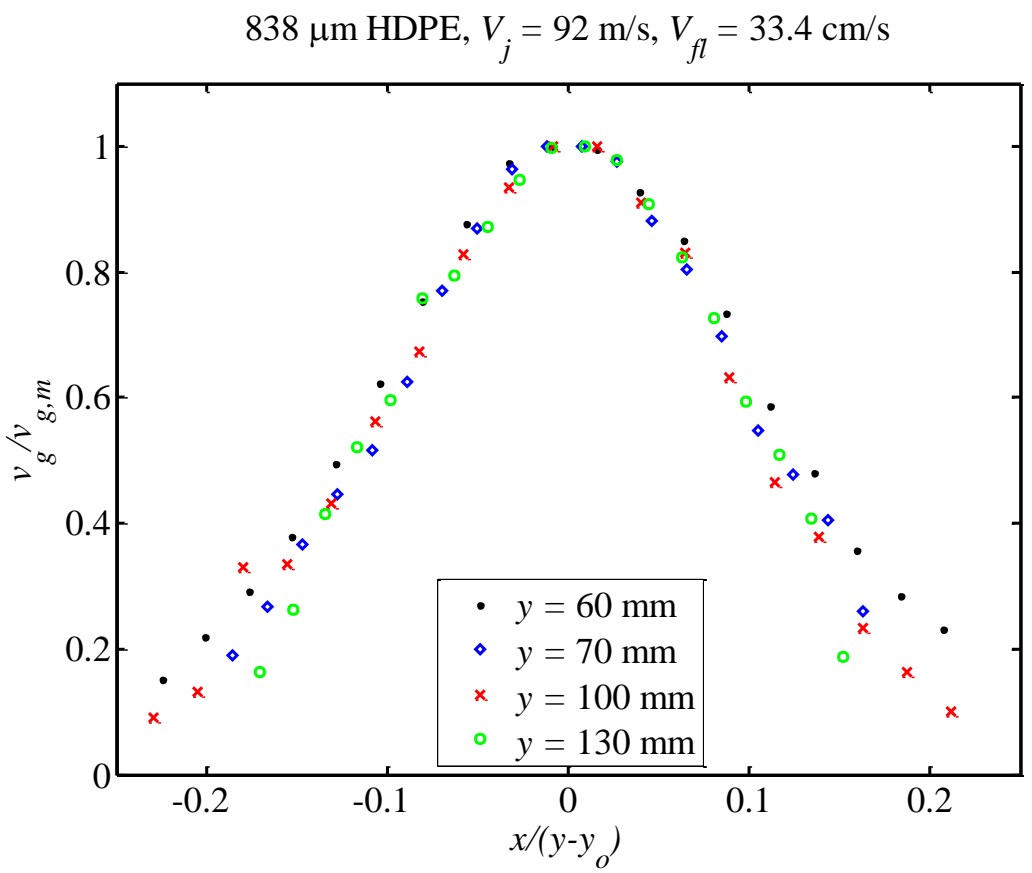

Figure 12: Normalized gas phase velocity profiles scaled with respect to the empty bed virtual origin 


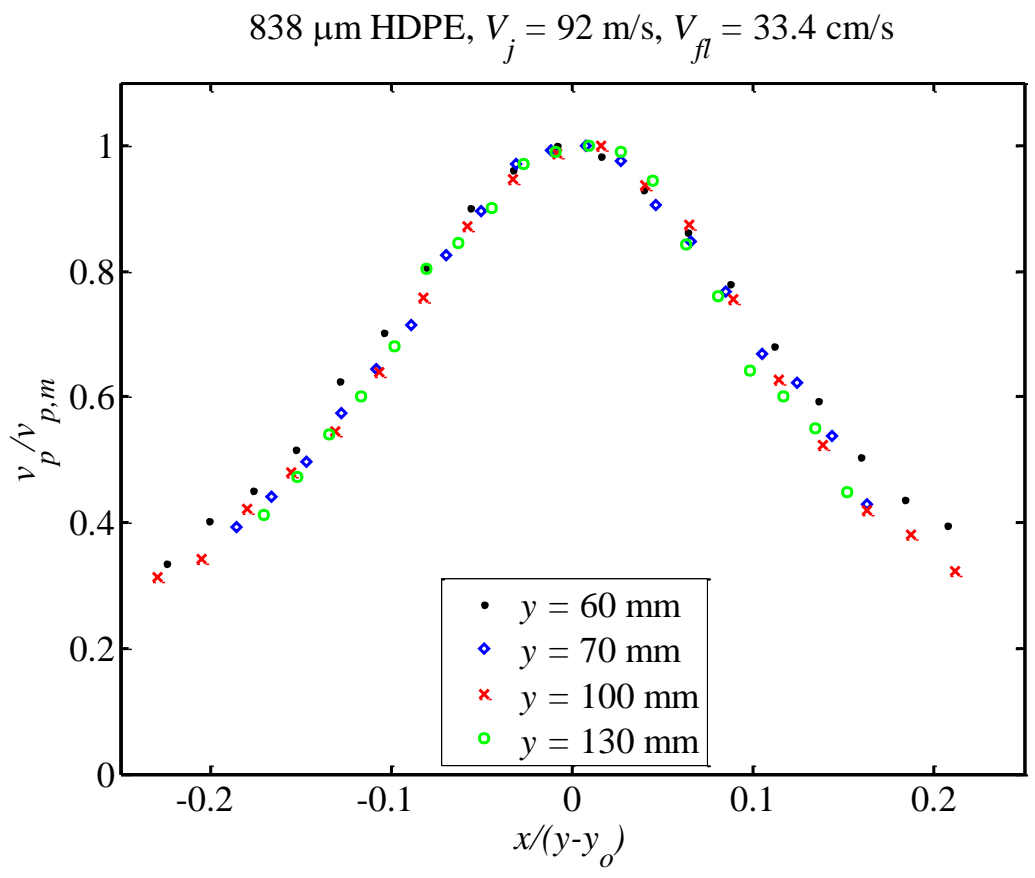

Figure 13: Normalized particle phase velocity profiles scaled with respect to the empty bed virtual origin

It must be noted that the values of the half velocity points are determined by the slope of the core data when plotted on a semi-log plot.

The nature of the jet plume spreading and centerline velocity decay is shown in Figure 14 and Figure 15. 


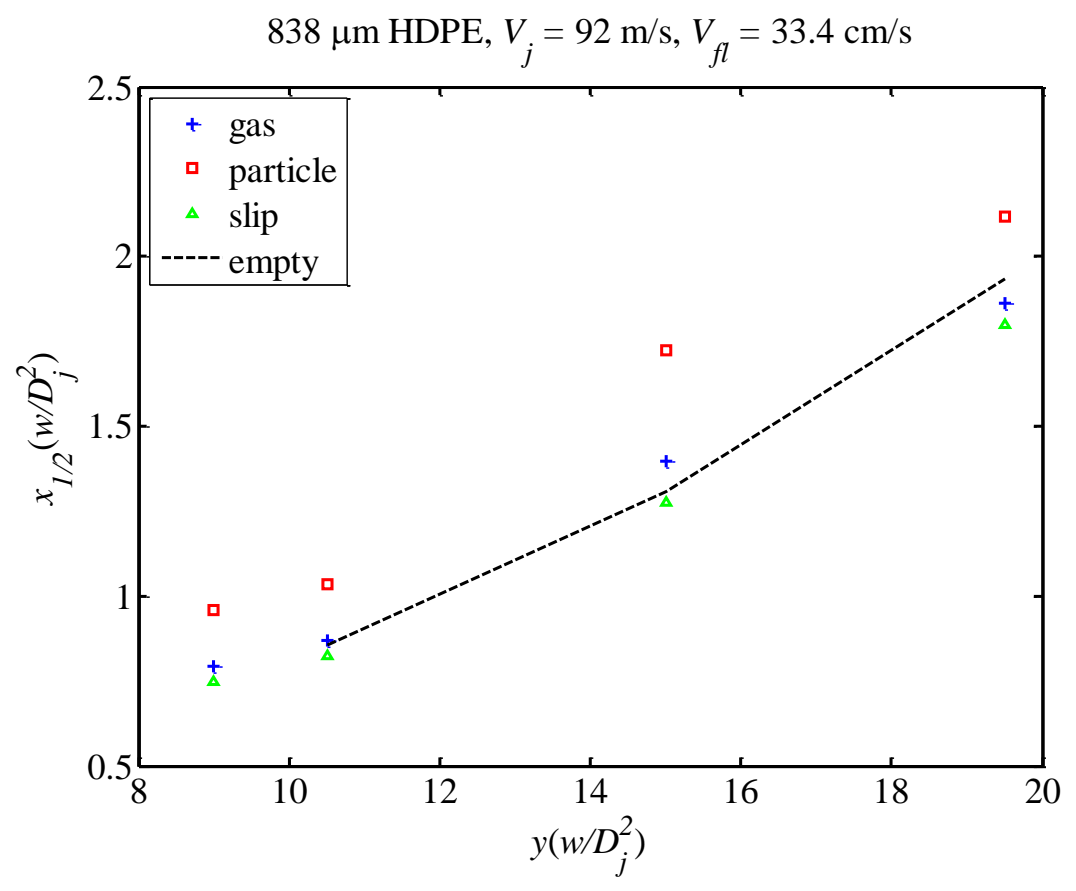

Figure 14: Half-velocity point values for the gas, particulate, and slip velocity profiles compared to the empty bed gas phase data

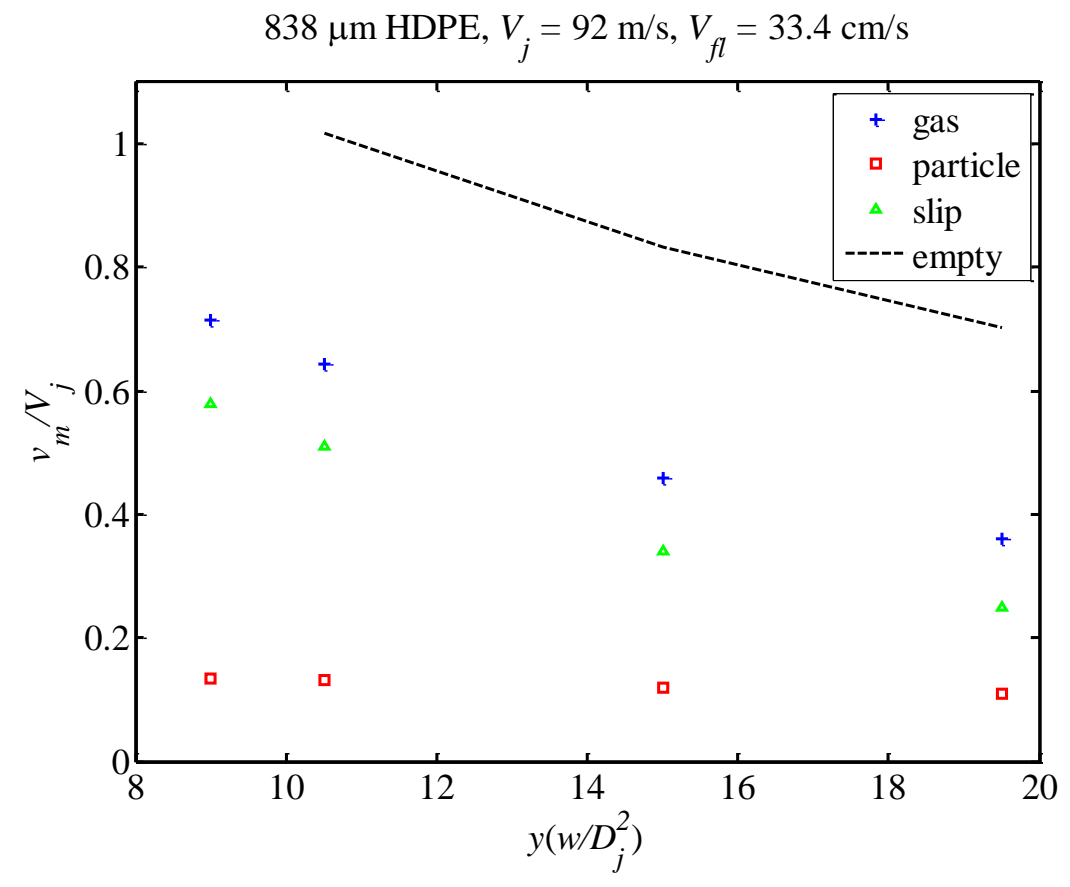

Figure 15: Maximum velocity values for the gas, particulate, and slip velocity profiles compared to the empty bed gas phase data 
The values are juxtaposed with the gas phase of the empty bed at the $y=70,100$, and $130 \mathrm{~mm}$ axial locations. Figure 14 indicates that particulate phase velocity profile is slightly wider than the gas phase velocity profile. This is reasonable since all of the particles in the jet plume are entrained from rest along the emulsion boundary whereas the majority of the gas in the plume originates from the jet orifice. However, the half-velocity point growth for the gas phase in the bubbling and empty bed is remarkably similar. As expected, the presence of particles significantly contributes to the decay of the gas phase velocity, as shown in Figure 15. The decline in the measured particulate phase Eulerian velocity is due to the entrainment of relatively stationary particles.

An average void fraction at various axial locations can be determined by a momentum balance with the jet inlet momentum to yield

$$
\dot{J}_{j}=w C_{2}\left[\int_{-b}^{b} \varepsilon \rho_{g} v_{g}^{2} d x+\int_{-b}^{b}(1-\varepsilon) \rho_{p} v_{p}^{2} d x\right]
$$

The phase concentration is considered to be uniform across the jet so that $\varepsilon=\varepsilon(y)$ as particles are entrained and the jet expands. The momentum averaged volumetric void fraction at each axial location is shown in Figure 16.

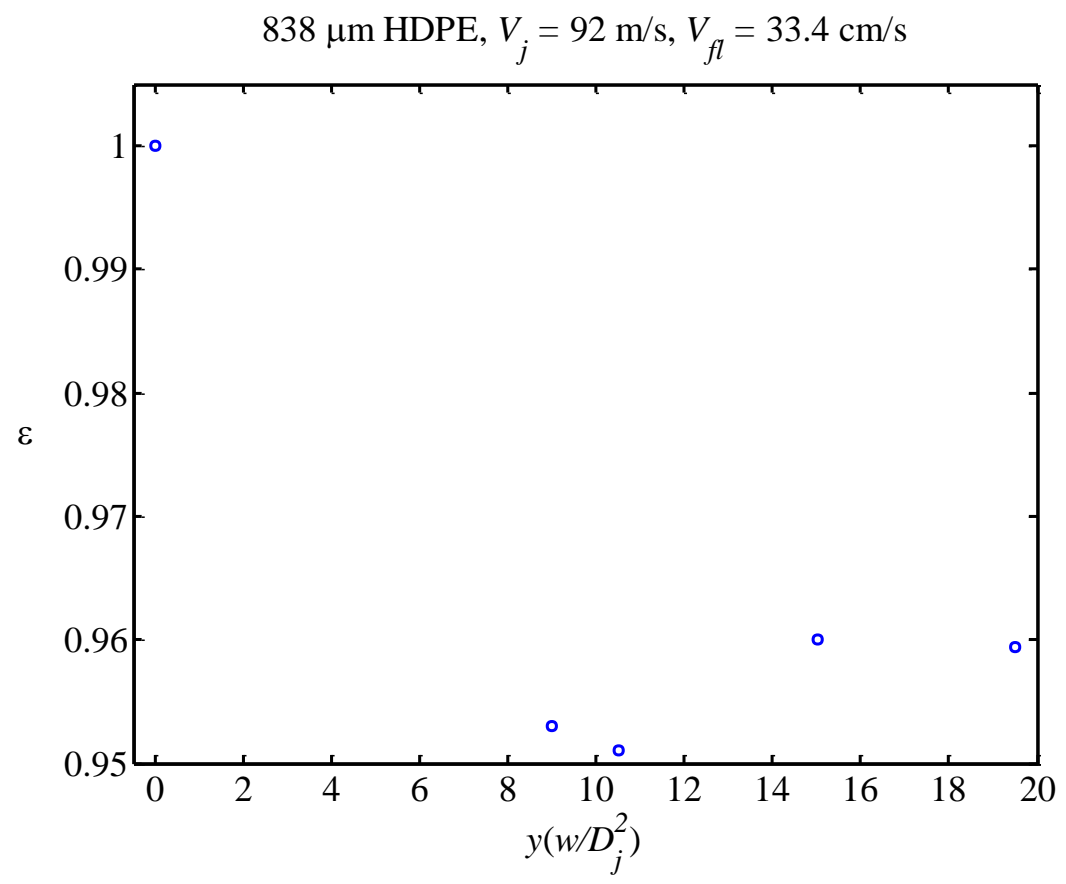

Figure 16: Void fraction values determined from a momentum balance

The calculated values suggest that, perhaps contrary to intuition, the solids fraction actually decreases in the streamwise direction shortly beyond the jet orifice. However, this is consistent 
with the work of Merry (1971) and Xuereb et al. (1991), who defined an initial entrainment zone followed by a linear expansion region where the particle entrainment rate gradually decreases.

The mass flow and momentum rates for the two phases can be calculated at each downstream location, assuming that the densities and void fraction are constant and are plotted in Figure 17 and Figure 18. The mass flow data indicates that particle entrainment near the jet inlet is significant and that the rate of entrainment into the jet plume decreases with streamwise distance. Once again, this is consistent with an initial entrainment zone followed by a linear expansion region where the particle entrainment rate gradually decreases. On the other hand, the gas phase mass flow in the jet plume remains nearly constant at the inlet value. The momentum data indicates that more than half of the initial jet gas momentum is already transferred to the particulate phase at first axial measurement location. Significant initial momentum transfer is to be expected due to high particle entrainment and large relative slip velocity values near the jet inlet.

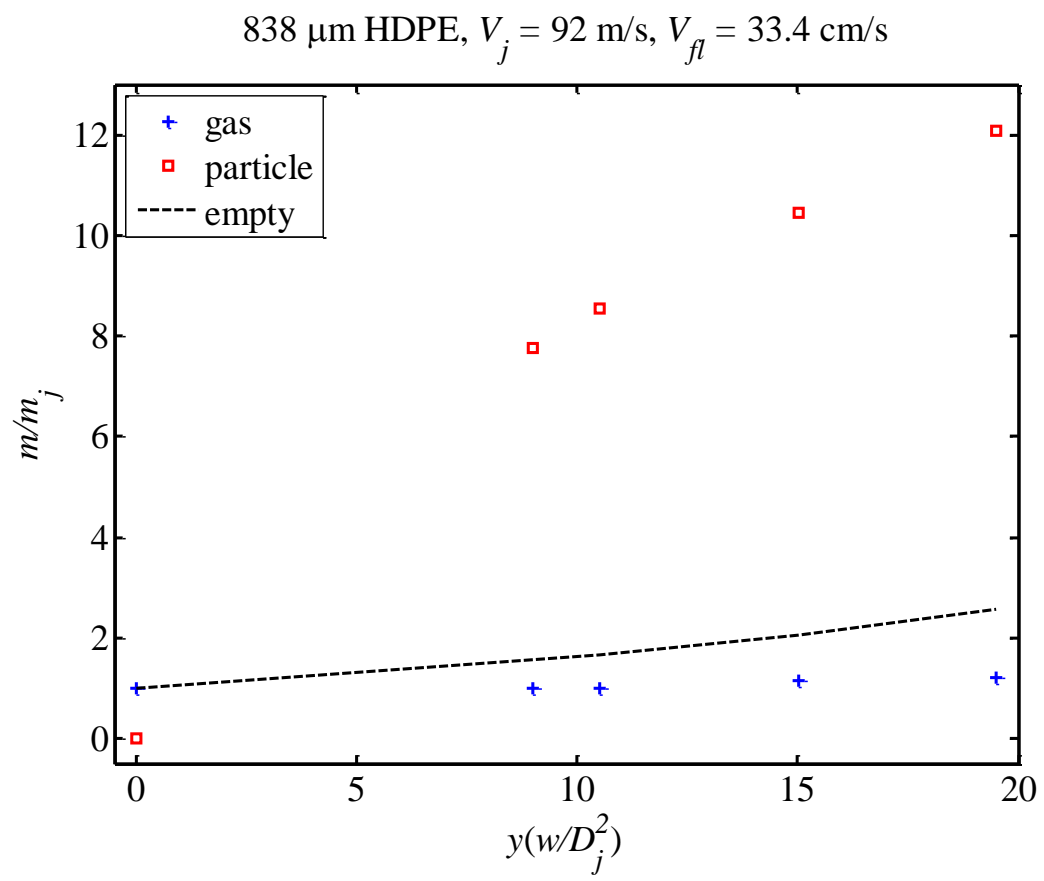

Figure 17: Gas and particulate phase mass flow rates in the jet plume determined from the Gaussian profiles and calculated void fractions. The two-phase data is compared to the empty bed gas phase data. 


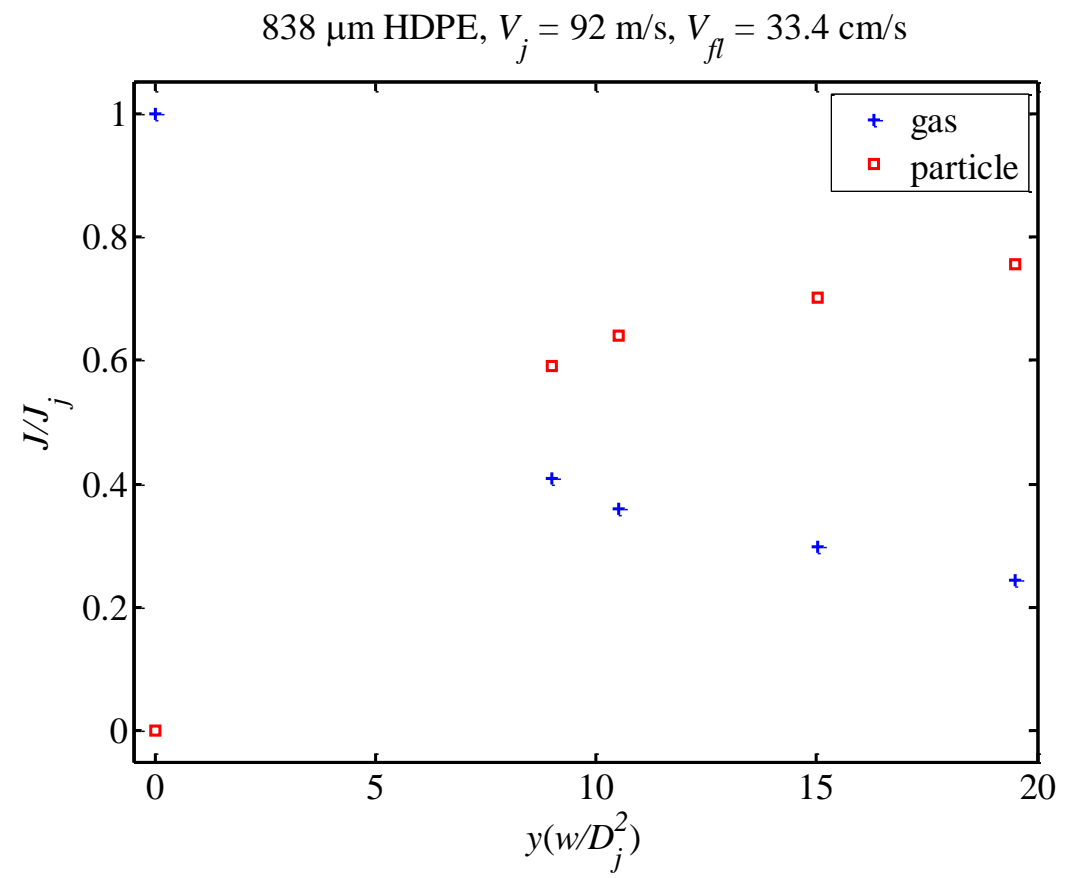

Figure 18: Gas and particulate phase momentum rates in the jet plume determined from the Gaussian profiles and calculated void fractions. The empty bed gas phase momentum rate remains constant at the inlet value.

Applying the Eulerian equation of motion to the particulate phase with the measured velocity profiles, the bed particle drag coefficient is given by the expression

$$
C_{D}=\left(\frac{2 \mathrm{~V}_{\mathrm{p}} \rho_{p}}{A_{p} \rho_{g}}\right) \frac{4 g \int_{y 1}^{y 2}(1-\varepsilon) x_{p, 1 / 2} d y+1.5\left\{\left[(1-\varepsilon) v_{p, m}^{2} x_{p, 1 / 2}\right]_{y 2}-\left[(1-\varepsilon) v_{p, m}^{2} x_{p, 1 / 2}\right]_{y 1}\right\}}{1.5 \int_{y 1}^{y 2}(1-\varepsilon) v_{s, m}^{2} x_{s, 1 / 2} d y}
$$

Table 4 shows that the drag coefficients recovered are found to be consistent with the established empirical value.

\begin{tabular}{|c|c|}
\hline Physical Distance, $y_{2}-y_{1}(\mathrm{~mm})$ & $C_{D}$ \\
\hline $60-70$ & 0.47 \\
\hline $70-100$ & 0.29 \\
\hline $100-130$ & 0.40 \\
\hline
\end{tabular}

Table 4: Particle drag coefficients calculated from equation. The established empirical value is approximately 0.4. The HDPE micropellets are treated as spheres and the particulate phase and slip velocity Gaussian profiles as well as the calculated solids fraction values are used. The major source of error is the uncertainty of the solids volume fraction at each axial location. 


\subsubsection{Effect of fluidization on mean dynamics and analysis}

The effect of fluidization velocity on the jet dynamics was examined by fluidizing the emulsion at $V_{f l} / V_{m f}=0,0.7,1,1.15,1.3$, and 1.5 .

Increasing the fluidization velocity decreases the maximum centerline velocity and widens the velocity profiles for both phases as shown in Figure 19 to Figure 22 and Figure 23 to Figure 25 respectively. As expected, Figure 19 shows that the centerline gas phase velocity for all bubbling bed cases is significantly reduced when compared to the empty bed case due to momentum transfer to the particulate phase. However, Figure 23 reveals that the gas phase velocity profile width at minimum fluidization is comparable to the empty bed. The gas velocity profile is narrower when the emulsion is fluidized below this point and widens with increasing fluidization. Another important parameter affected by fluidization is the phase volume fraction in the jet plume. In Figure 26, it is evident that void fraction has a strong dependency on the fluidization state of the emulsion. In a spouted bed (no fluidization), the momentum averaged void fraction is roughly $94 \%$. At $50 \%$ excess fluidization, this value increases to about $98 \%$. Once again, this corresponds to a significant change in the solids fraction, $(1-\varepsilon)$, and thus the particulate phase transport rates.

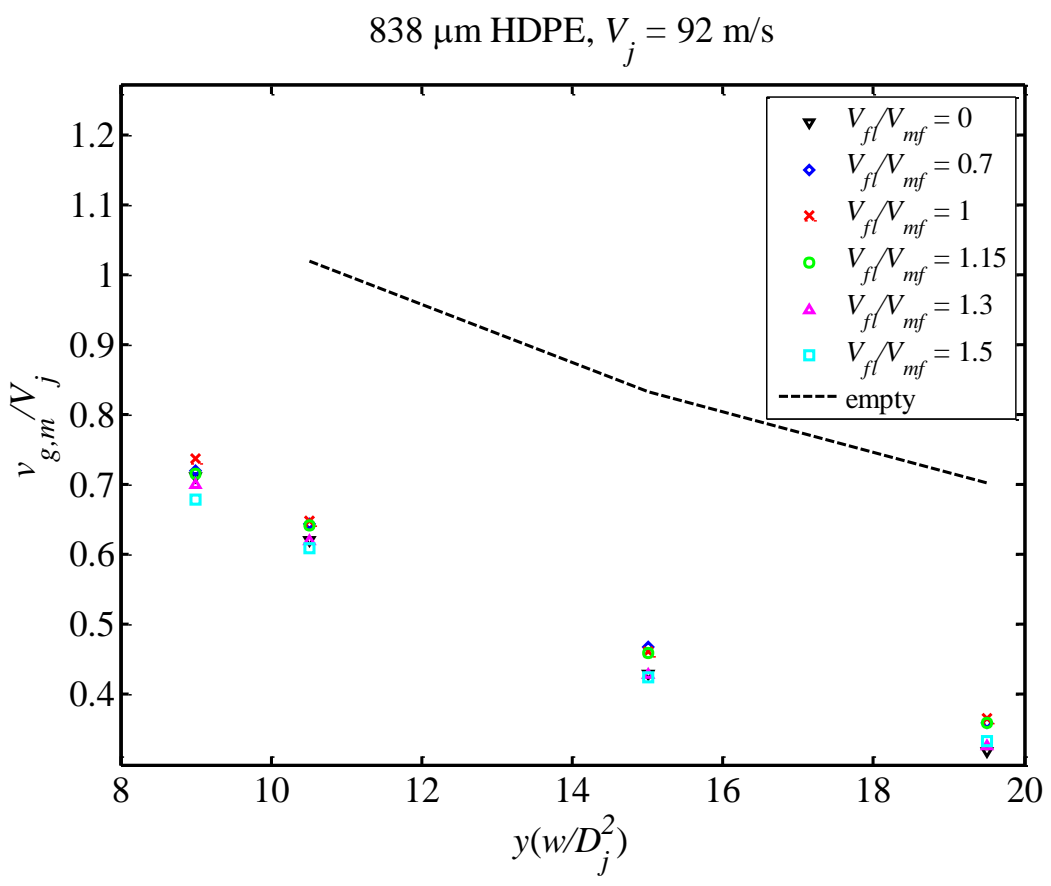

Figure 19: Maximum velocity values for the gas phase with varying fluidization velocity compared with the empty bed data. The momentum transfer from the gas to the particulate phase significantly reduces the maximum velocity values. 


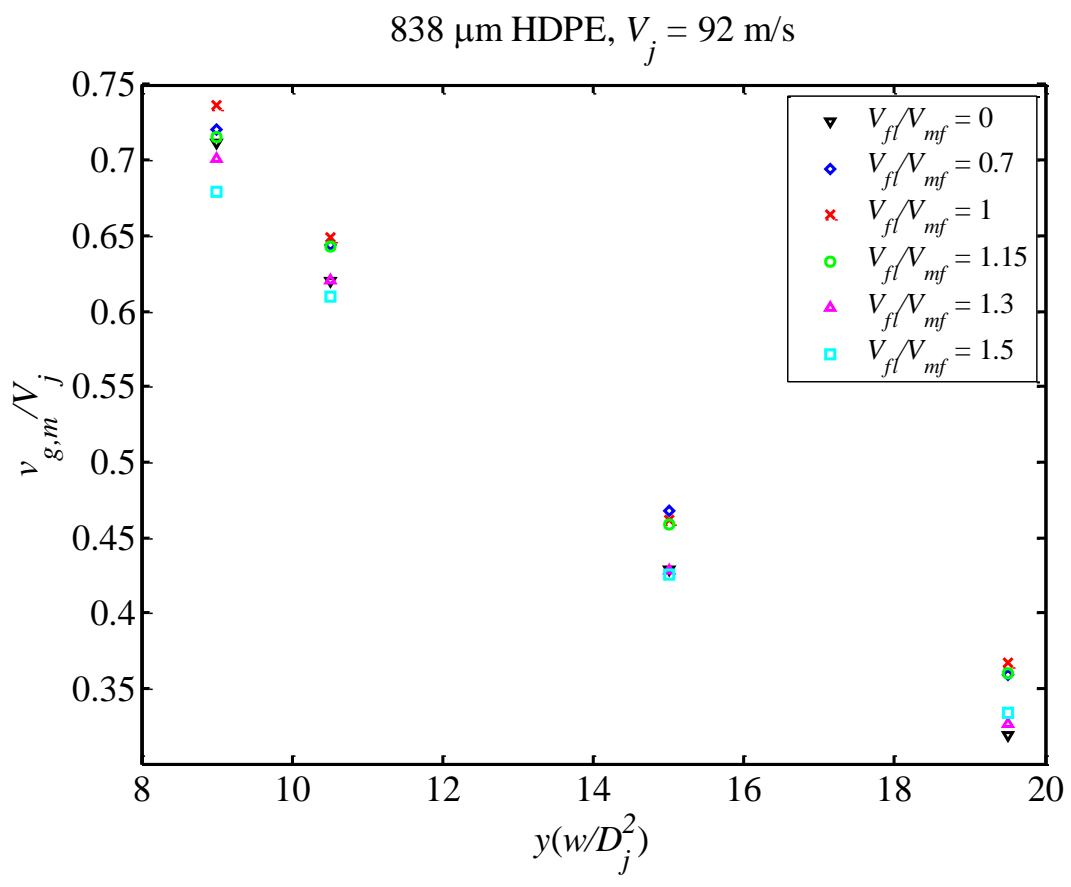

Figure 20: Maximum velocity values for the gas phase with varying fluidization velocity. Increasing the fluidization velocity tends to decrease the maximum velocity values.

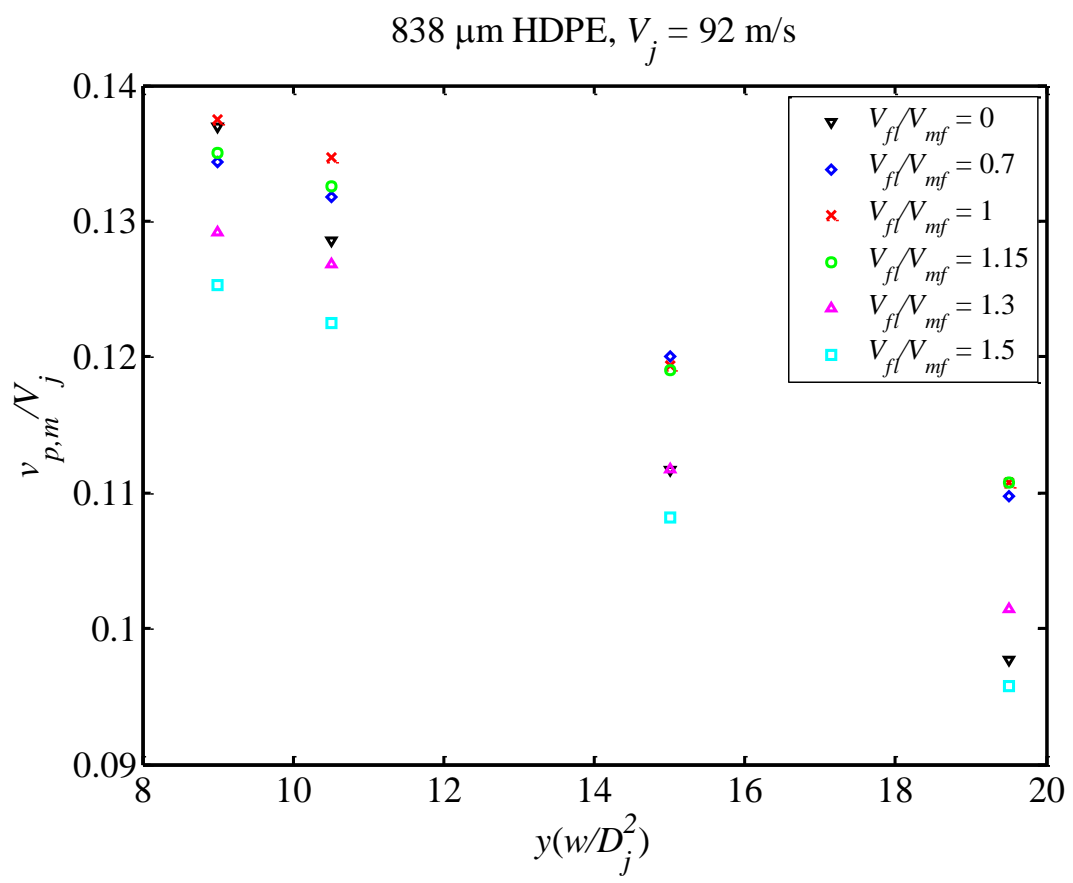

Figure 21: Maximum velocity values for the particulate phase with varying fluidization velocity. Increasing the fluidization velocity tends to decrease the maximum velocity values. 


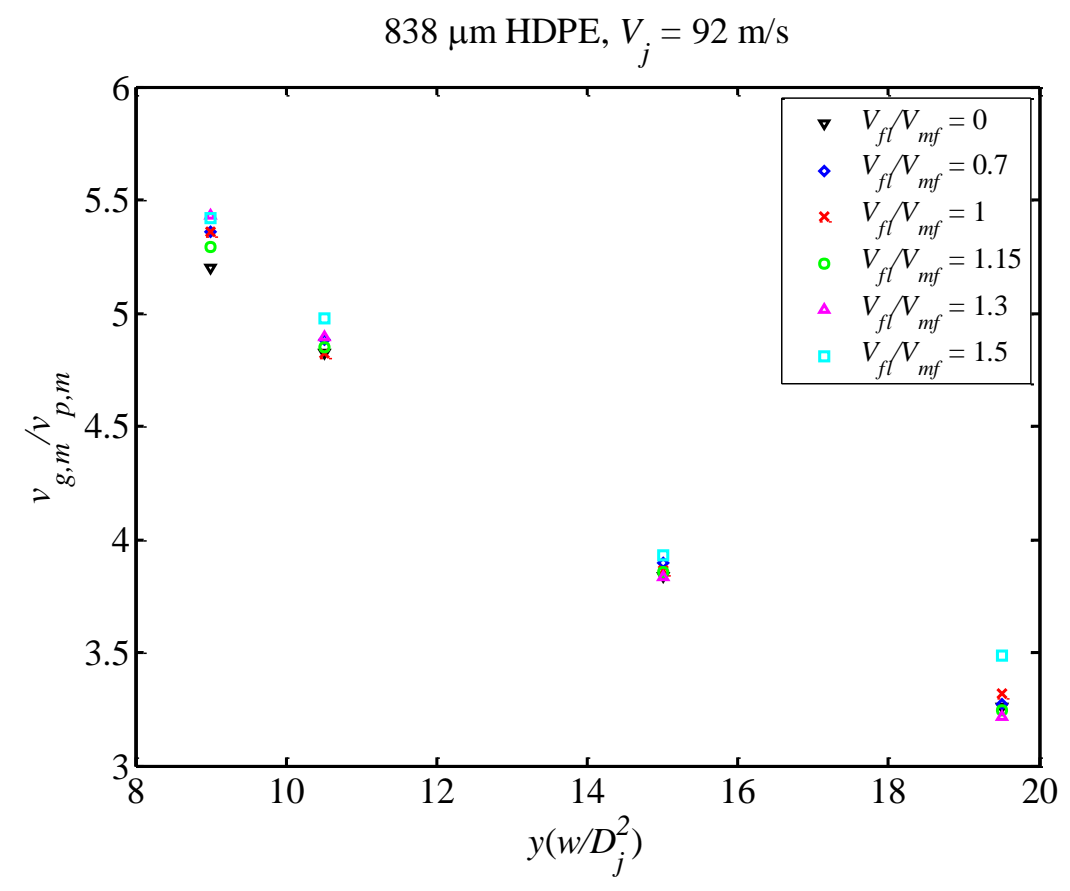

Figure 22: Ratio of the maximum velocity values for the gas and particulate phase with varying fluidization velocity. The ratio of maximum velocities appears to be independent of the fluidization velocity.

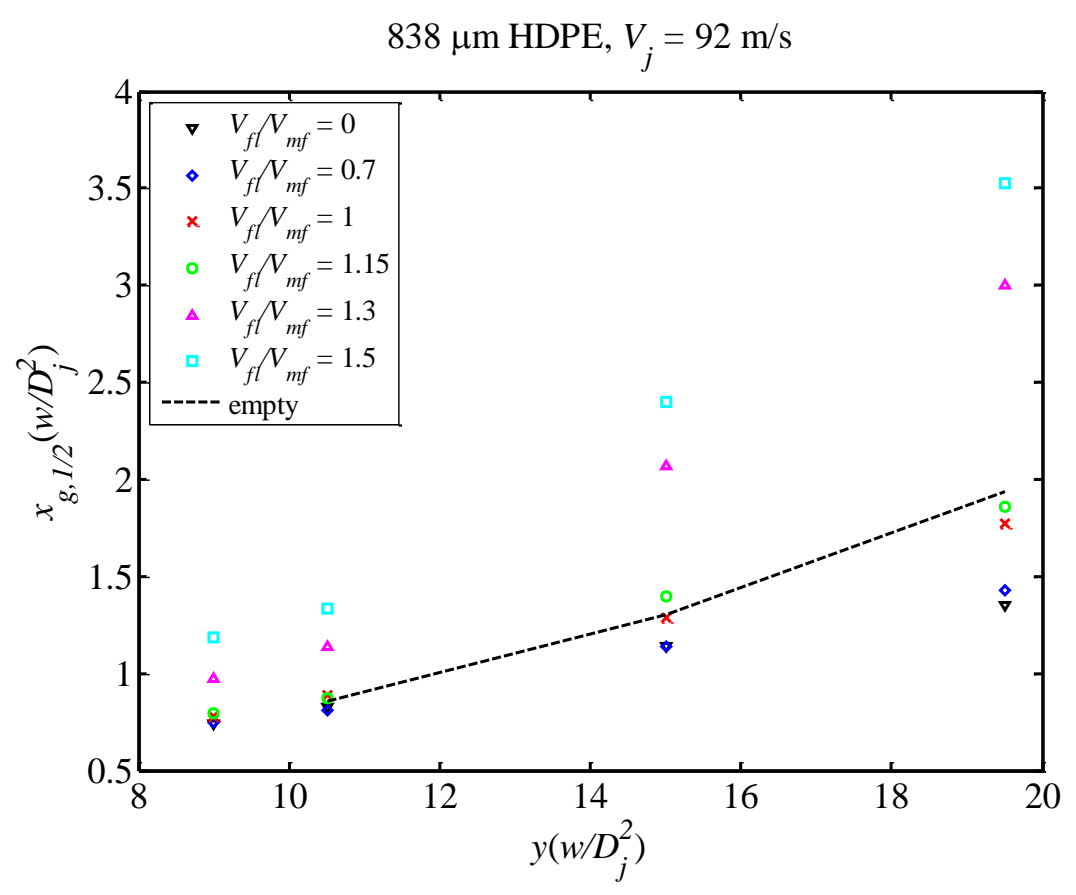

Figure 23: Half-velocity point values for the gas phase with varying fluidization velocity compared with the empty bed data. The gas phase velocity profile width at minimum fluidization is comparable to the empty bed. Increasing the fluidization velocity tends to widen the velocity profile. 


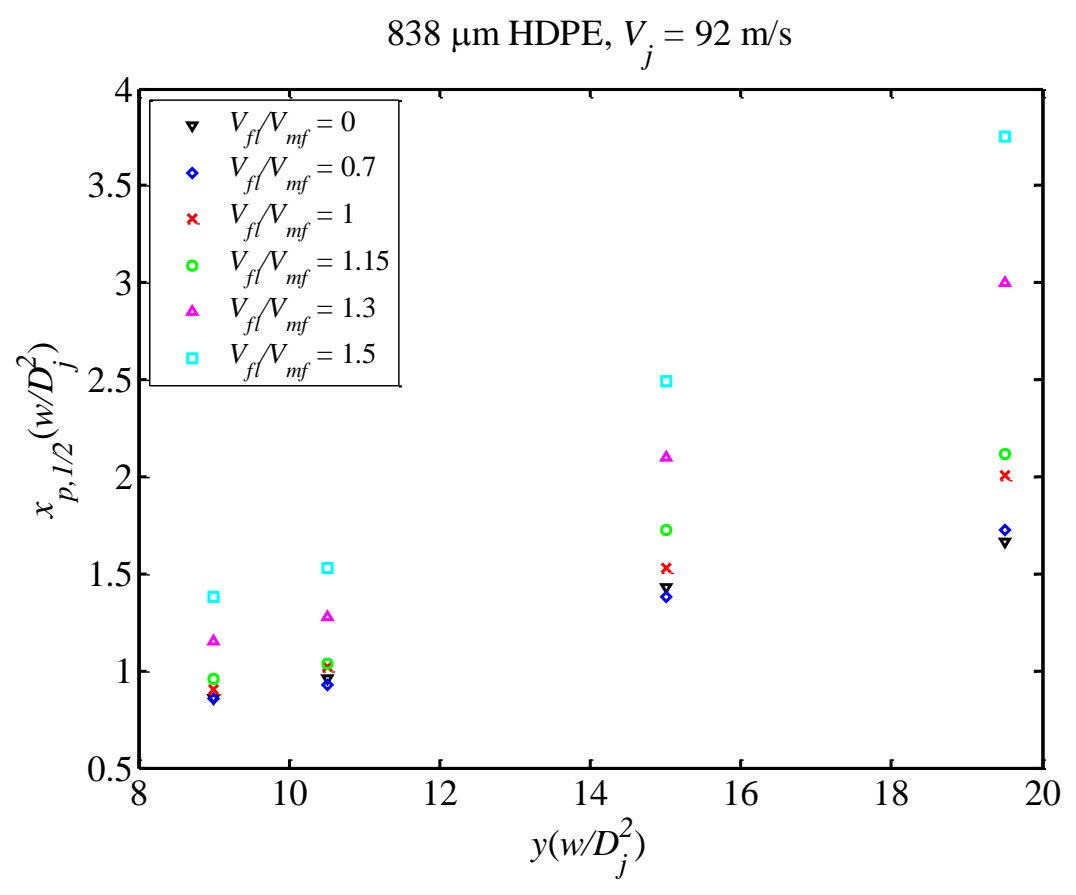

Figure 24: Half-velocity point values for the particulate phase with varying fluidization velocity. Increasing the fluidization velocity tends to widen the velocity profile.

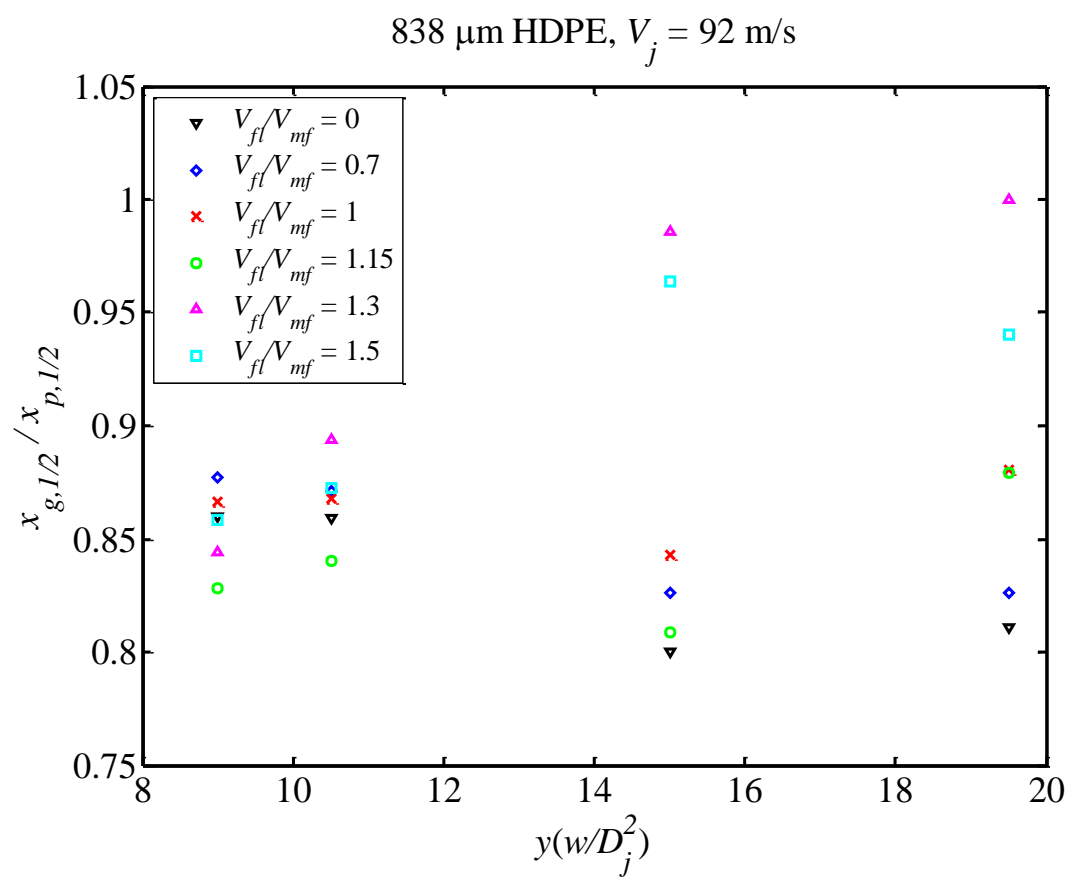

Figure 25: Ratio of the half-velocity point values for the gas and particulate phases with varying fluidization velocity. Increasing the fluidization velocity tends to widen the gas velocity profile with respect to the particulate phase velocity profile as more interstitial gas is entrained. 


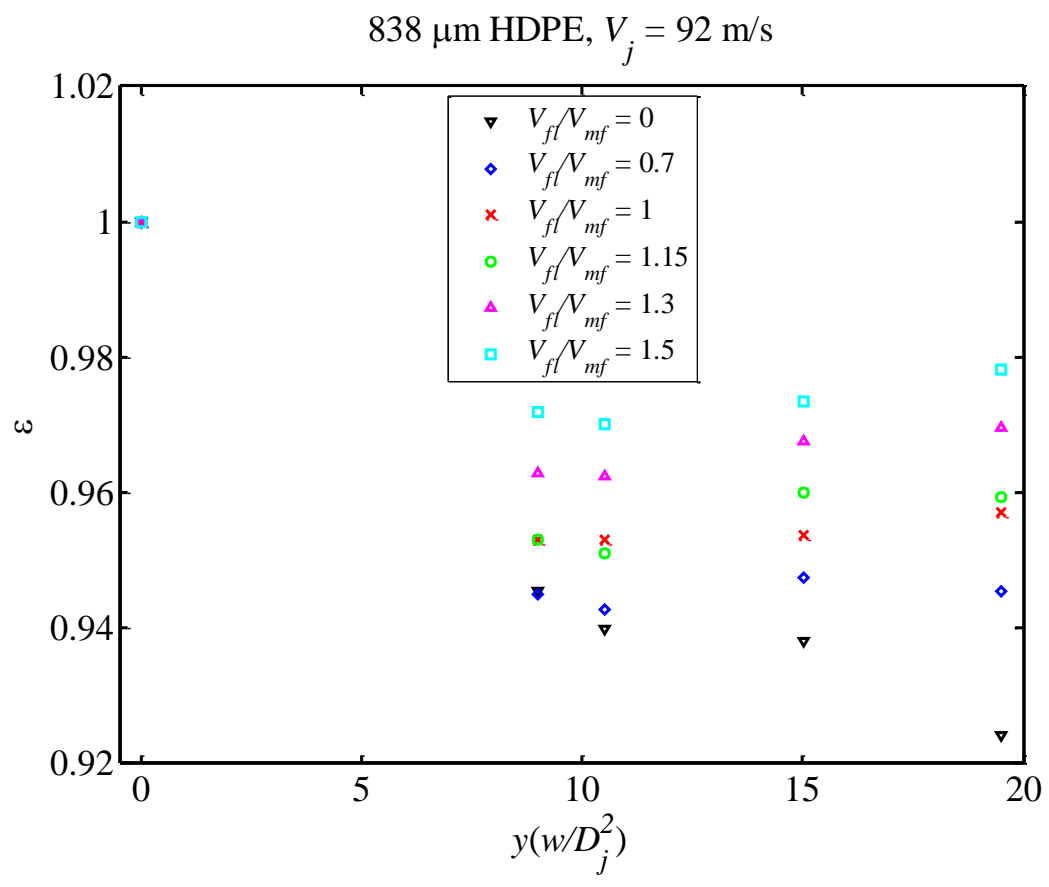

Figure 26: Void fraction values with varying fluidization velocity. Increasing the fluidization velocity tends to increase the void fraction in the jet plume.

The gas phase mass flow rates at the various fluidization rates are compared with the jet inlet value and the empty bed case in Figure 27. This figure indicates that when the emulsion is fluidized below the minimum fluidization rate, gas originating from the jet inlet diffuses into the emulsion downstream to locally fluidize the particles as the gas phase mass flow decreases downstream. Above the minimum fluidization rate, interstitial gas and bubbles in the emulsion are entrained into the jet plume as the gas phase mass flow increases downstream. (Unfortunately, this trend cannot be verified by the lateral velocity flux of the gas phase near the plume boundaries as the interstitial gas is not seeded with LDV ice tracer crystals; only the gas that originates at the inlet is seeded, which mixes laterally outwards). As the fluidization rate increases, the gas phase mass flow increases and approaches the empty bed values. The two phases compete for entrainment into the jet plume, as is indicated by the decrease in particulate phase mass flow with increasing fluidization (Figure 28).

The dependency of the gas and particulate phase momentum rates on the fluidization rate are shown in Figure 29 and Figure 30 respectively. As the fluidization rate increases, the gas phase momentum increases due to increased interstitial gas entrainment. Once again, the particulate phase momentum decreases with increasing fluidization due to competition with the increased interstitial gas entrainment. 


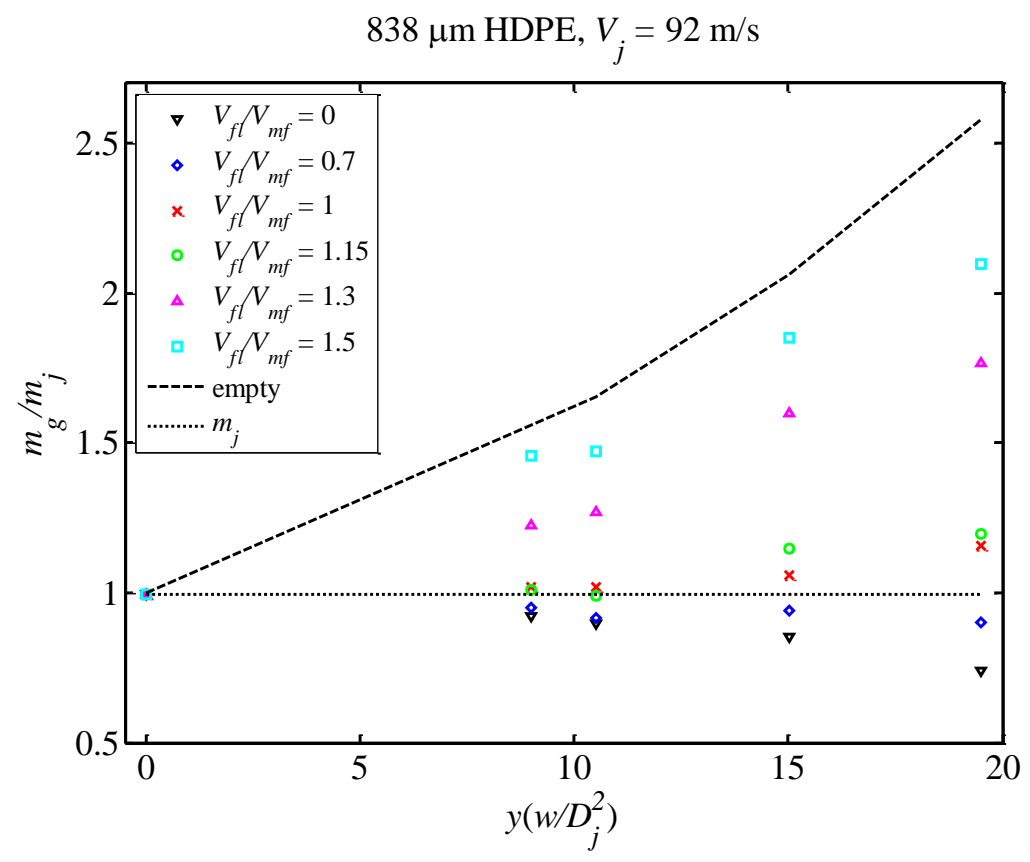

Figure 27: Mass flow rates for the gas phase with varying fluidization velocity compared with the empty bed data and jet inlet value. When the emulsion is fluidized below the minimum fluidization rate, gas originating from the jet inlet diffuses into the emulsion downstream to locally fluidize the particles as the gas phase mass flow decreases downstream. Above the minimum fluidization rate, interstitial gas and bubbles in the emulsion are entrained into the jet plume as the gas phase mass flow increases downstream. As the fluidization rate increases, the gas phase mass flow increases and approaches the empty bed values.

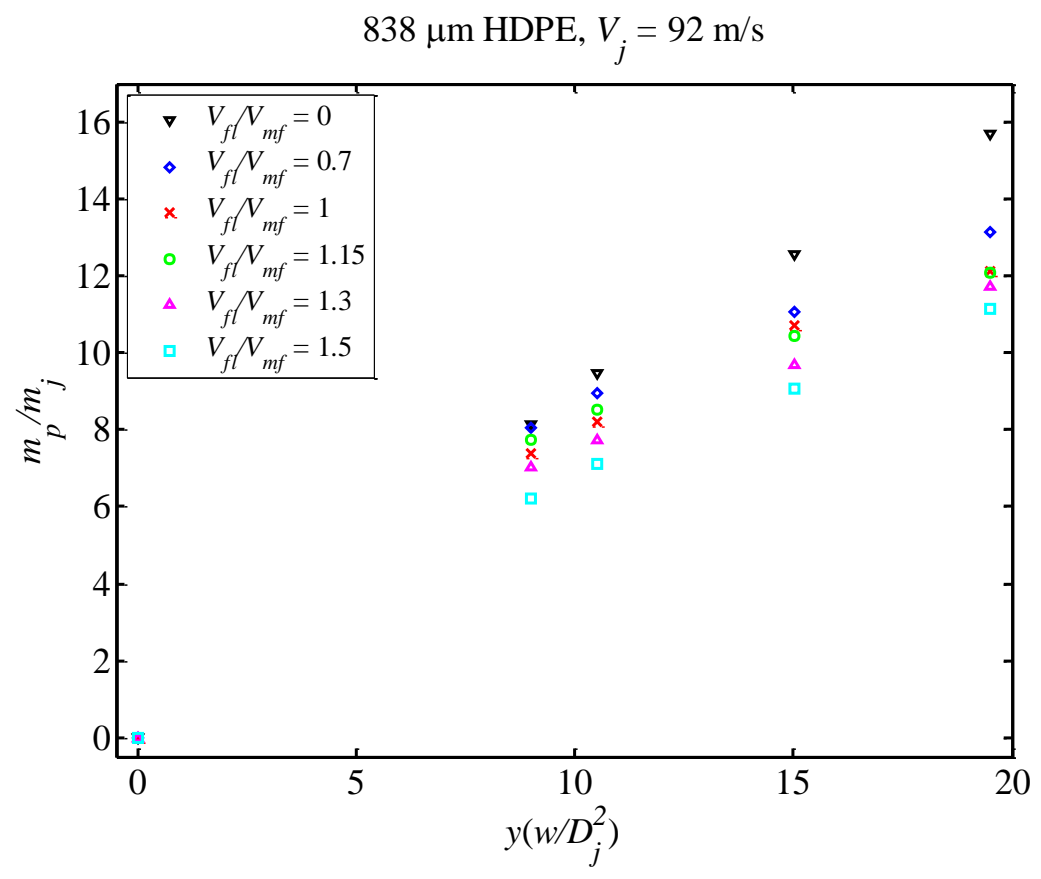

Figure 28: Mass flow rates for the particulate phase with varying fluidization velocity. As the fluidization rate increases, the particulate phase mass flow decreases due to competition with the increased interstitial gas entrainment. 


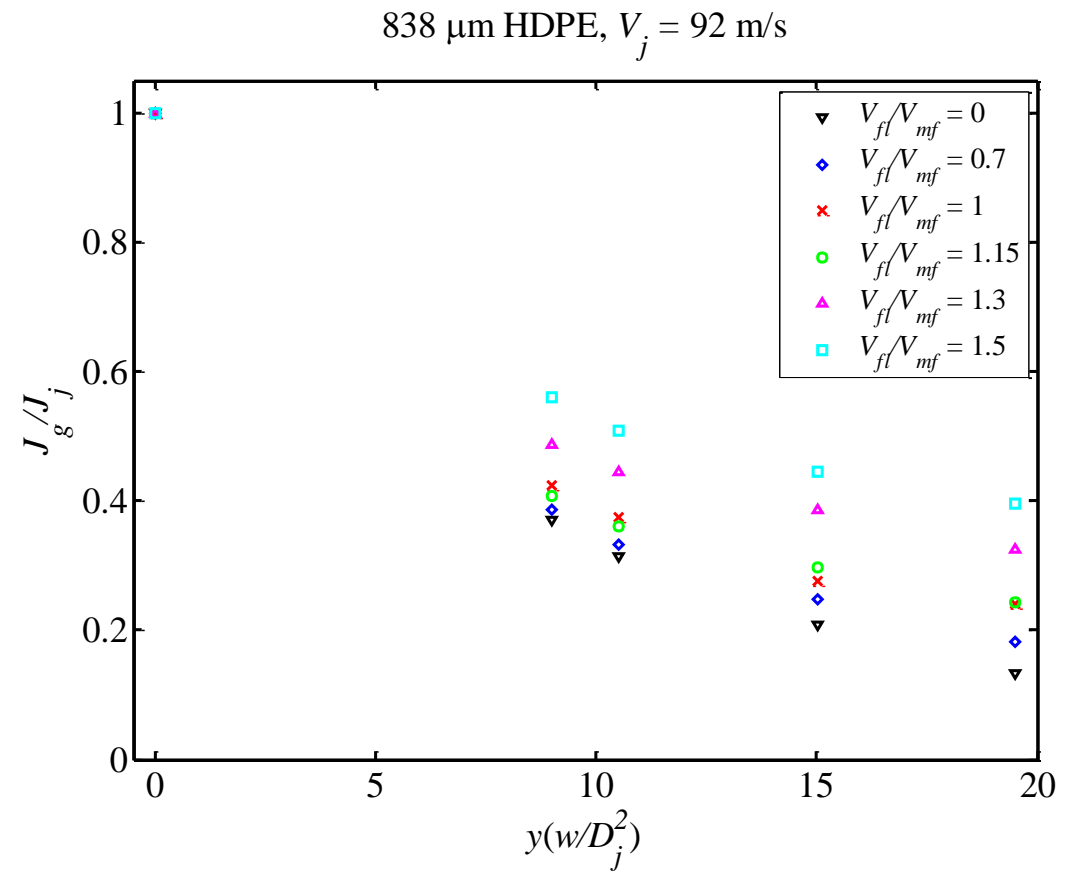

Figure 29: Momentum rates for the gas phase with varying fluidization velocity. As the fluidization rate increases, the gas phase momentum increases due to increased interstitial gas entrainment.

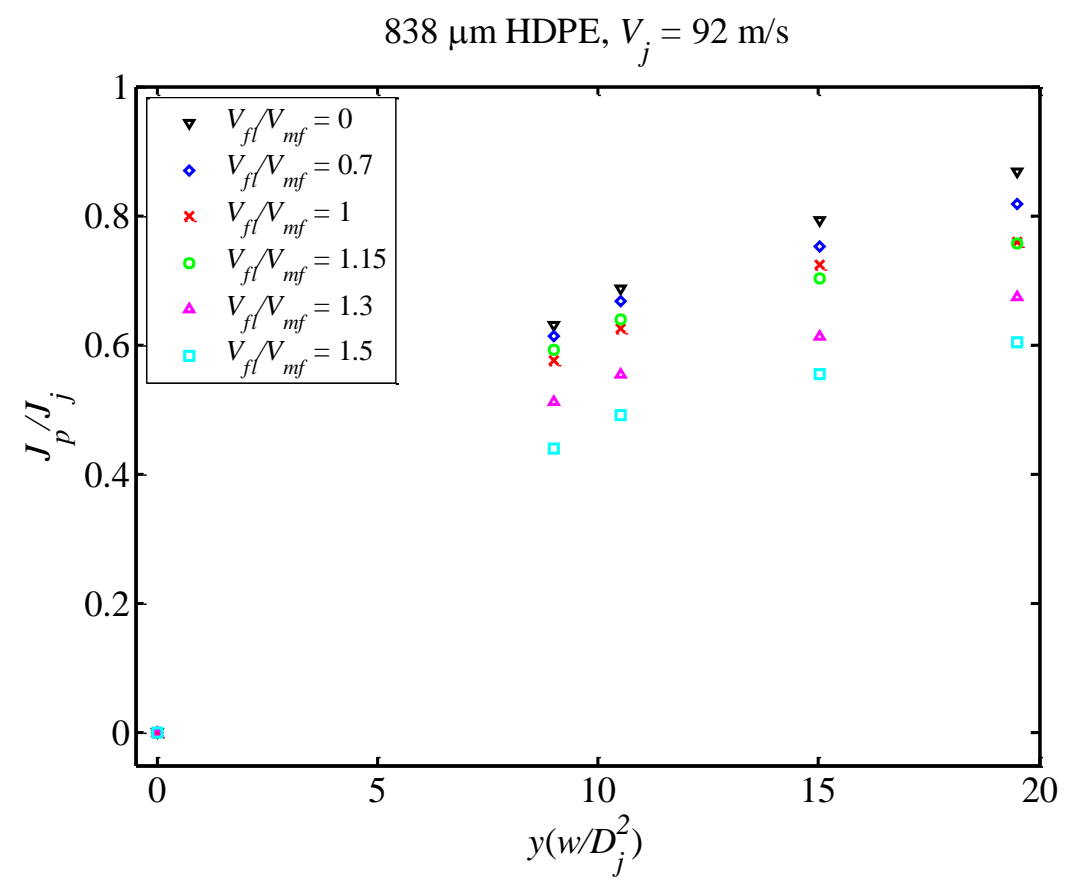

Figure 30: Momentum rates for the particulate phase with varying fluidization velocity. As the fluidization rate increases, the particulate phase momentum decreases due to competition with the increased interstitial gas entrainment. 
Finally, the particle drag coefficient was calculated using the Gaussian particulate and slip velocity profiles as well as the calculated void fractions as described earlier. The average values for the axial locations in the jet plume are reported in Table 5. The particle drag coefficient values at every fluidization condition are in good agreement with the established empirical value of 0.4 .

\begin{tabular}{|c|c|}
\hline$V_{f l} / V_{m f}$ & $C_{D}$ \\
\hline 0 & 0.48 \\
\hline 0.7 & 0.42 \\
\hline 1 & 0.38 \\
\hline 1.15 & 0.38 \\
\hline 1.3 & 0.37 \\
\hline 1.5 & 0.43 \\
\hline
\end{tabular}

Table 5: Particle drag coefficients. The values were determined in the same manner as described earlier, using the Gaussian particulate phase and slip velocity profiles along with the calculated void fraction values. 


\subsubsection{Effect of fluidization on fluctuating velocities and analysis}

The same LDV technique and data used to measure the mean velocities was extended to yield the corresponding fluctuations after ensuring that enough statistics were available to estimate second order moments. One significant difference between the mean profiles and turbulent profiles is that the axial distance at which the measurements were made was not sufficient to observe selfsimilarity in fluctuations. The same normalizing variables of maximum centerline velocity and half-plume width based on mean streamwise velocity are used. However the effect of emulsion fluidization can still be investigated. For the sake of convenience the different emulsion fluidization states are named as cases according to Table 6 .

\begin{tabular}{|c|c|}
\hline Case & Description \\
\hline 1 & No particles (Empty bed) \\
\hline 2 & $V_{f l}=0$ (Spouted bed) \\
\hline 3 & $V_{f l}=0.7 V_{m f}$ \\
\hline 4 & $V_{f l}=V_{m f}$ \\
\hline 5 & $V_{f l}=1.15 V_{m f}$ \\
\hline 6 & $V_{f l}=1.3 V_{m f}$ \\
\hline 7 & $V_{f l}=1.5 V_{m f}$ \\
\hline
\end{tabular}

Table 6: Experimental cases considered

The fluctuating intensity in the velocity of a gas jet through the empty column also referred to in the present work as the "Empty Bed" (case 1) is compared to other planar jet experimental data in Figure 31. It must be noted that the data previously reported in literature has been restricted to one half of the domain, namely $x / x_{1 / 2} \geq 0$ and has been reflected along the centerline. Figure 31 shows good agreement with Miller and Comings (1957) but poor agreement with Gutmark and Wygnanski (1975). This is because the axial locations of the measurements made by Miller and Comings (1957) match better with the present study and both happen to lie within the potential core or non self-similar region of turbulence. On the other hand, measurements of Gutmark and Wygnanksi (1975) were made at axial locations beyond $y / D_{j}=95$ which is in the self-similar region. 


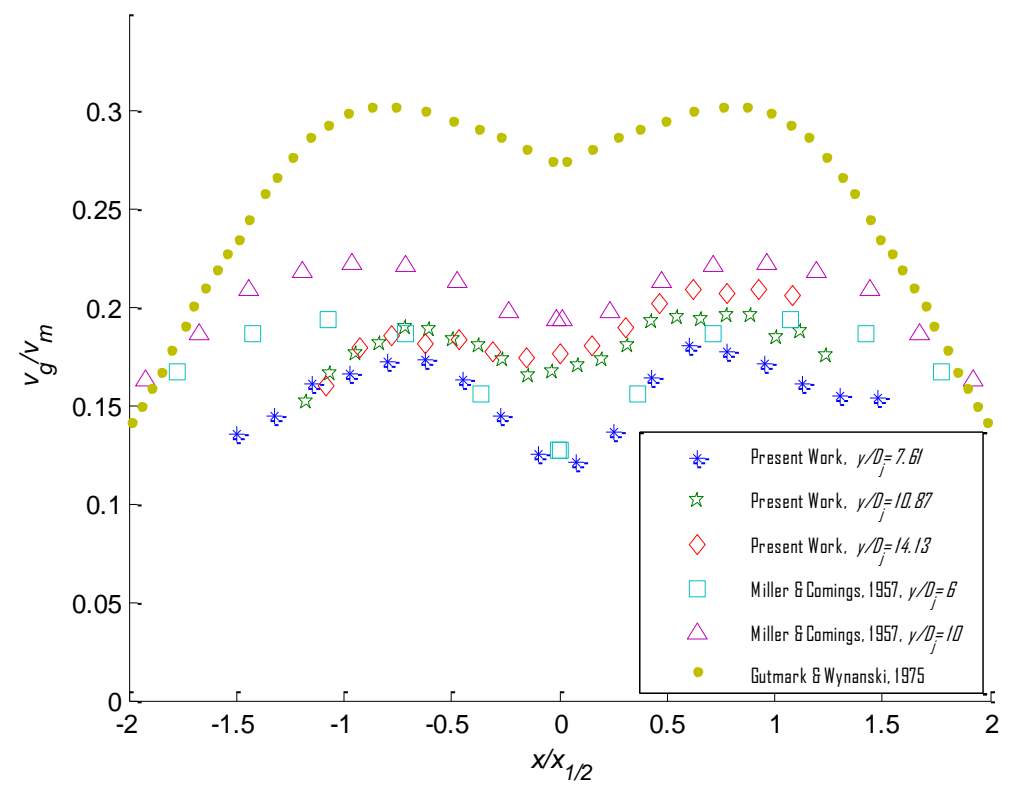

Figure 31: Comparison of fluctuating velocity in the Empty bed, case 1, with planar, single-phase turbulent jet data from literature

The transverse (radial) profiles of the intensity of fluctuations in the axial velocity for different experimental cases for both gas and particle phases are shown at three axial distances of $y / D_{j}=$ 7.61, 10.87 and 14.13 respectively, in Figure 32 to Figure 34 and Figure 35 to Figure 37. To enable better comparison between the fluctuations in the two phases, Empty Bed (case 1) gas fluctuations are added along with the particle phase profiles. It can be seen that the particle fluctuations are higher, close to 1.5 times the magnitude of gas fluctuations. In general, the shapes of the profiles of both the phases are similar to the Empty Bed (case 1) profile. Figure 38 and Figure 39 show the fluctuating intensity in the axial velocity of the two phases along the centerline of the jet for different experimental cases at three axial distances of $y / D_{j}=7.61,10.87$ and 14.13 . Some significant trends can be observed from these figures. Firstly, the fluctuating velocities tend to increase when moving downstream for the same experimental case. Secondly, there is an increase in gas turbulence in the Spouted Bed (case 2) as compared to the Empty Bed (case 1). Thirdly, the effect of increasing the distributor gas velocity is to initially decrease and then increase the fluctuations in both phases. Further, the fact that the particle and the gas velocity fluctuations complement each other is illustrated. 


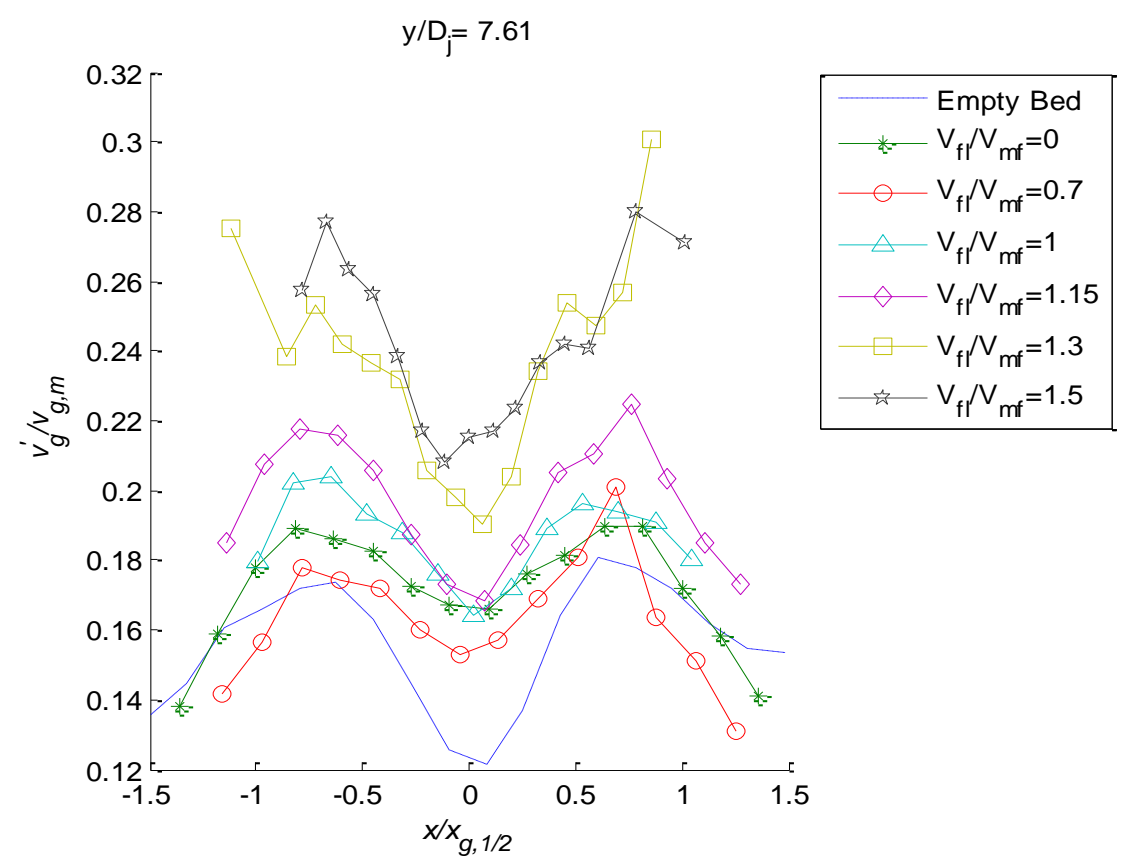

Figure 32: Radial variation in gas axial fluctuating velocity for different experimental cases at $y / D_{j}=7.61$

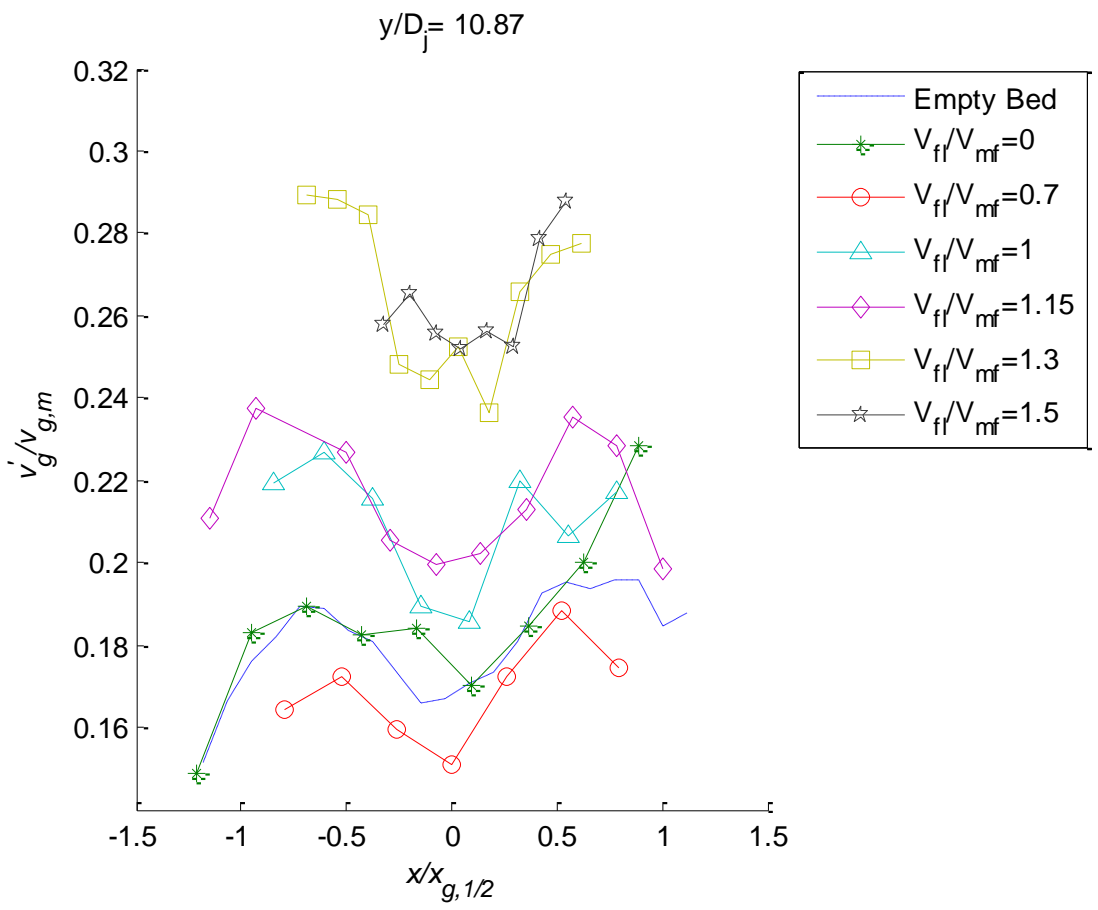

Figure 33: Radial variation in gas axial fluctuating velocity for different experimental cases at $y / D_{j}=10.87$ 


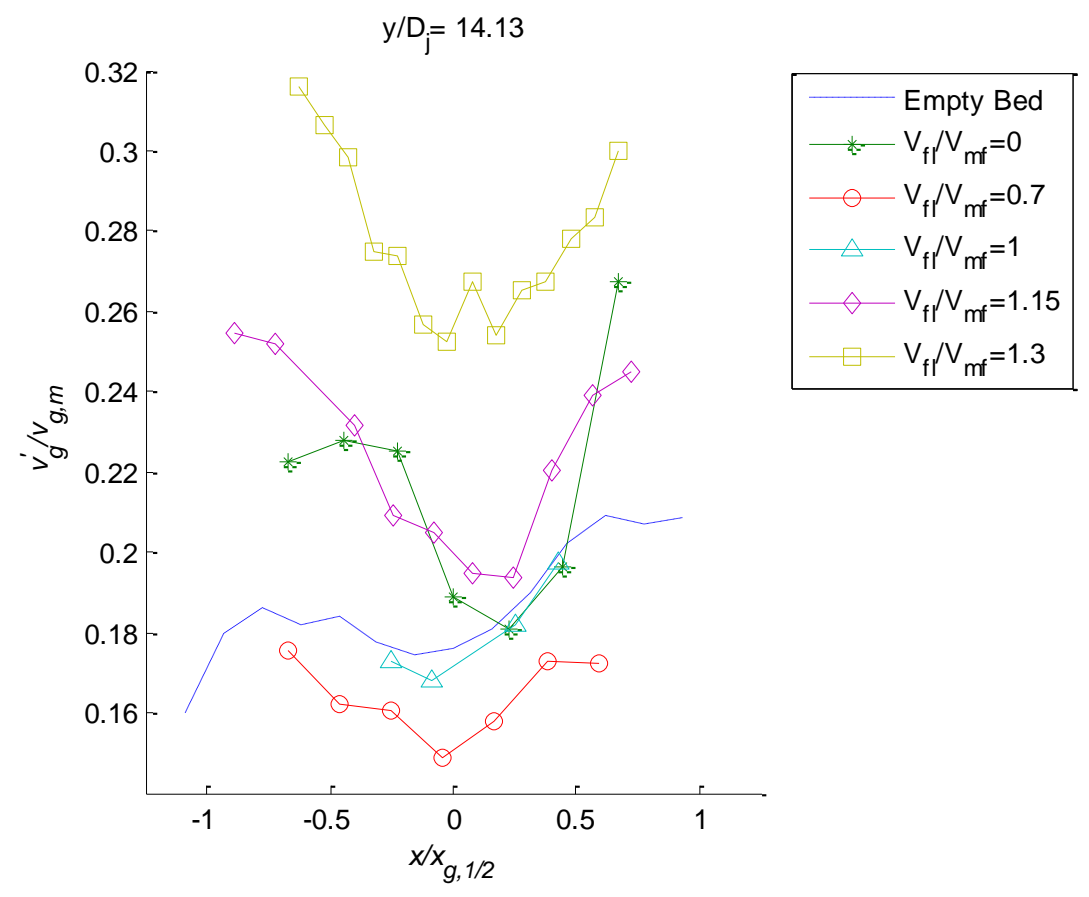

Figure 34: Radial variation in gas axial fluctuating velocity for different experimental cases at $y / D_{j}=14.13$

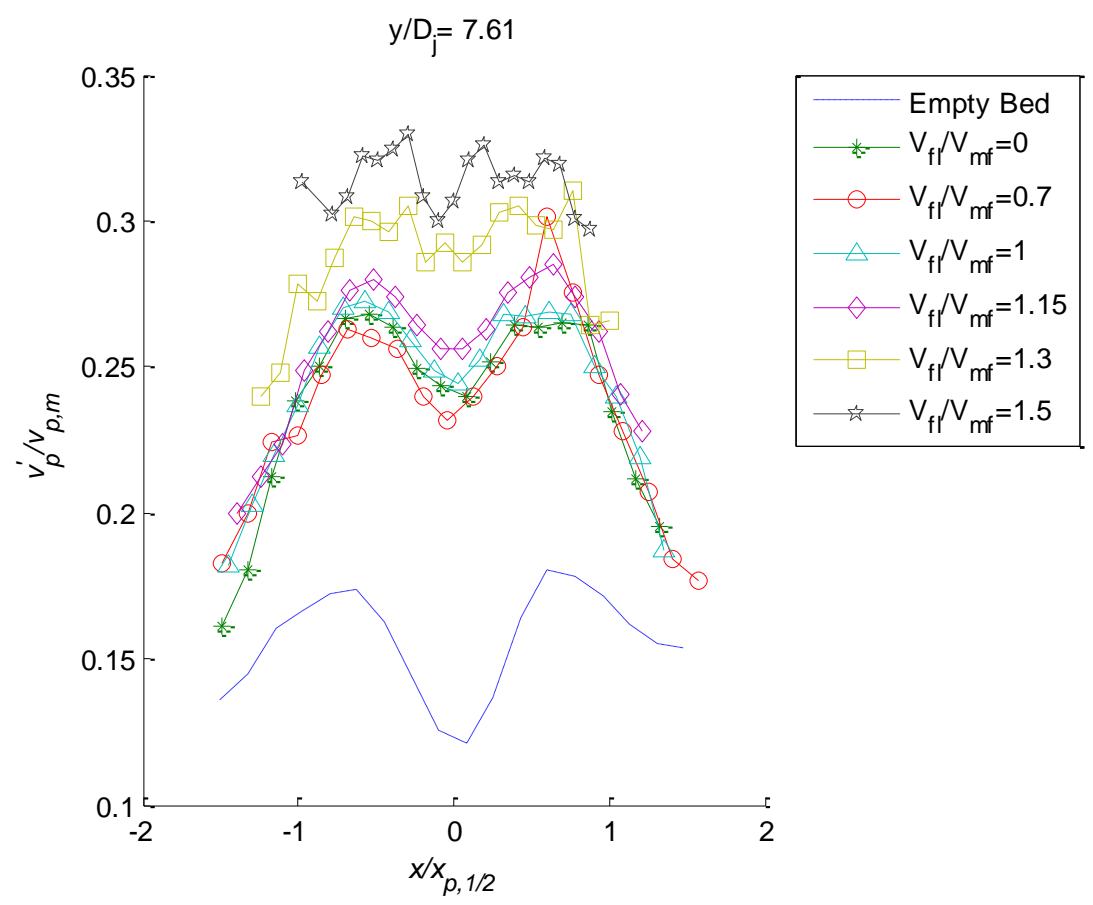

Figure 35: Radial variation in particle axial velocity fluctuations for different experimental cases at $y / D_{j}=7.61$ 


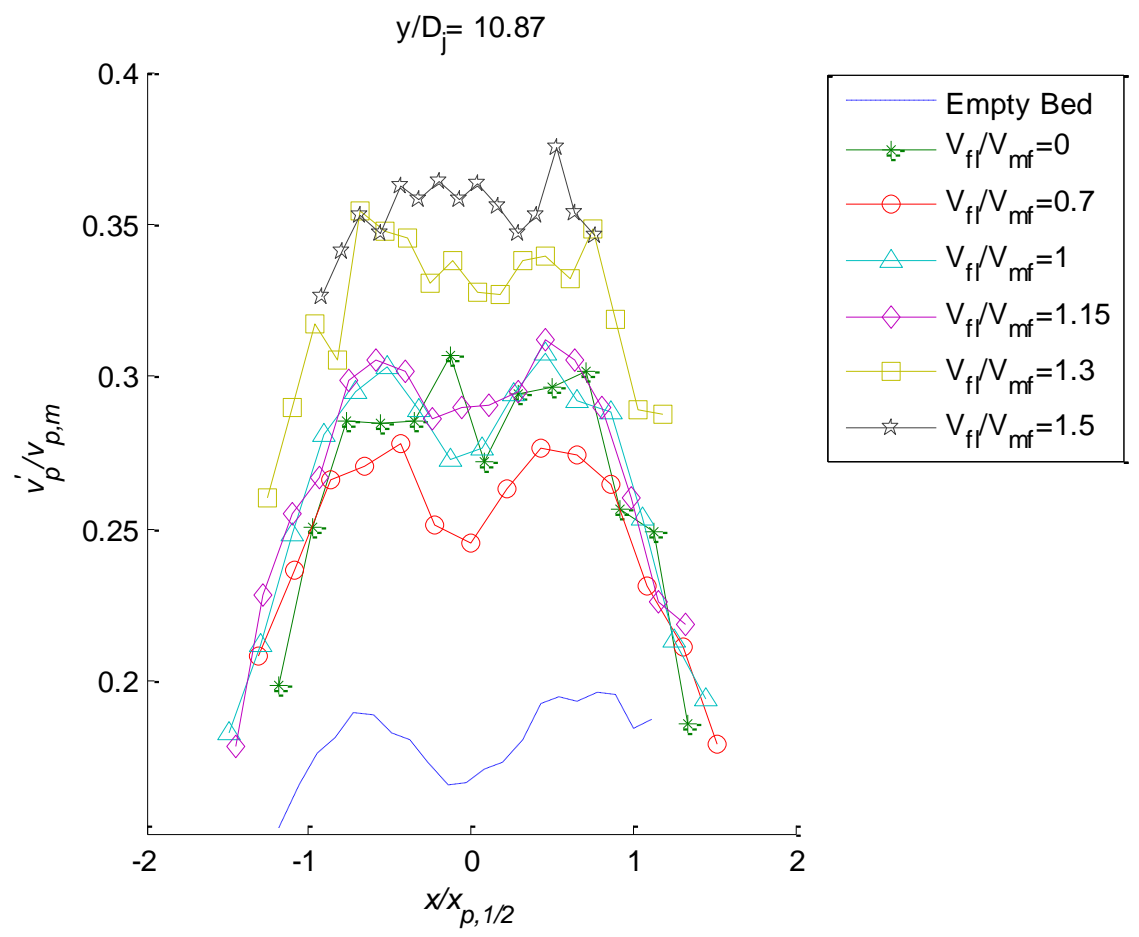

Figure 36: Radial variation in particle axial velocity fluctuations for different experimental cases at $y / D_{j}=10.87$

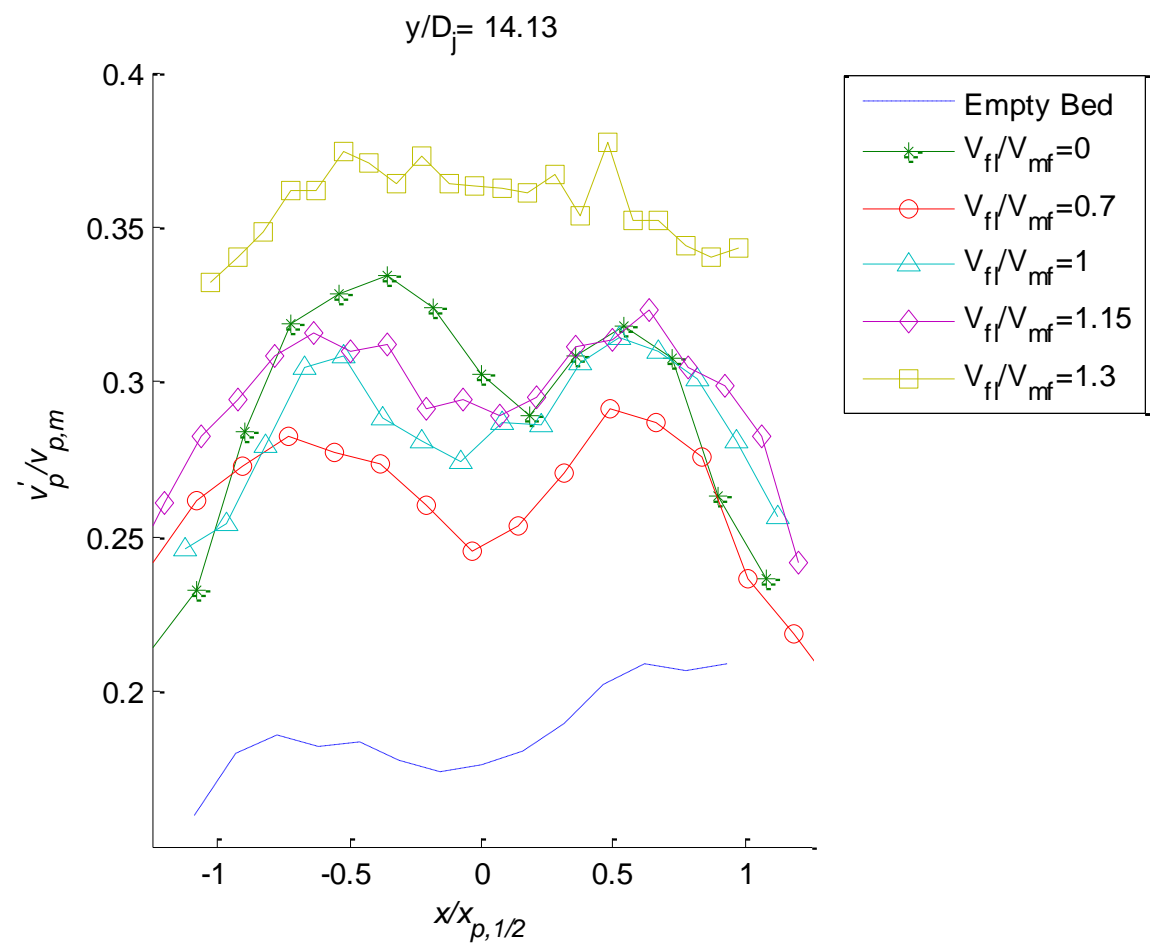

Figure 37: Radial variation in particle axial velocity fluctuations for different experimental cases at $y / D_{j}=14.13$ 


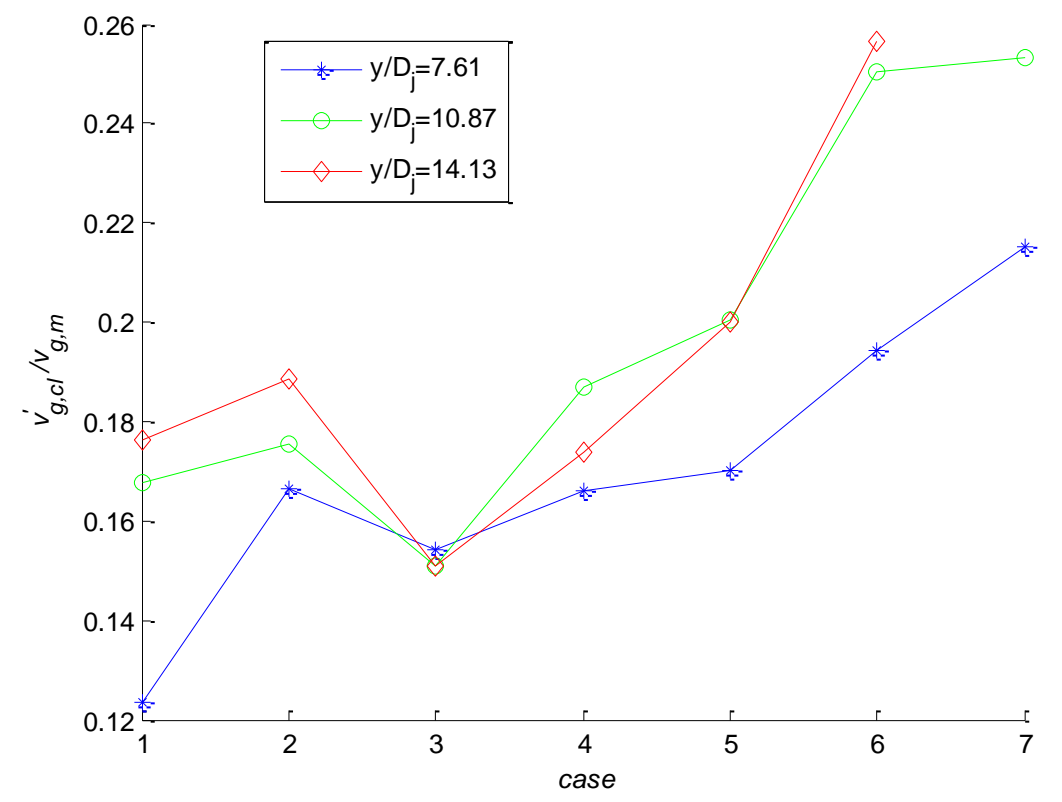

Figure 38: Axial gas fluctuating velocity along the centerline for different experimental cases

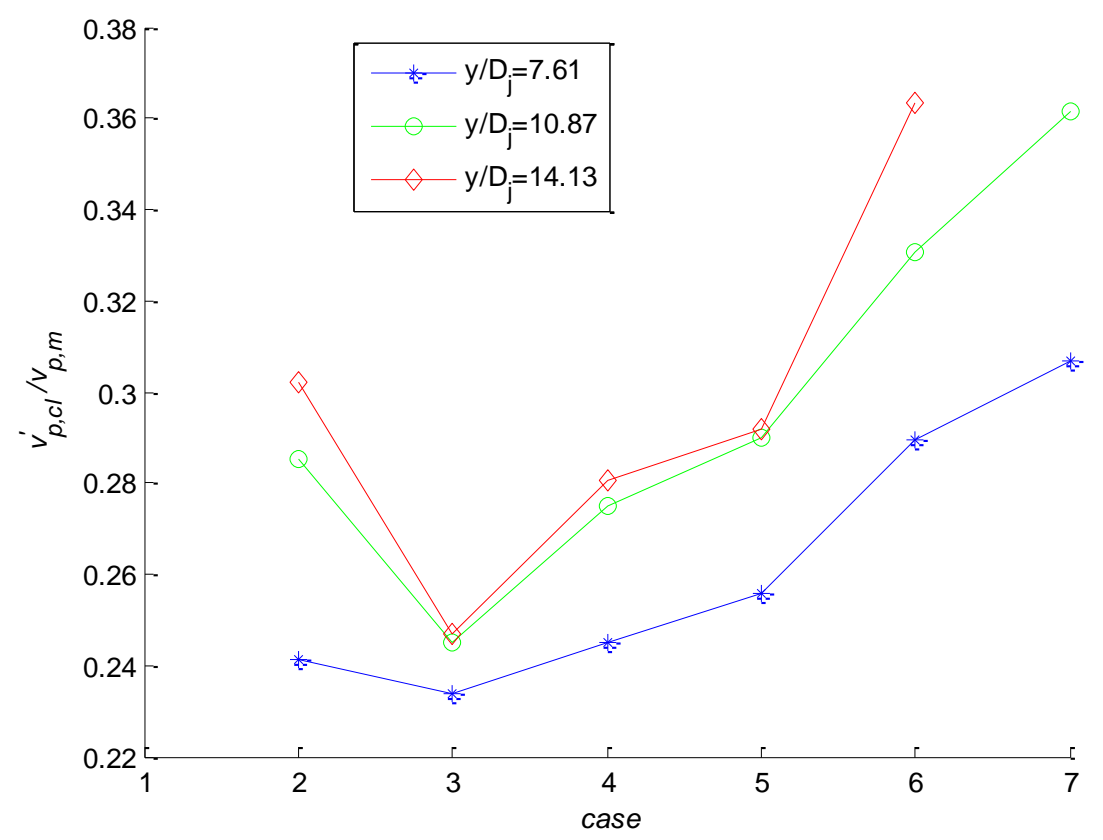

Figure 39: Axial particle fluctuating velocity along the centerline for different experimental cases 
It can be postulated that the effect of the particle phase on the fluctuating behavior of the gas phase and vice versa occurs through only the mean flow variables, namely the half plume width and the maximum axial velocity, for a given axial location within the jet plume. The relationship is direct with the former and inverse with respect to the latter. The reason for making this assumption is simply because the half plume width can be considered a measure of the eddy length scale for gas phase turbulence and the maximum axial velocity, a measure of the magnitude of mean velocity. For the particle phase, on the other, the half plume width can be considered a measure of the mean free path of particle collisions, though its relationship to particle fluctuations is still the same as that of eddy length scale to gas turbulence.

Figure 20 and Figure 21, and Figure 23 and Figure 24, illustrate the variation in the ratio of $x_{1 / 2}$ and $v_{m}$ for gas and particle phases for different fluidization cases respectively. When moving from the Empty bed to the Spouted bed case, the gas flow rate inside the jet plume decreases due to the lack of gas entrainment from the surrounding and the jet spreading width also decreases due to particles constricting the flow. However, the decrease in the maximum mean velocity caused by the lack of entrainment is much more significant than the reduction in the plume width. This causes the gas turbulence intensity to increase in the Spouted bed. Starting with case 4, which is the minimum fluidization case, increasing fluidizing air rate widens the jet spreading, as gas and particles from the emulsion phase and the jet plume interact more freely. Thus, the increase in fluctuating intensity with fluidizing rate beyond minimum fluidization can be attributed to the increasing plume half widths for both the gas and particle phases.

However, before reaching minimum fluidization it is seen that increasing fluidizing air rate decreases the fluctuating velocities. This can be explained by arguing that the additional gas flow within the voids of a packed bed facilitates a higher rate of gas and particles to be entrained from the emulsion into the jet. Hence, while the system cannot deform easily and there is negligible change in the half plume widths, there is a small increase in the gas and particle velocities within the plume which causes the turbulence intensity to decrease in both phases (case 3). In summary, an analysis of turbulence modulation based on coupling through mean flow variables (Figure 40 and Figure 41) mirrors the behavior seen in the gas and particle fluctuating velocities shown in Figure 38 and Figure 39. 


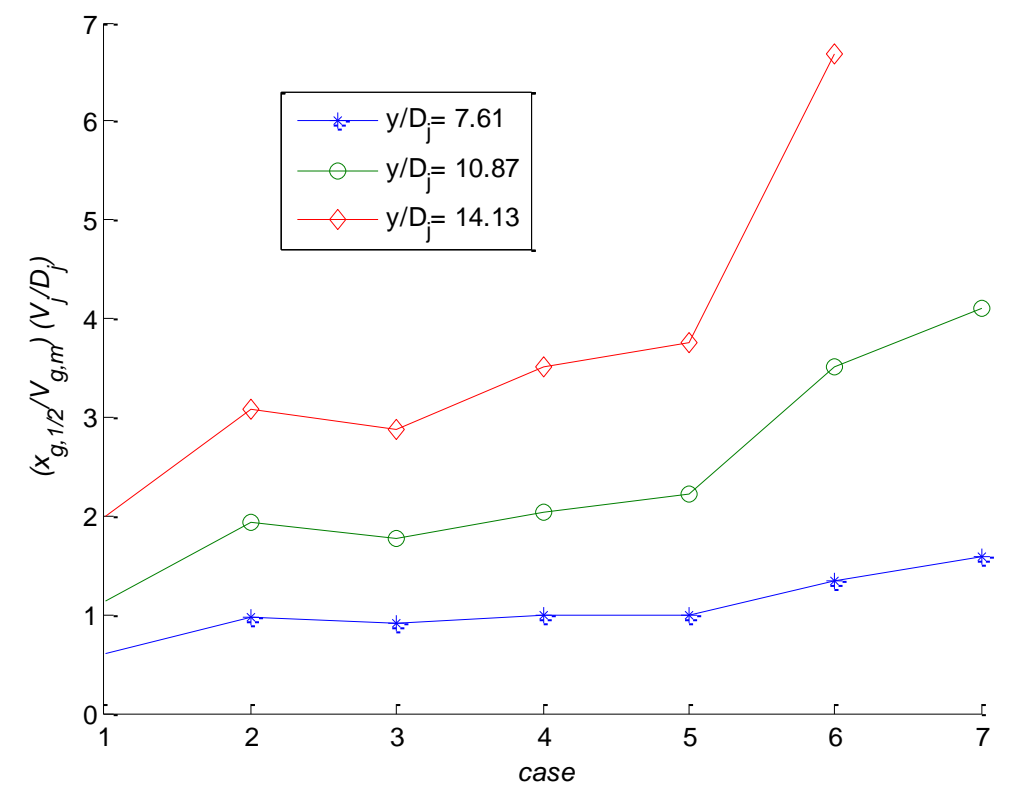

Figure 40: Variation in the ratio of gas half plume width to maximum axial velocity for different experimental cases

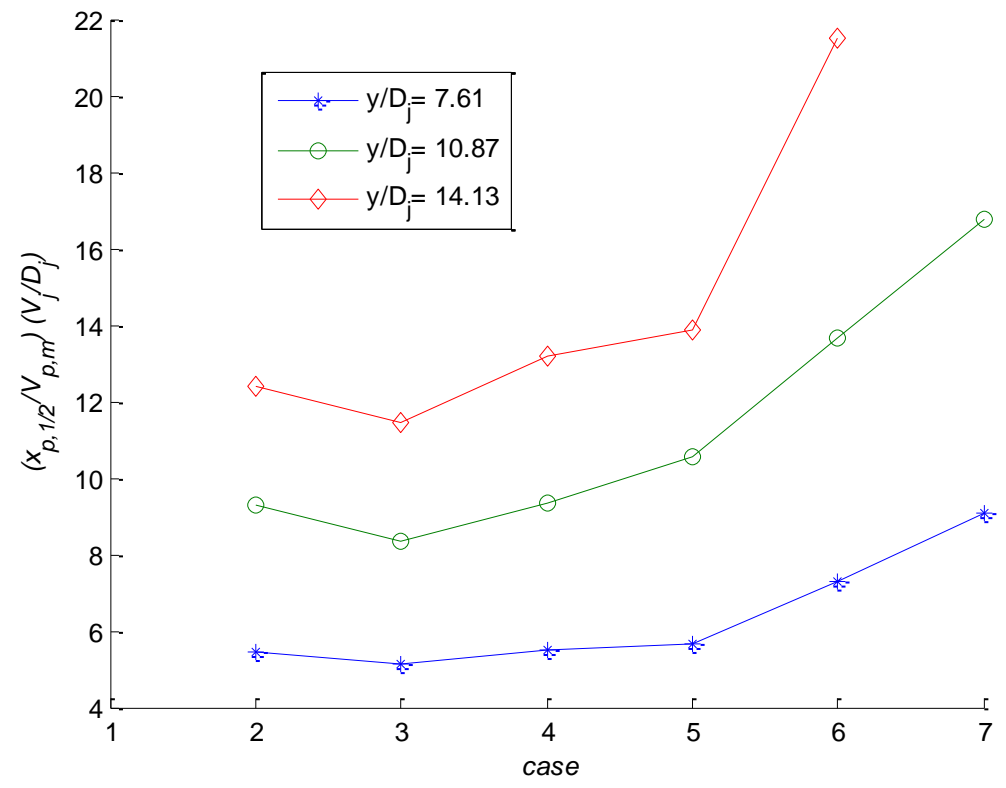

Figure 41: Change in ratio of particle half plume width to maximum axial velocity for different experimental cases 


\subsubsection{Uncertainty analysis}

In order to obtain stable mean and fluctuating statistics in the jet, LDV data was acquired at each location for a duration of 120 seconds. Typical data counts for both the gas and particulate phases in the core region are approximately 5,000 to 10,000 bursts. Based on Figure 42 and Figure 43 , it can be seen that a reasonably good estimation of both the mean and fluctuating quantities of gas and particles can be obtained from data with bursts greater than 1000. While measurements made at most locations had counts of more than a 1000, a few locations had insufficient number of bursts due to either poor seeding of tracer ice crystals (at higher axial locations and fluidization rates) or low bed particle concentrations (towards the boundary of the jet plume). These data points were eliminated while reporting the fluctuating velocity profiles.
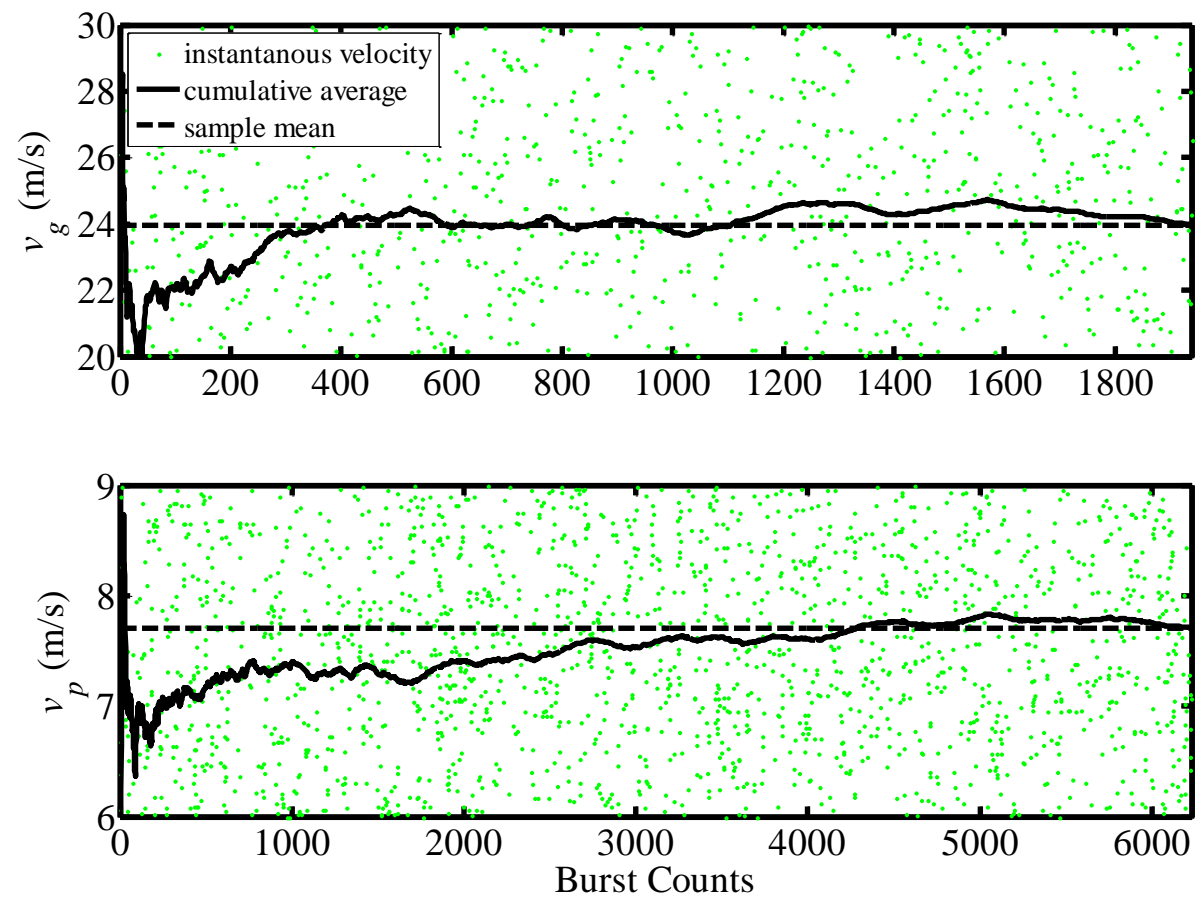

Figure 42: LDV gas and particulate phase velocity measurements at

$y=130 \mathrm{~mm}, x=10 \mathrm{~mm}$. 1,938 bursts were recorded for the gas phase and 6,231 bursts for the particulate phase over the recording period of 120 seconds. 

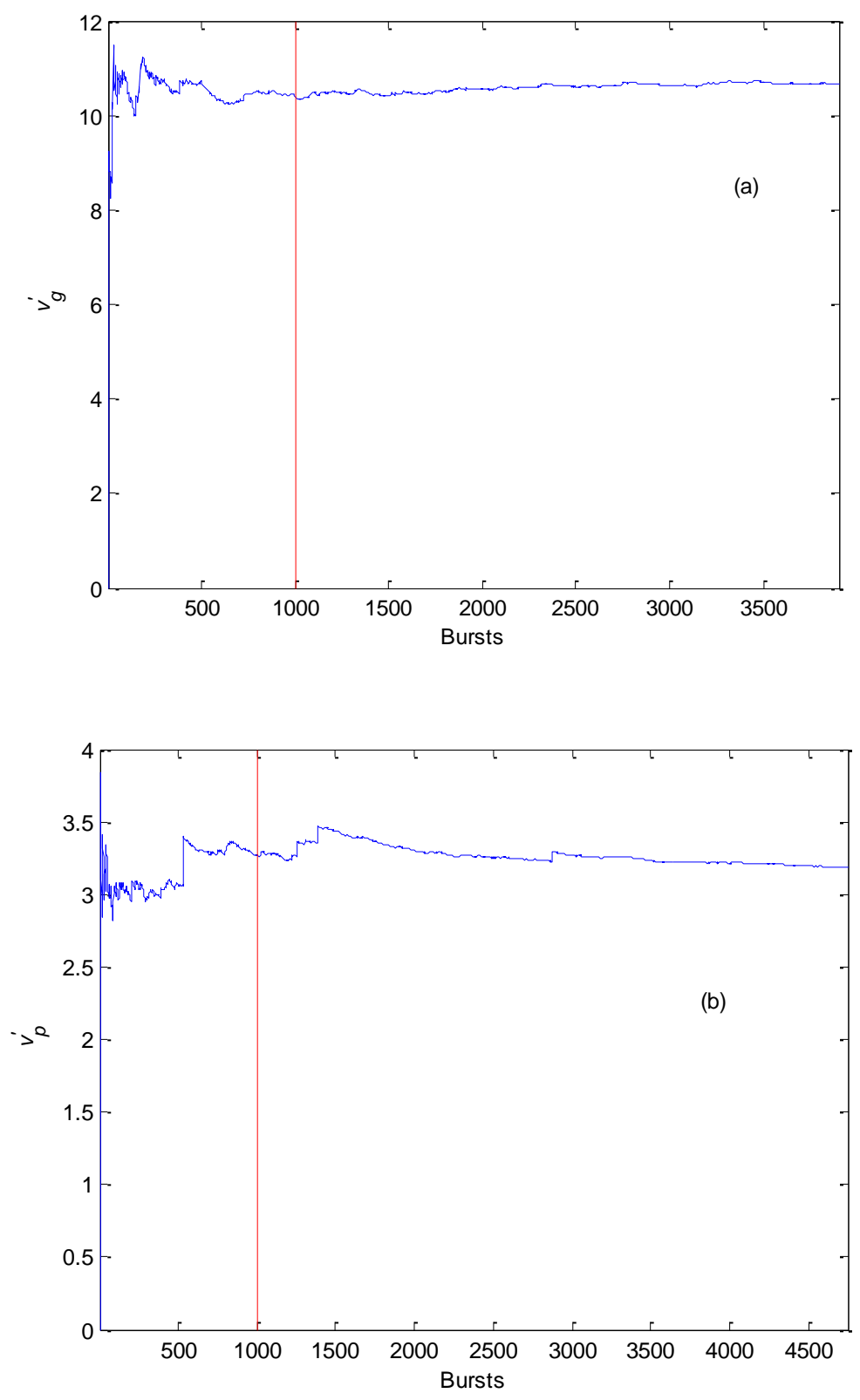

Figure 43: Evolution of fluctuation statistics for gas tracer (a) and bed particles (b), at $y=70 \mathrm{~mm}$ and $x=1.5 \mathrm{~mm}$ $\left(y / D_{j}=7.61\right.$ and $\left.x / x_{1 / 2}=0.237\right)$ for case 2, Spouted Bed. Only locations having burst counts greater than a 1000 are considered.

The jet in the bubbling bed was run twice more at the same conditions as in the prior sections. In addition, an experiment was carried out with a non-seeded jet $\left(T_{j}=15^{\circ} \mathrm{C}\right)$ at the same inlet momentum $\left(J_{j}=0.735 \mathrm{~kg} \cdot \mathrm{m} / \mathrm{s}^{2}\right)$ in order to determine if there are any unforeseen effects of the colder ice crystal seeded jet gas. Furthermore, the bed particle Doppler bursts from this run were processed with and without the subranging procedure, to examine the effects of this data subranging technique. The gas and particulate phase mean velocity profiles at the axial location of $y=100 \mathrm{~mm}$ for the three seeded jet runs as well as the subranged and non-subranged, non- 
seeded jet run are shown in Figure 44 and Figure 45. Less deviation was seen at lower downstream distances $(y=60,70 \mathrm{~mm})$. The deviations are due to 1$)$ the swaying and pulsating nature of the jet and 2) the decreased burst data count outside the jet core. The non-seeded runs indicate that subranging has no noticeable effect on the particulate phase velocity values in the jet core. The corresponding non-dimensional fluctuating velocity profiles are shown in Figure 46.

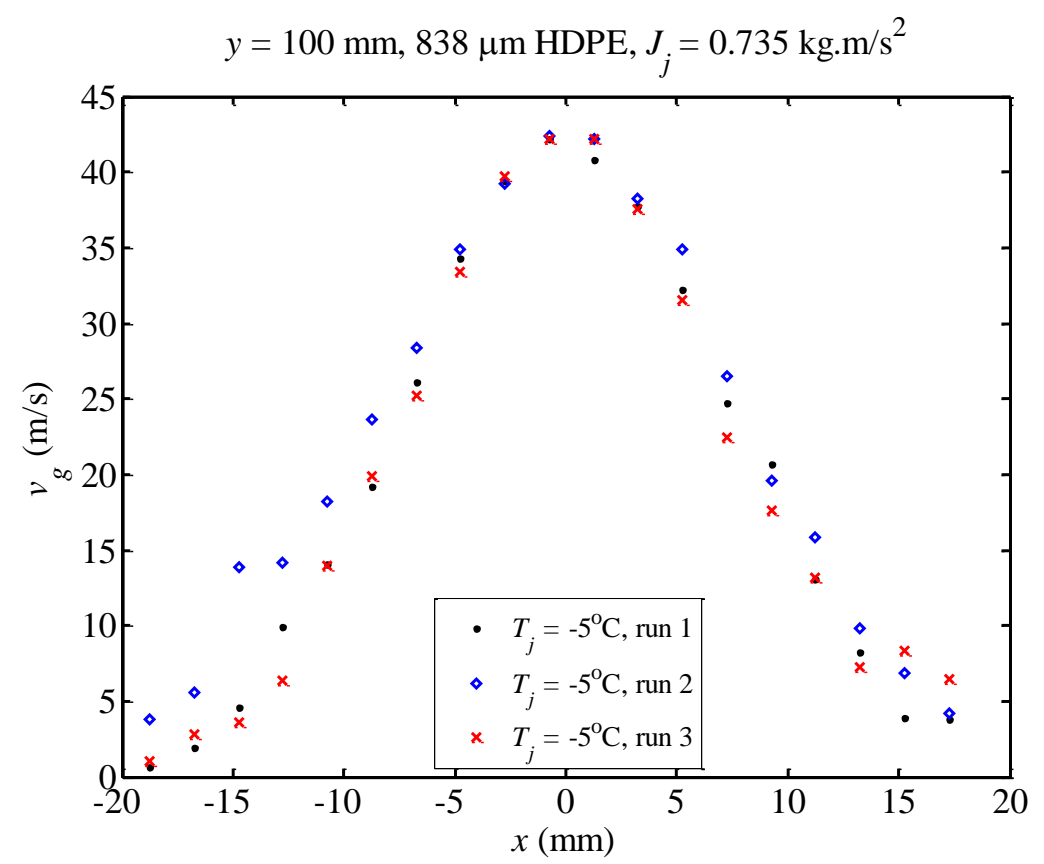

Figure 44: Gas phase velocity profiles at $y=100 \mathrm{~mm}$ 


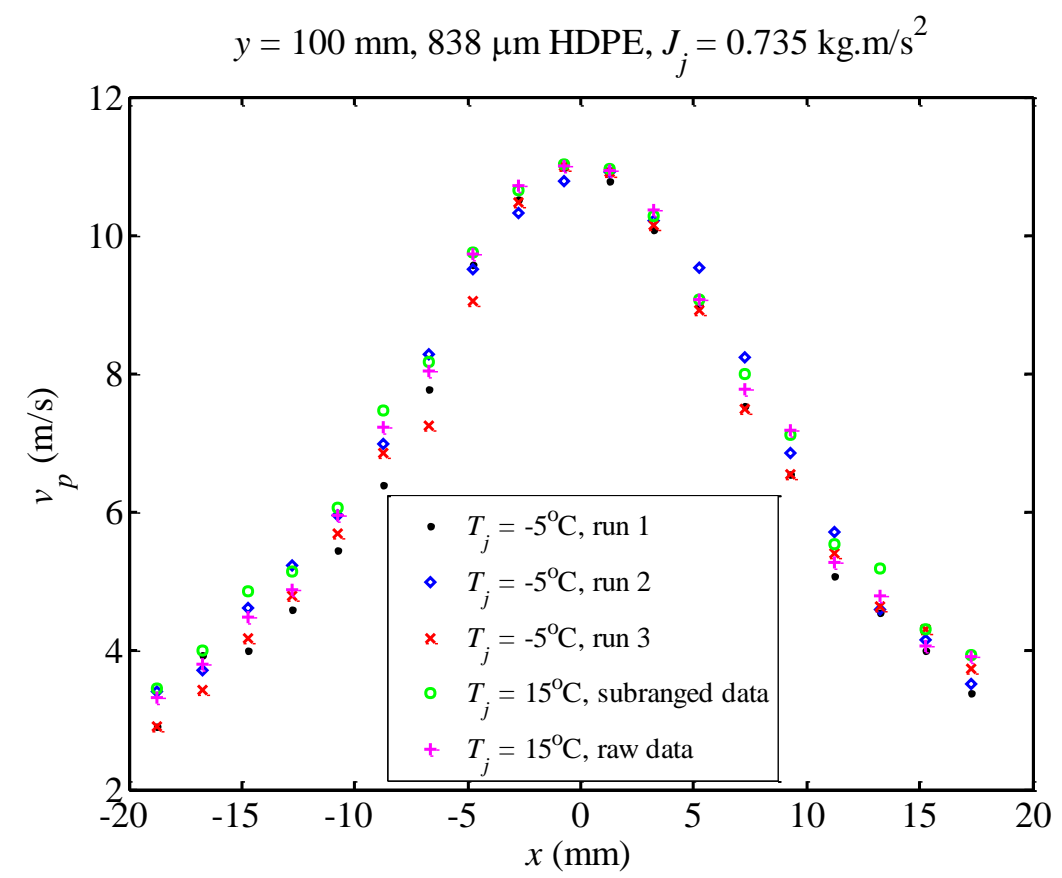

Figure 45: Particulate phase velocity profiles at $y=100 \mathrm{~mm}$

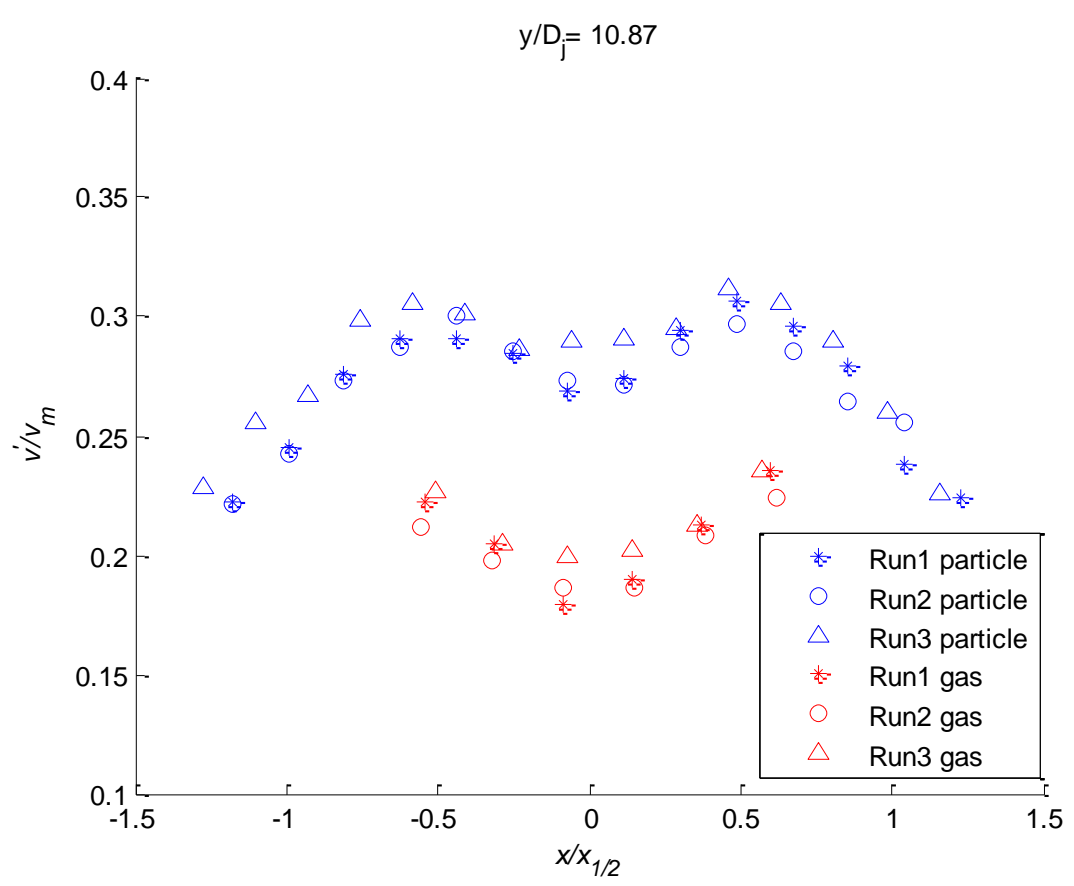

Figure 46: Repeatability in the measurement of fluctuating intensities of particle and gas phases at $y / D_{j}=10.87$ for case $5, V_{f l} / V_{m f}=1.15$

In such a complex system, it is difficult to identify all of the sources of uncertainty and error. The air flow rates are controlled by volumetric flow meters, which have an uncertainty of \pm 7.5 SLPM, which translates into $\pm 1.72 \mathrm{~m} / \mathrm{s}$ for the jet velocity and $\pm 2.18 \mathrm{~cm} / \mathrm{s}$ for the fluidization 
velocity. The temperature of the jet gas was maintained within $\pm 2{ }^{\circ} \mathrm{C}$. The largest sources of uncertainty are most likely due to particle size and shape variation. This is not only due to particle fabrication, but also to particle attrition and abrasion due the harsh flow conditions inside the bubbling bed. The bulk consistency of the particles was verified by repeating the fluidization curve tests before and after every experiment. Static levels were controlled as mentioned before but could become problematic as the amount of Larostat in the emulsion decreased over the duration of an experiment. Finally, optical alignment is critical due to the strong velocity gradients in the jet plume. Care was taken to ensure that the LDV probe head was oriented perpendicular to the 2D bed so that the LDV measurement volume was located in the center of the bed gap at all $x$ and $y$ locations. 


\subsubsection{Validating non-spherical minimum fluidization correlations}

Fluidization correlations are primarily based on the behavior of mono-size spheres in a fluid. Though most of them try to include the effect of the non-spherical nature of particles, such equations have not been tested widely and have been found to perform differently for different shapes and particle Reynolds numbers (Lippens and Mulder, 1992). An attempt was made to study the performance of 6 such correlations found in literature (Table 7) in predicting the minimum fluidization of cylindrical polycarbonate particles (Table 8) by comparing them to the experimental value. The same experimental setup was used with the jet inlet turned off.

\begin{tabular}{|c|c|c|}
\hline Name & Expression & Length scale \\
\hline Ergun (1952) & $A r=\frac{150\left(1-\varepsilon_{m f}\right)}{\varepsilon_{m f}^{3}} R e_{m f}+1.75 \frac{R e_{m f}^{2}}{\varepsilon_{m f}^{3}}$ & $D_{s v}$ \\
\hline Wen \& Yu (1966) & $R e_{m f}=33.7\left[\left(1+3.59 \times 10^{-5} A r\right)^{0.5}-1\right]$ & $D_{v}$ \\
\hline $\begin{array}{c}\text { Chitester et. al } \\
\text { (1984) }\end{array}$ & $R e_{m f}=28.7\left[\left(1+6 \times 10^{-5} A r\right)^{0.5}-1\right]$ & $D_{v}$ \\
\hline $\begin{array}{c}\text { Haider \& } \\
\text { Levenspiel (1989) }\end{array}$ & $\begin{array}{c}C_{D}=\frac{24}{R e}\left[1+\{8.1716 \exp (-4.0655 \psi)\} \times R e^{(0.0964+0.5565 \psi}\right] \\
+\frac{73.69 R \exp (-5.0748 \psi)}{R e+5.378 \exp (6.2122 \psi)}\end{array}$ & $D_{v}$ \\
\hline Ganser (1993) & $\begin{array}{c}\frac{C_{D}}{K_{2}}=\frac{24}{\operatorname{ReK}_{1} K_{2}}\left\{1+0.1118\left(\operatorname{ReK}_{1} K_{2}\right)^{0.6567}\right\}+\frac{0.4305}{1+\frac{3305}{\operatorname{Re} K_{1} K_{2}}} \\
K_{1}=\left[\left(d_{n} / 3 d\right)+(2 / 3) \psi^{-0.5}\right]^{-1} \\
K_{2}=10^{1.8418(-\log \psi)^{0.5743}}\end{array}$ & $D_{v}$ \\
\hline Chien (1994) & $C_{D}=(30 / R e)+67.289 \exp (-5.03 \psi)$ & $D_{v}$ \\
\hline
\end{tabular}

Table 7: Minimum fluidization correlations for non-spherical particles

\begin{tabular}{|c|c|c|}
\hline Parameter & Description & Value \\
\hline$x_{p}$ & diameter of the cylindrical particle $(\mathrm{mm})$ & 0.5 \\
\hline$h_{p}$ & height of the cylindrical particle $(\mathrm{mm})$ & 0.72 \\
\hline$\rho_{p}$ & density $\left(\mathrm{kg} / \mathrm{m}^{3}\right)$ & 1200 \\
\hline$v$ & solids fraction at random closest packing & 0.58 \\
\hline$x_{s v}$ & surface-volume diameter $(\mathrm{mm})$ & 0.557 \\
\hline$x_{v}$ & equivalent volume diameter $(\mathrm{mm})$ & 0.646 \\
\hline$\psi$ & sphericity & 0.86 \\
\hline$A r_{s v}$ & Archimedes number based on $d_{s v}$ & 8934 \\
\hline$A r_{v}$ & Archimedes number based on $d_{v}$ & 13981 \\
\hline
\end{tabular}

Table 8: Particle properties used for fluidization study 
Additionally the Khan and Richardson (1989) equation is used for finding the hindered settling velocity for all drag correlations, given the settling velocity of a single particle.

$$
\begin{gathered}
u_{s}=u_{t} \varepsilon^{n} \\
n=\frac{4.8+0.1032 \times A r^{0.57}}{1+0.043 \times A r^{0.57}}
\end{gathered}
$$

In the above the Archimedes number $A r$ is based on the surface-volume diameter, $d_{s v}$ (Martin Rhodes, 2008).

The minimum fluidization velocity was experimentally found to be $11.5 \mathrm{~cm} / \mathrm{s}$. The results

\begin{tabular}{|c|c|c|c|c|}
\hline Correlation & \multicolumn{2}{|c|}{$V_{m f}(\mathrm{~cm} / \mathrm{s})$} & \multicolumn{2}{|c|}{$\%$ Error } \\
\hline Ergun & \multicolumn{2}{|c|}{16.56} & \multicolumn{2}{|c|}{44} \\
\hline Wen \& Yu & \multicolumn{2}{|c|}{18.77} & \multicolumn{2}{|c|}{63} \\
\hline Chitester et. al & \multicolumn{2}{|c|}{25.22} & \multicolumn{2}{|c|}{119} \\
\hline & $\begin{array}{c}V_{m f}(\mathrm{~cm} / \mathrm{s}) \\
\text { (Projected } \\
\text { Area 1) }\end{array}$ & $\begin{array}{c}V_{m f}(\mathrm{~cm} / \mathrm{s}) \\
(\text { Projected } \\
\text { Area 2) }\end{array}$ & $\begin{array}{c}\text { \%Error } \\
\text { (Projected } \\
\text { Area 1) }\end{array}$ & $\begin{array}{c}\text { \%Error } \\
\text { (Projected } \\
\text { Area 2) }\end{array}$ \\
\hline Ganser & 31.99 & 20.72 & 178 & 80 \\
\hline Haider \& Levenspeil & 38.72 & 26.71 & 237 & 132 \\
\hline Chien & 35.80 & 25.60 & 212 & 123 \\
\hline
\end{tabular}
obtained are tabulated in Table 9.

Table 9: Results of minimum fluidization prediction for cylindrical particles

The two projected areas considered are the circular, radial projection (Projected Area 1) and the rectangular, lengthwise projection (Projected Area 2) of the cylinder. The sensitivity of the results to the orientation or the projected area is high. The drag prediction of Ganser seems to match closest to the experimental value though it is still off by $80 \%$. Ergun's correlation gives the best match overall. 


\subsection{Computational results}

\subsubsection{CFD study on spanwise confinement}

In order to enable a more accurate comparison of our experimental data with the widely studied two-dimensional cases, it is important to quantitatively identify and, preferably, isolate the role of the walls.

As a first step, the influence of spanwise walls on the gas velocity in a single phase turbulent planar jet was considered. This problem has been encountered previously in literature, since many workers have tried to use a thin geometry to "enforce two-dimensionality" when studying planar jets (Alhannal and Panidis, 2009). This is also the arrangement for which our Empty Bed profiles hold true. Each simulation takes approximately 10 days running on 2 processor distributed memory. The streamwise evolutions of the mean and turbulence variables are plotted in Figure 47 to Figure 49 as a function of spanwise separation. The results of a truly 2D simulation, the experimental data of the planar jet experiment conducted by Gutmark and Wygnanski (1976) and those of our experiments are added in these plots to enable comparison. It should be noted that the simulation results were obtained from the central spanwise layer of grids, i.e. at a $z$ value of approximately $w / 2$. Based on the plots, we see that all the different spanwise widths follow the 2D jet up to a certain streamwise distance from the orifice after which they show deviation in both mean and turbulence quantities. The deviation corresponds to decay in a centerline velocity which is not as steep as in a 2D jet and a dip in turbulent kinetic energy. This point where the transition occurs is related to the spanwise width. In fact, larger the spanwise width, the larger is the streamwise distance for the transition from 2D to occur. The above result qualitatively matches the findings of Deo et al. (2004) who found that the downstream distance at which 3-D effects emerge depends on spanwise width to jet diameter. The higher the ratio, the longer will be this distance. The fact that our experimental results lie almost within the $2 \mathrm{D}$ region suggests that the Empty bed data may not be influenced by the spanwise confinement. It must be noted here that since we only obtained streamwise fluctuations in our experiment certain assumptions had to be made in order to calculate the turbulent kinetic energy. It was assumed that the same $2 \mathrm{D}$ anisotropy exists in the two directions (radial: $u^{, 2} / v^{, 2}=$ 0.6724 and spanwise: $w^{, 2} / v^{2}=0.5041$ as in Gutmarak and Wygnanski, 1976).

From Figure 50 it can be seen that there is a tendency of the flow to reach a maximum turbulent viscosity upon reaching the transition point, instead of continuing to increase with streamwise distance. It can be hypothized that the flow shows a combination of the influence of free shear arising from the jet evolution and wall shear arising from the spanwise confinement. The contribution from the free shear is dominant close to the jet orifice, but the wall shear catches up once the jet half-width scale approximates the spanwise width. When the wall shear starts to dominate, the flow field resembles that of flow between parallel plates. 


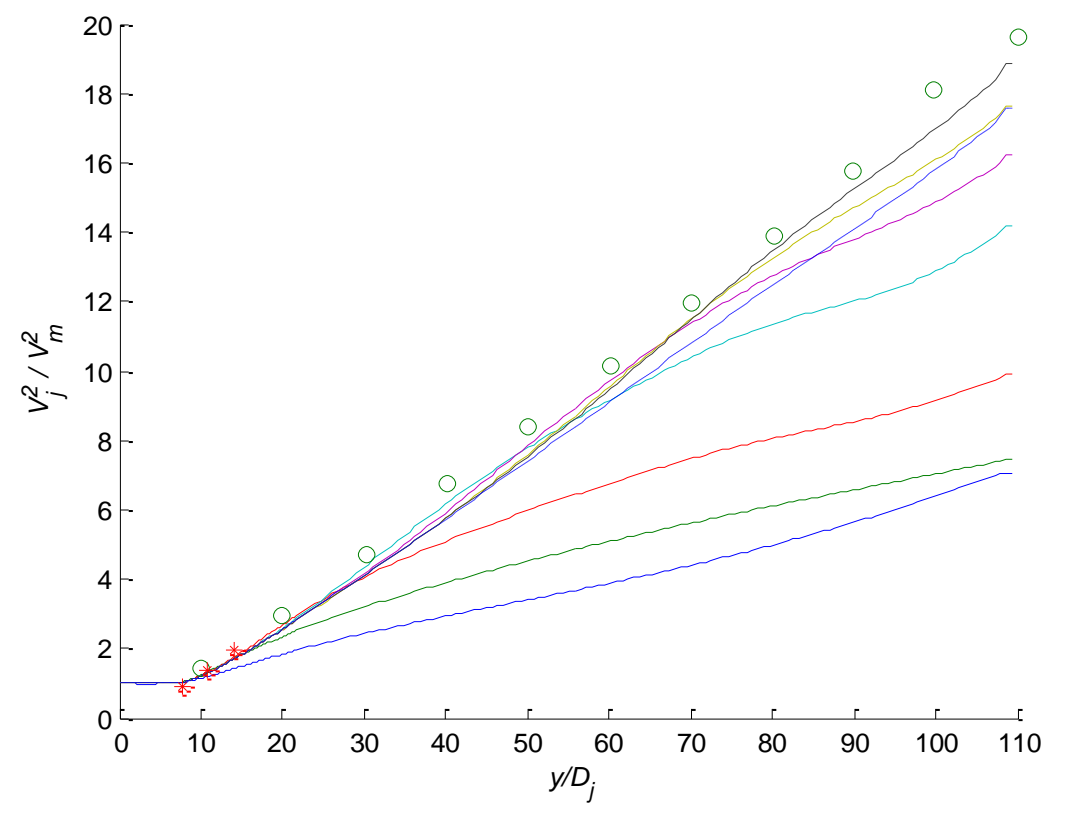

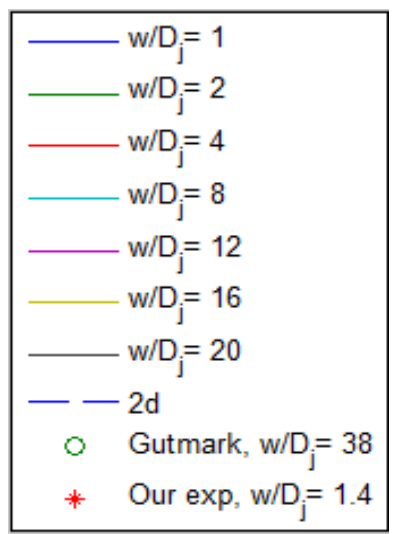

Figure 47: Steamwise centerline mean velocity decay in a single-phase jet

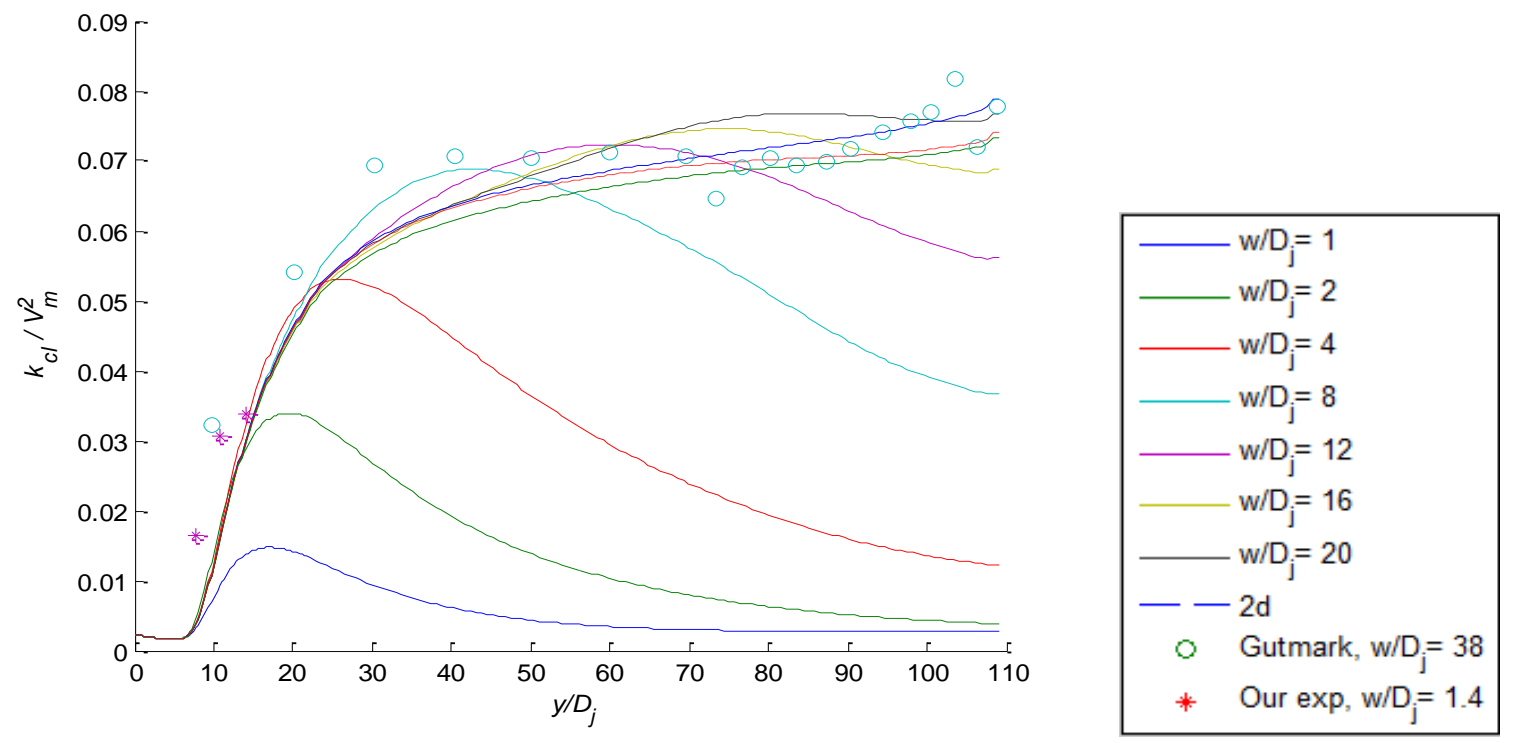

Figure 48: Streamwise variation in centerline turbulent kinetic energy in a single-phase jet 


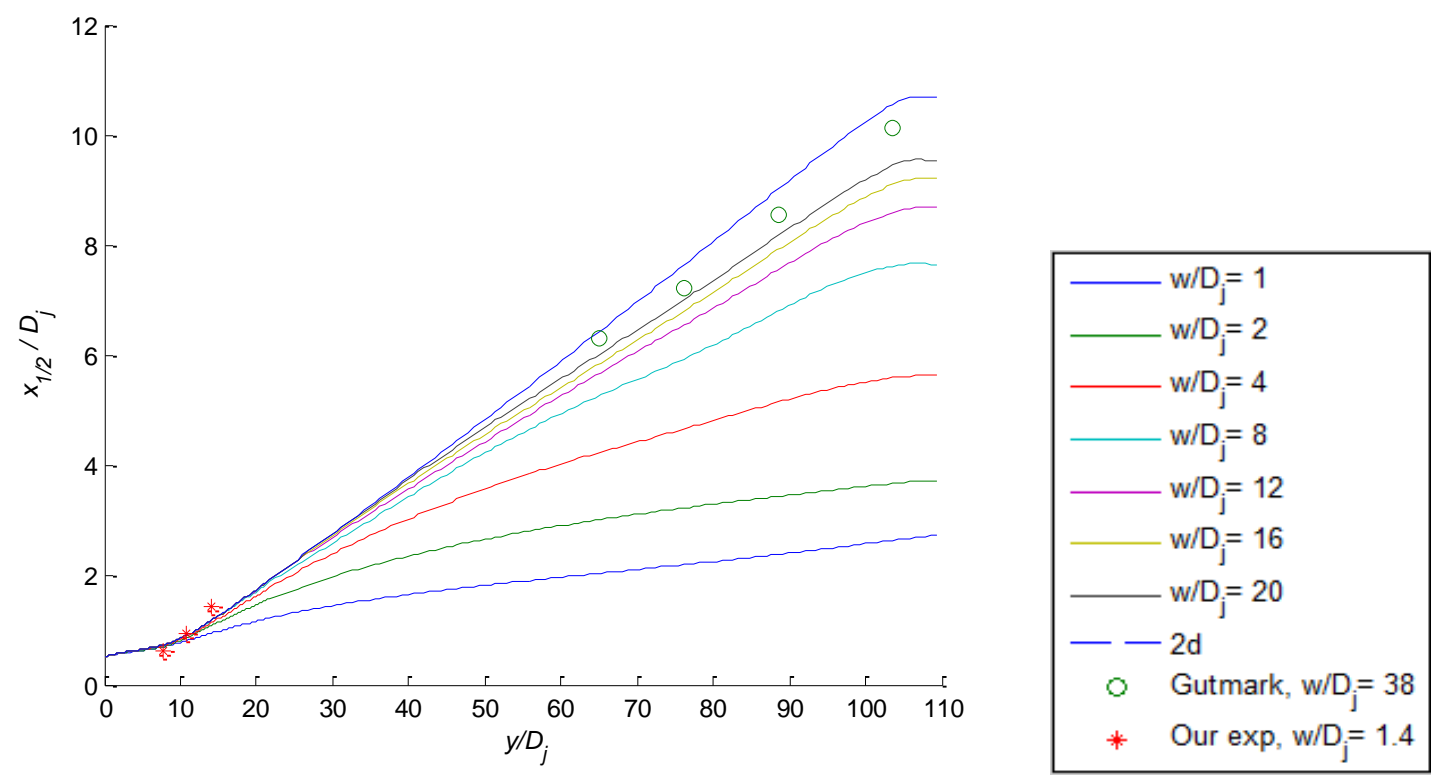

Figure 49: Streamwise variation in jet half-width in a single-phase jet

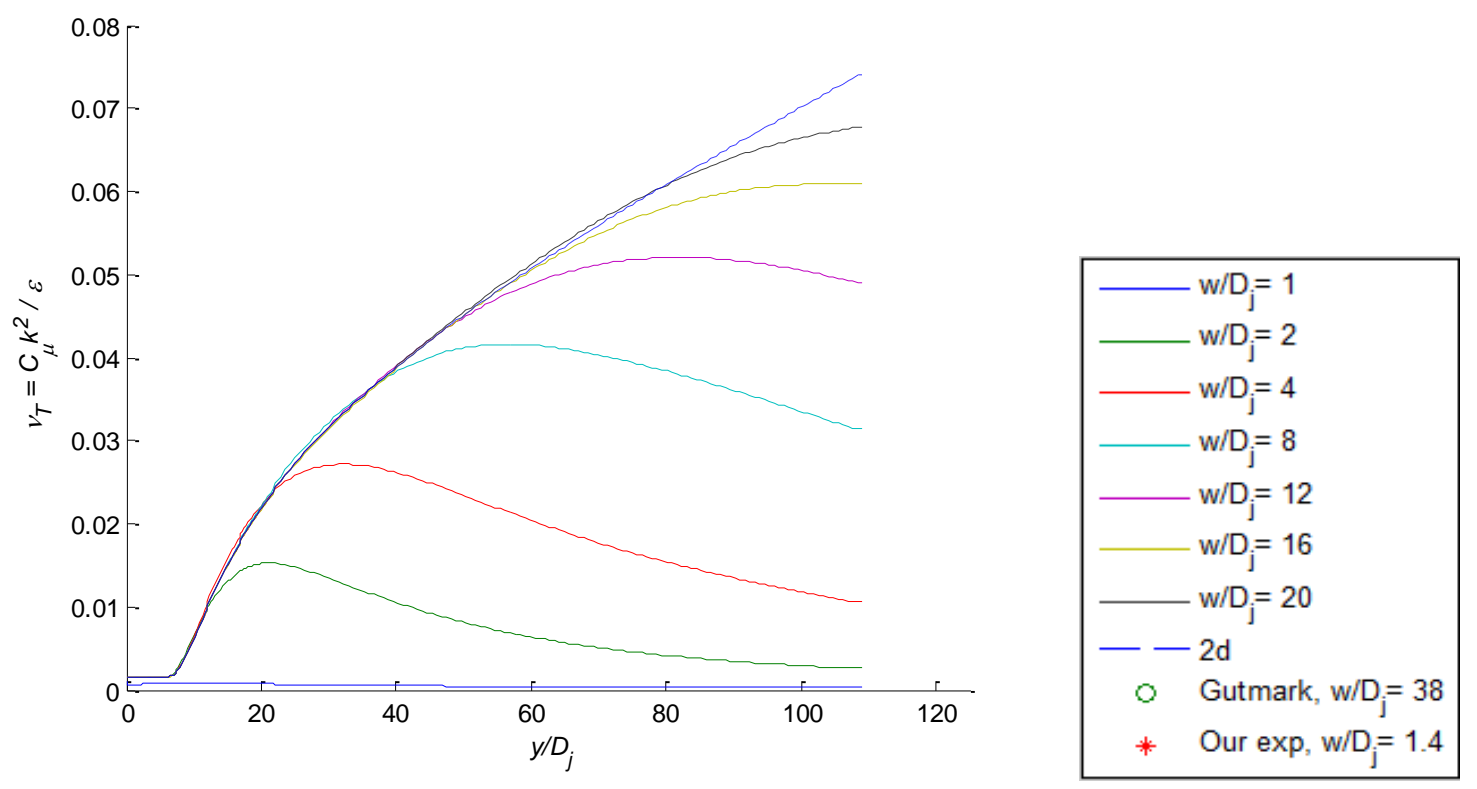

Figure 50: Non-normalized streamwise turbulent viscosity profiles in a single-phase jet

In the next step, the role played by the walls when solids are added to the system was investigated. Figure 51 shows the difference in the fluidization curves for the wall confined and 2D simulations that were conducted. While it was observed that the fluctuations in pressure drop upon reaching minimum fluidization are larger in the 3D wall confined case, once they reach 
reasonable stability the pressure drops match well with the $2 \mathrm{D}$ case as seen in Figure 51 . Hence, it can be said that there is negligible influence of wall confinement in predicting the minimum fluidization velocity of the experimental system. This is not surprising since the solid velocities are low and the surface area of the wall exposed to gas flow is small compared to surface area along the particle layers in a bed. Hence, a spanwise width of 15 particle diameters is sufficiently large to ensure that the wall effects can be ignored during fluidization.

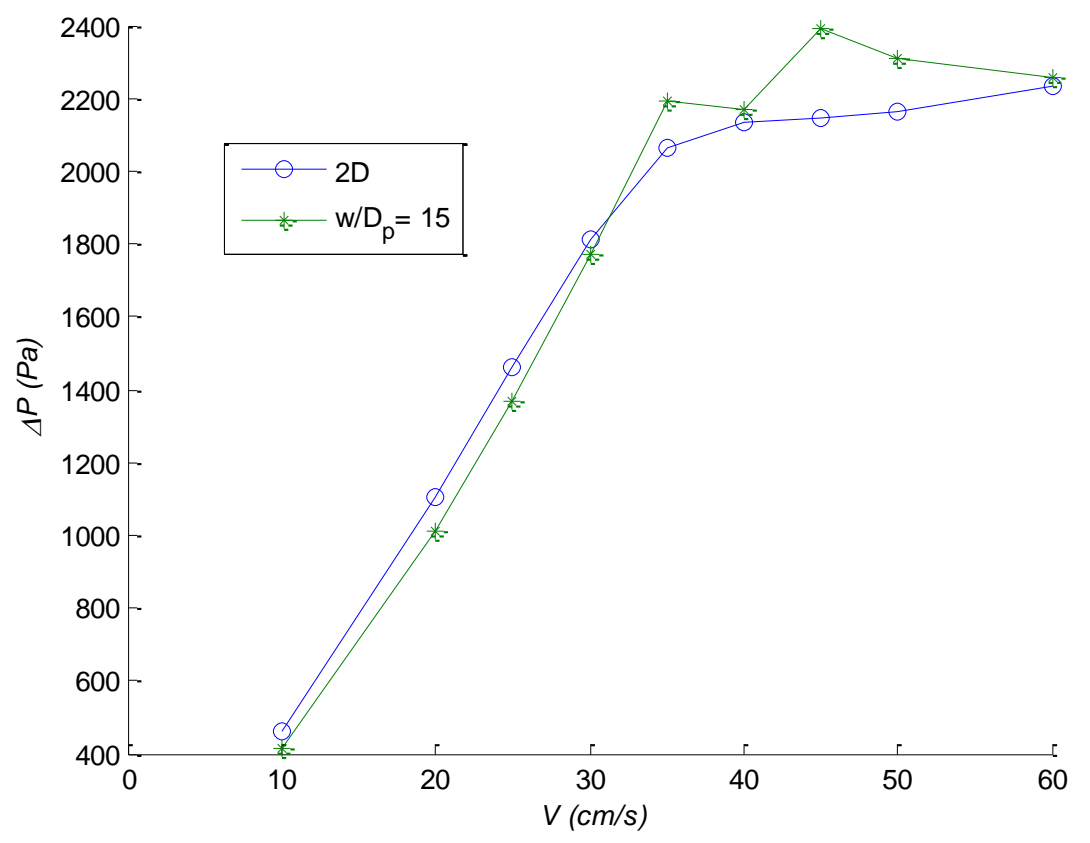

Figure 51: Fluidization curve in the confined and non-confined simulations 


\subsubsection{CFD study on the sensitivity of frictional models in predicting minimum fluidization velocity}

The frictional models, which are expressions to calculate the frictional stress $\left(\sigma_{f}\right)$, can be divided into two main categories- one is activated only in the regions where the solids volume fraction is above maximum packing (SRO) and the other is activated even in regions below maximum packing (Princeton). The latter, called the Princeton models, can be further divided depending on the exact form of frictional pressure and frictional viscosity used. However, if one makes the critical state assumption (the granular assembly deforms without any volume change) that $P_{f}=P_{c}$, which was assumed in this study, then all the Princeton frictional models have the same expression for frictional pressure and differ only in the frictional viscosity. The frictional viscosity may depend only on the granular temperature (Savage), only on the solids rate of strain tensor (Solid-strain) or on a combination of both (SS). Additionally, a modified form which sets frictional viscosity to zero was used to study the significance of frictional viscosity relative to frictional pressure.

A brief summary of the continuum friction models found in literature is shown in Table 10. Figure 52 reveals that the value of $F r$ significantly affects the prediction of minimum fluidization velocity. In particular, $F r=0.05 \mathrm{~Pa}$ seems to match best with the experimentally obtained result of $29 \mathrm{~cm} / \mathrm{s}$. Figure 53 on the other hand reveals that the minimum fluidization velocity is independent of the form of frictional viscosity. In fact, setting frictional viscosity equal to zero does not change the minimum fluidization prediction suggesting that the viscous component of frictional stress is negligibly small in the flow under consideration.

\begin{tabular}{|c|c|c|}
\hline Model & Frictional pressure & Frictional viscosity \\
\hline $\begin{array}{c}\text { SRO } \\
\text { (Symlal } \text { et al., } \\
\text { 1993) }\end{array}$ & $P_{f}=P_{c}=\left\{\begin{array}{cl}10^{25}\left(\varepsilon_{s}-\varepsilon_{s}^{\max }\right) & \varepsilon_{s}>\varepsilon_{s}^{\max } \\
0 & \varepsilon_{s} \leq \varepsilon_{s}^{\max }\end{array}\right.$ & $\mu_{f}=\frac{P_{c} \sin (\delta)}{2 \sqrt{I_{D}}}$ \\
\hline $\begin{array}{c}\text { SS } \\
\text { (Srivastava \& } \\
\text { Sundaresan, } \\
\text { 2003) }\end{array}$ & $\begin{array}{l}P_{f}=P_{c} \\
=\left\{\begin{array}{cc}10^{25}\left(\varepsilon_{s}-\varepsilon_{s}^{\max }\right) & \varepsilon_{s}>\varepsilon_{s}^{\max } \\
\operatorname{Fr} \frac{\left(\varepsilon_{s}-\varepsilon_{s}^{\text {min }}\right)^{r}}{\left(\varepsilon_{s}^{\max }-\varepsilon_{s}\right)^{s}} & \varepsilon_{s}^{\text {max }} \geq \varepsilon_{s}>\varepsilon_{s}^{\text {min }} \\
0 & \varepsilon_{s} \leq \varepsilon_{s}^{\max }\end{array}\right.\end{array}$ & $\mu_{f}=\frac{\sin (\delta)}{\sqrt{2}} \frac{P_{f}}{\sqrt{S: S+T / d_{p}^{2}}}$ \\
\hline $\begin{array}{c}\text { Savage } \\
\text { (Savage, 1998) }\end{array}$ & Same as above & $\mu_{f}=\frac{\sin (\delta)}{\sqrt{2}} \frac{P_{f}}{\sqrt{f(T)}}$ \\
\hline Solid-strain & Same as above & $\mu_{f}=\frac{\sin (\delta)}{\sqrt{2}} \frac{P_{f}}{\sqrt{S: S}}$ \\
\hline
\end{tabular}

Table 10: Frictional models in MFIX 


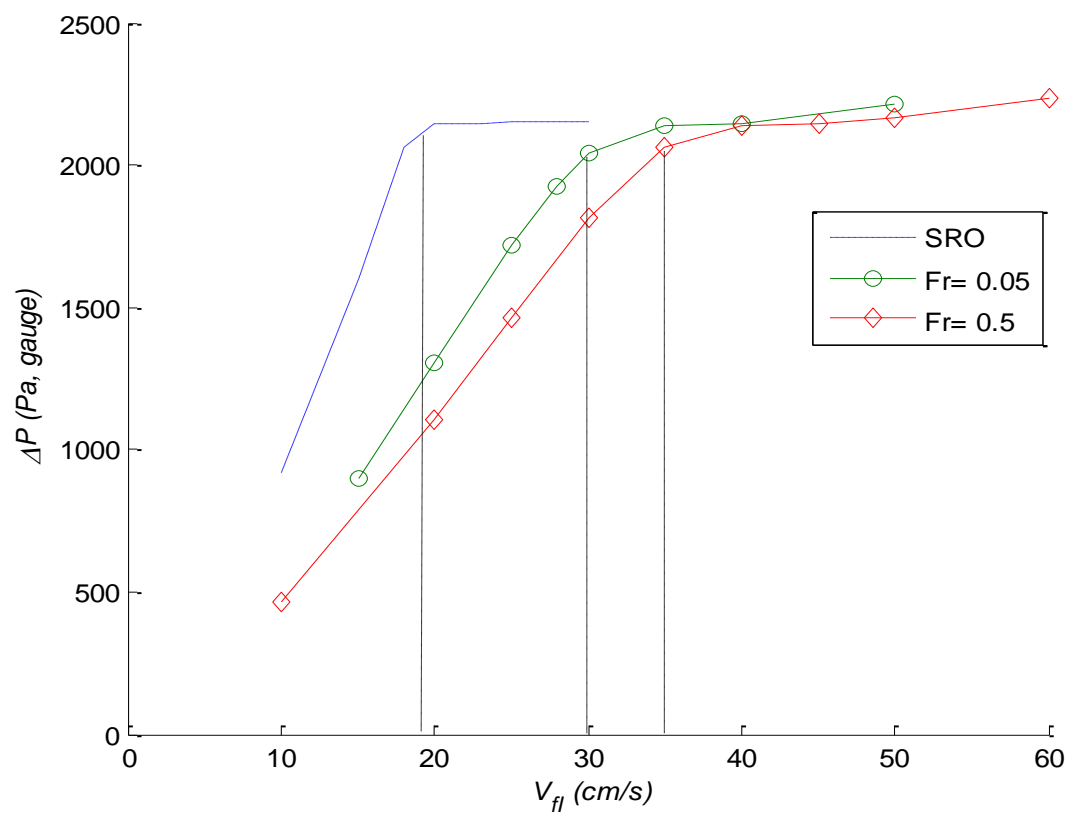

Figure 52: Fluidization curve for SRO and Savage frictional models as function of $\mathrm{Fr}$ (in $\mathrm{Pa}$ )

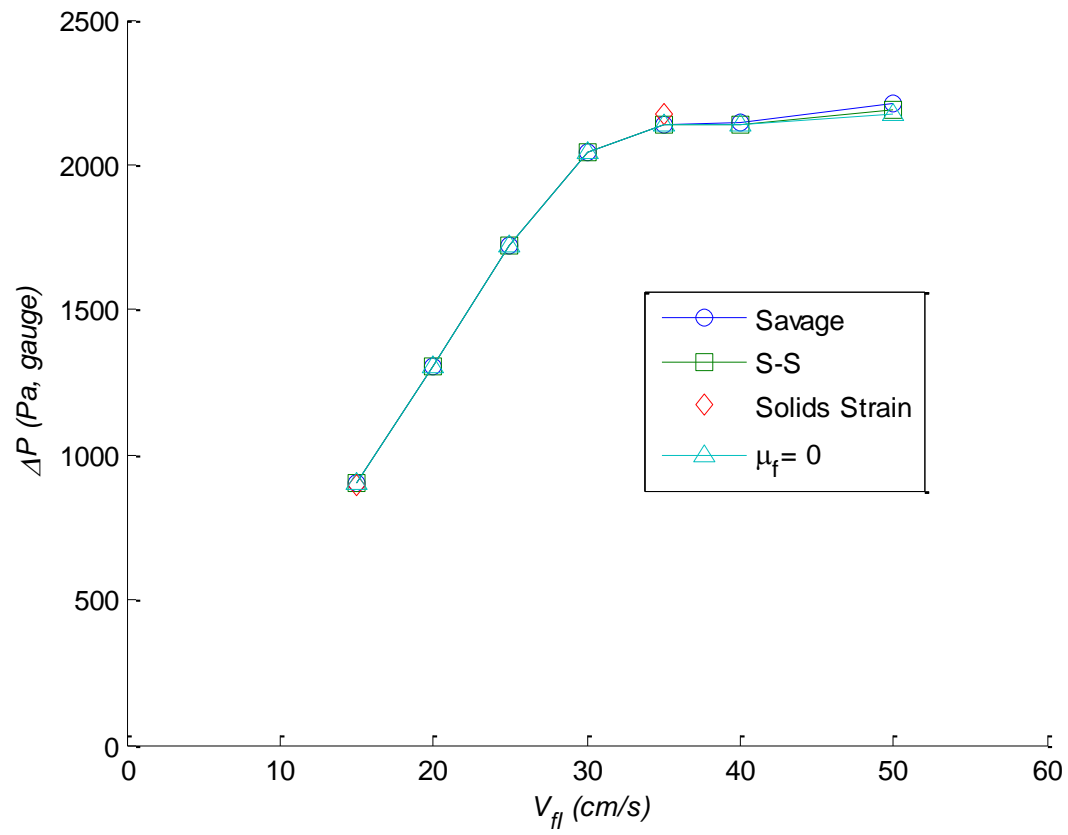

Figure 53: Fluidization curve for $F r=0.05 \mathrm{~Pa}$ as a function of frictional viscosity expression 


\subsubsection{CFD study on the sensitivity of frictional models in predicting flow caused by jet injection}

Finally, 2D simulations of the vertical gas jet penetrating a packed bed of HPDE particles were conducted. By using the experimental results, in particular, the mean gas and particle velocity profiles of the spouted bed, the performance of different frictional models was analyzed. In these simulations, the domain had to be extended in the vertical direction to prevent large amounts of solids from escaping as the bed expands immensely before stabilizing. It must be noted that in the experiments this was achieved by placing a screen at the top outlet.

Figure 54 shows the concentration profiles for the various models at $t=1.5 \mathrm{~s}$. While a stable plume has been formed in Savage run, the others are still showing continuous deformation.
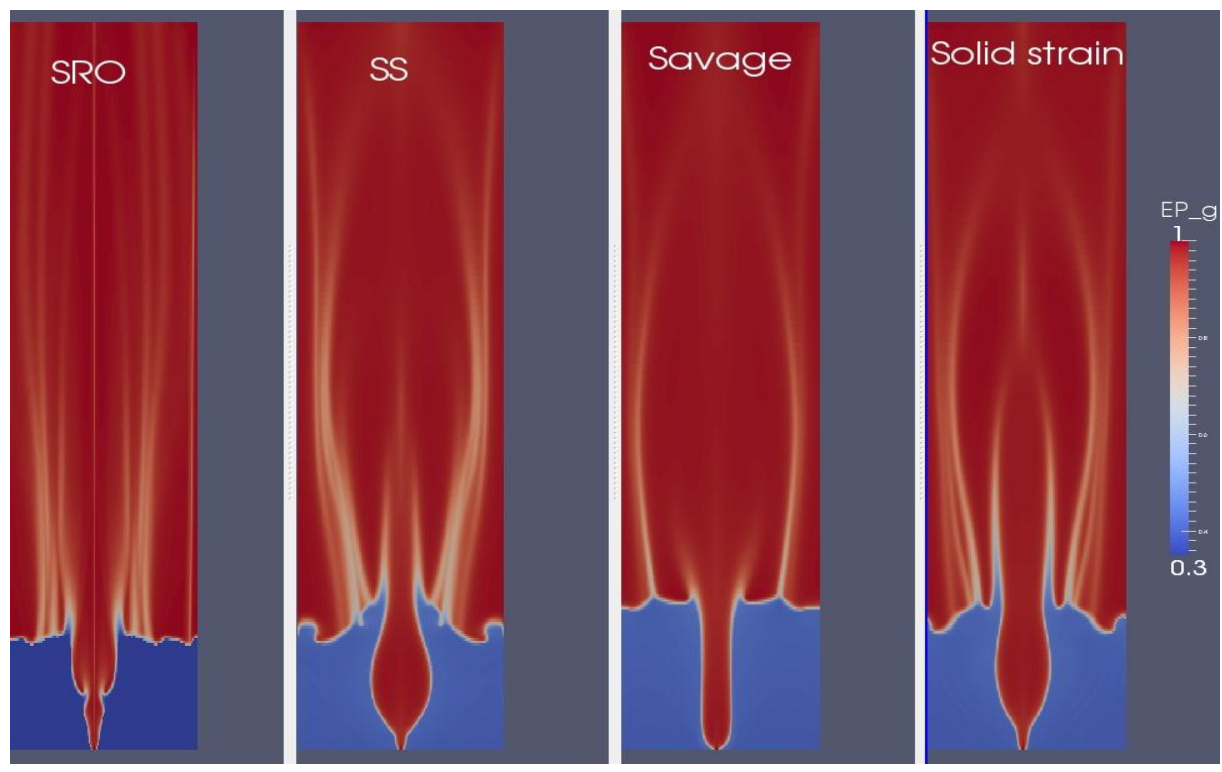

Figure 54: Concentration profiles (voidage) at $t=1.5 \mathrm{~s}$ for different frictional models

As seen in the plot of mean centerline streamwise velocity as a function of time (Figure 55), all the frictional models reach an average steady state at around $0.75 \mathrm{~s}$ even though SRO, SS, and Solid-strain show periodic fluctuations. The variations are on the order of $0.01 \mathrm{~s}$. While these small fluctuations in the mean cannot be validated from the LDV burst data due to limited data rates $(\sim 50 \mathrm{~Hz})$, they correspond to the plume region deforming continuously in the simulation as seen from the concentration profiles (Figure 54). From the video of the spouted bed experiment it was visually observed that such a rapid bulk deformation did not exist. Additionally, it is observed that the Savage frictional model does not show these fluctuations (Figure 55). Hence, the oscillations in the mean velocity are attributed to numerical errors that originate when using SRO, SS and Solid-strain frictional models.

The performance of the frictional models in predicting the gas and particle phase mean profiles is shown in Figure 56 to Figure 61. For SRO, SS and Solid-strain simulations a time average from 
$t=0.75 \mathrm{~s}$ to $t=1.5 \mathrm{~s}$ was taken in order to negate the effect of oscillations and for Savage, the results at $t=1.5 \mathrm{~s}$ was used. It can be seen that the all the frictional models capture the shapes of gas and particle profiles reasonably well (Figure 56 and Figure 57). The centerline gas velocity decay is best captured by the SS model (Figure 58). All the models overestimate the gas halfplume width (Figure 59). None of the models correctly capture the steep decay in particle centerline velocity (Figure 60) and SRO predicts the particle half-plume widths the best while the others over-predict them (Figure 61).

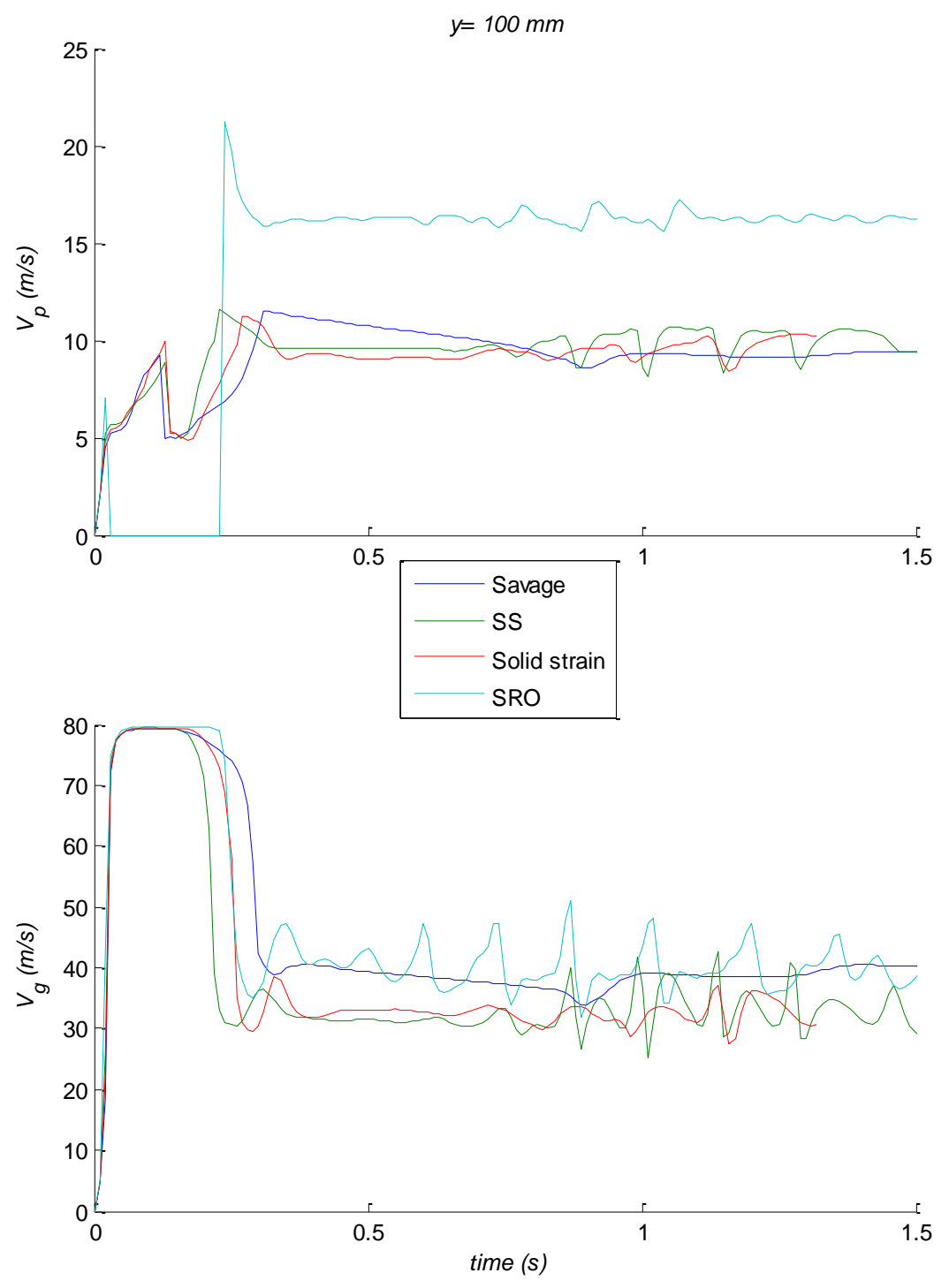

Figure 55: Evolution of centerline gas and particle phase velocity with time for different frictional models 


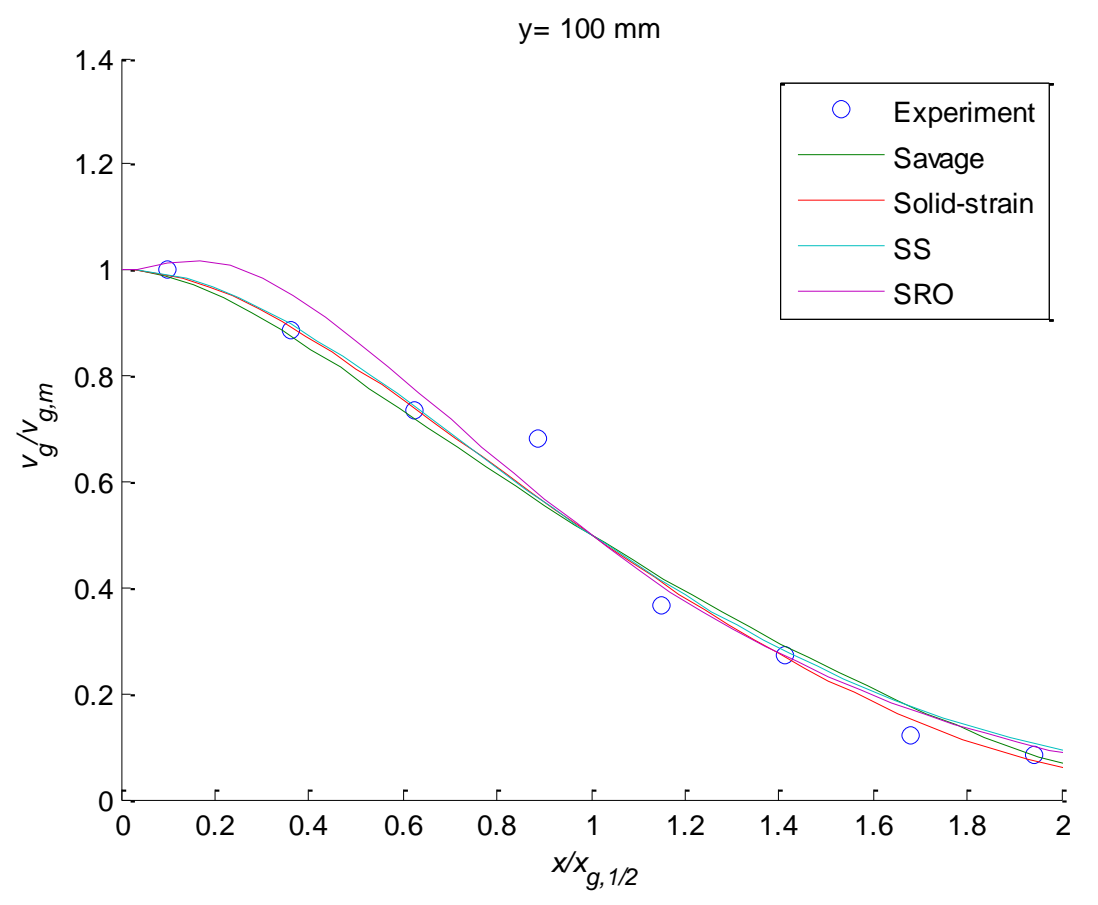

Figure 56: Non-dimensional gas phase profile for different frictional models

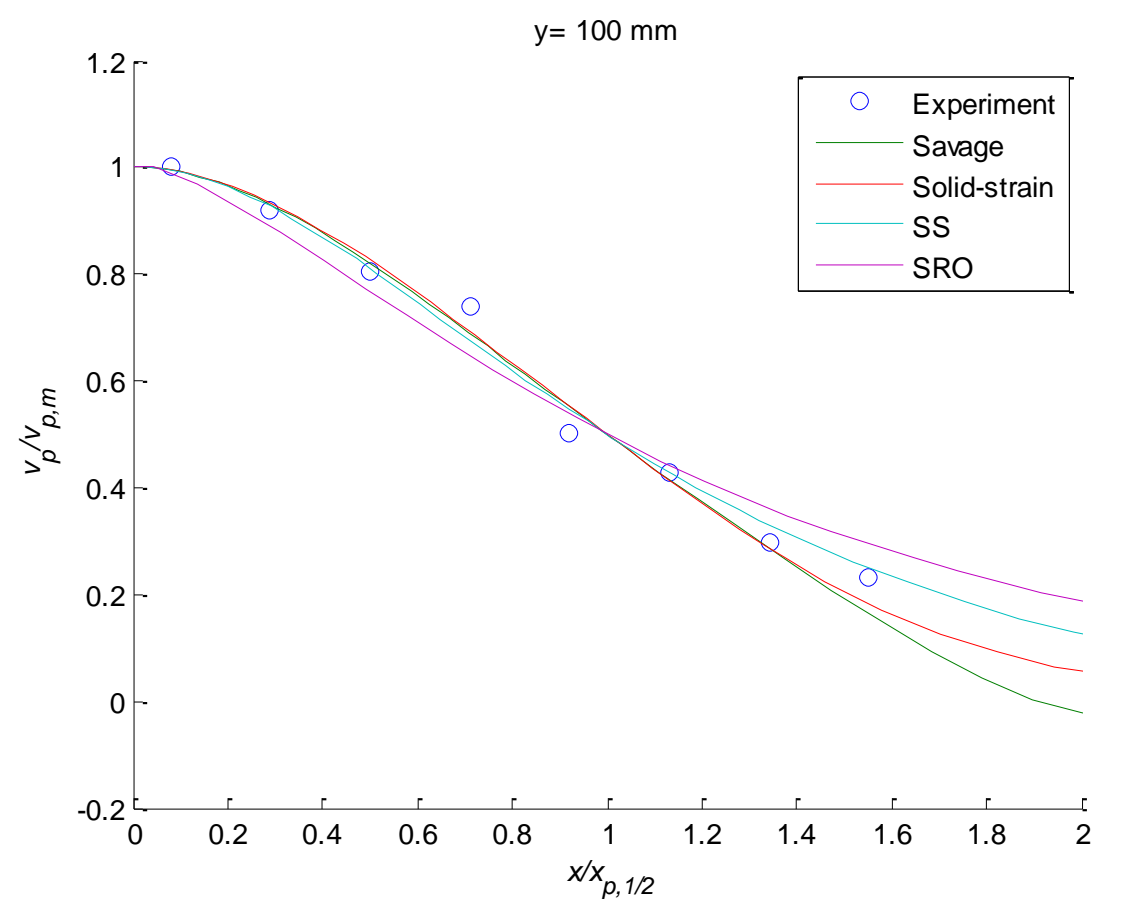

Figure 57: Non-dimensional particle phase profile for different frictional models 


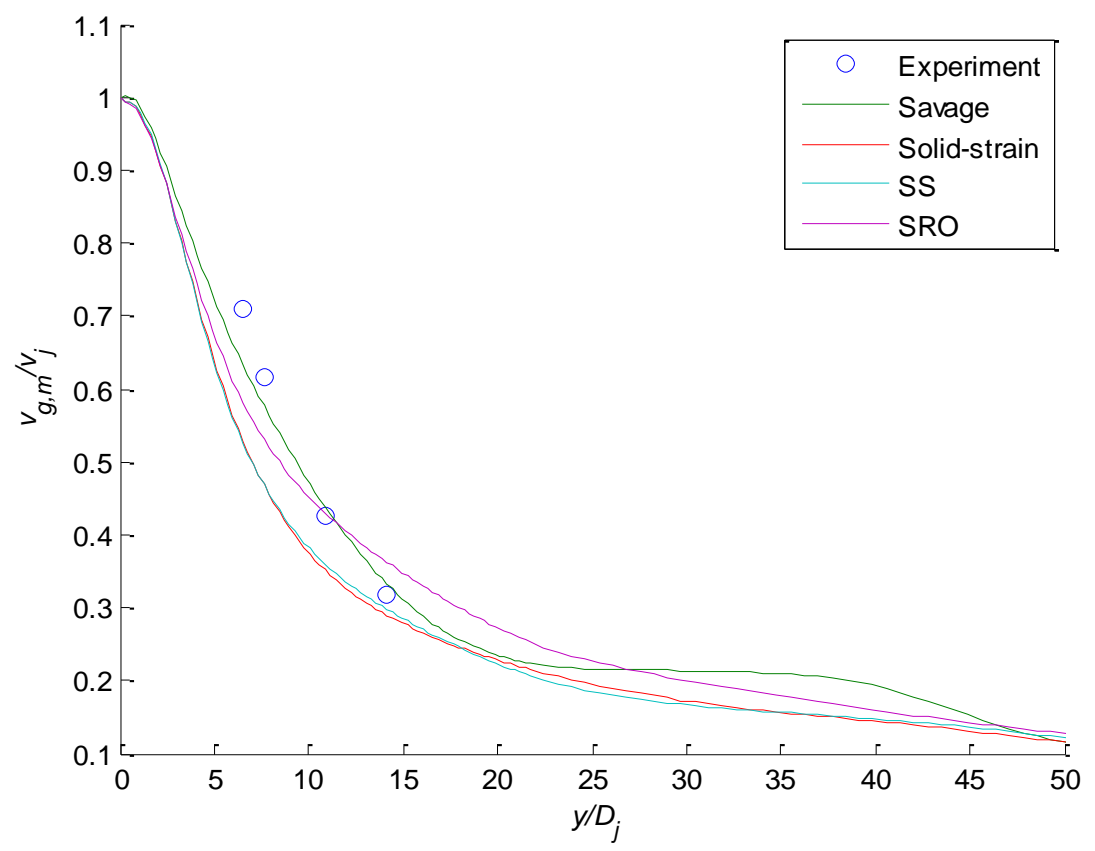

Figure 58: Centerline gas phase velocity decay for different frictional models

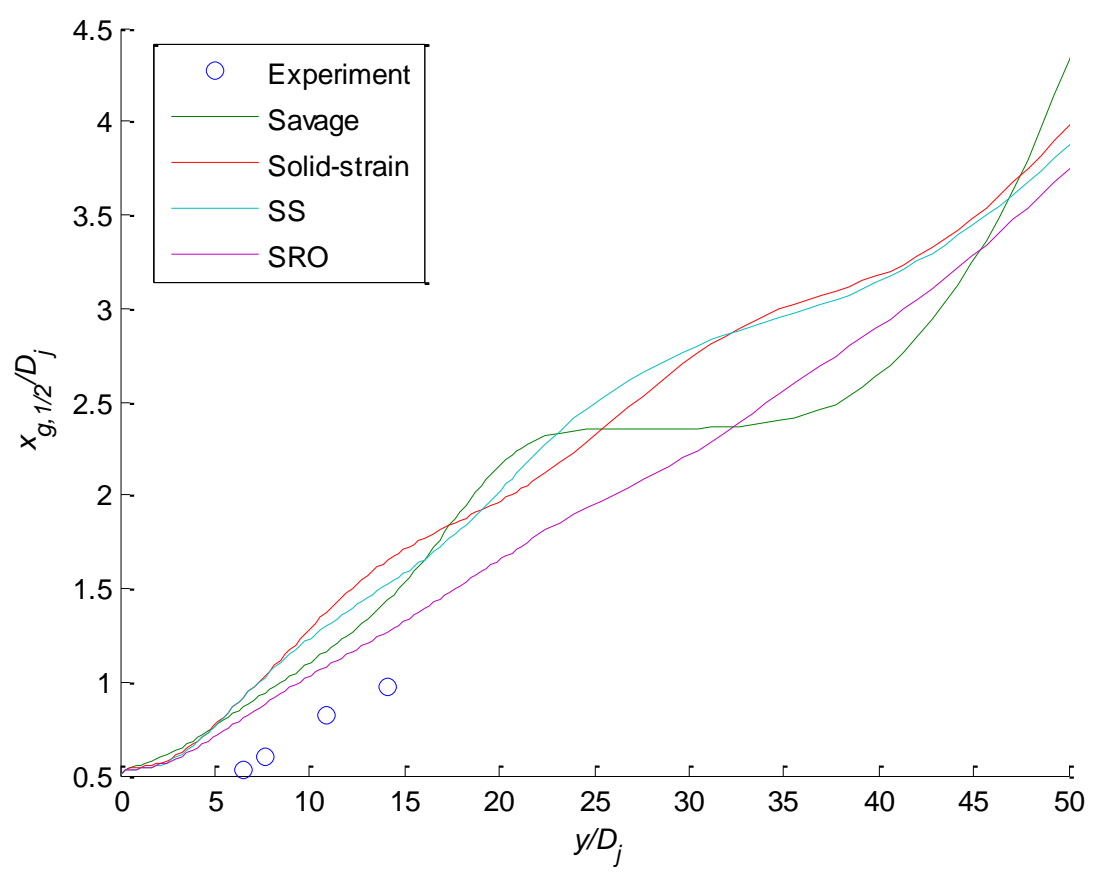

Figure 59: Gas phase plume half-width increase for different frictional models 


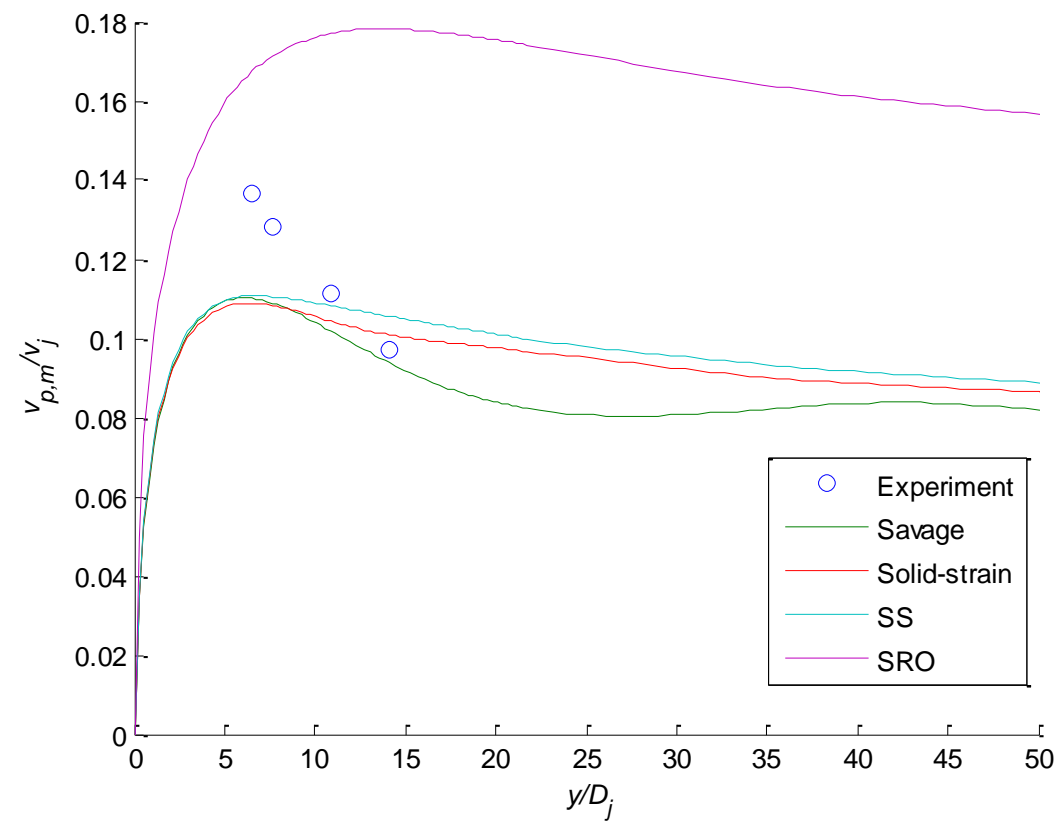

Figure 60: Centerline particle phase velocity decay for different frictional models

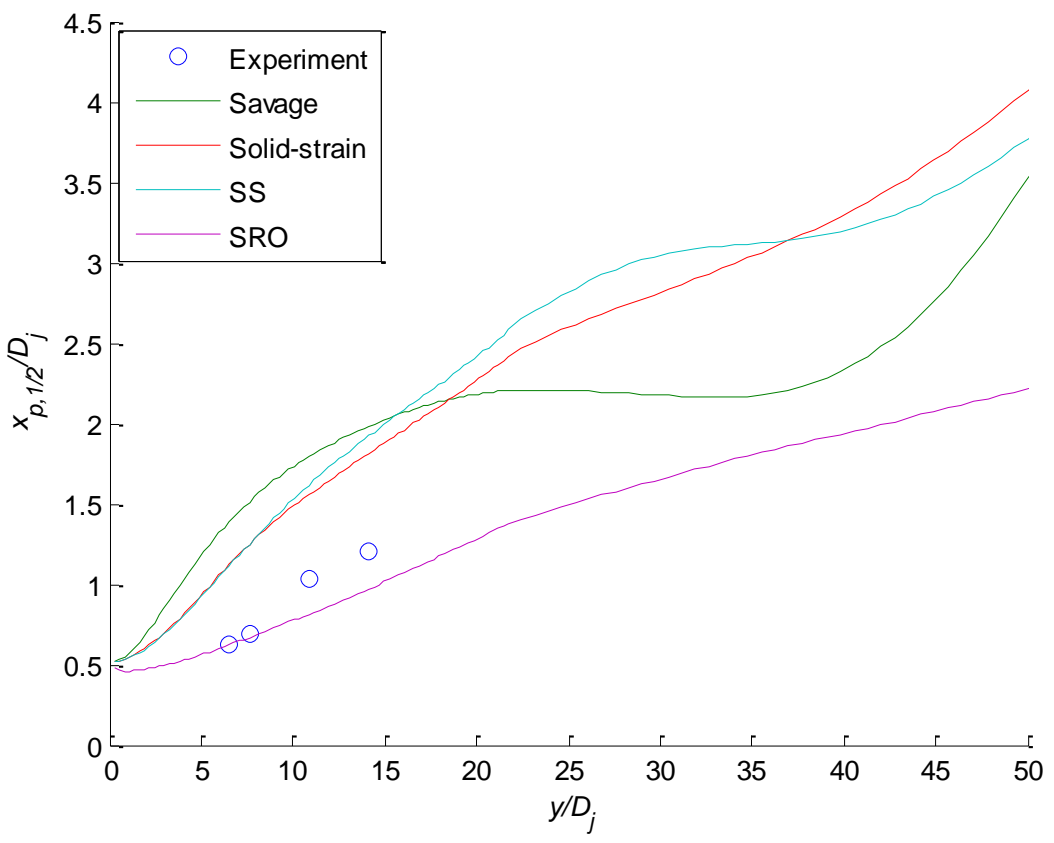

Figure 61: Particle phase plume half-width increase for different frictional models 
Finally, a comparison of the bulk plume width, obtained by measuring the distance between the two boundaries of the jet plume from the concentration profile (solid fraction > 0.5), was made with experimental photographs for the Savage model (Figure 62). This comparison has been extended to a 3D simulation in order to consider the effect of bounding walls. Since a relatively coarse mesh was used for computational ease in the 3D jet injection case, the results of the simulation are not used for studying individual velocity profiles. However, it is expected that there are enough grids to capture the bulk plume width with reasonable accuracy as seen from the match between the coarse and fine mesh plume sizes in the 2D case. The comparison shows that while both $2 \mathrm{D}$ and 3D simulations overestimate the plume width, the effect of walls (3D case) is to narrow down the width.
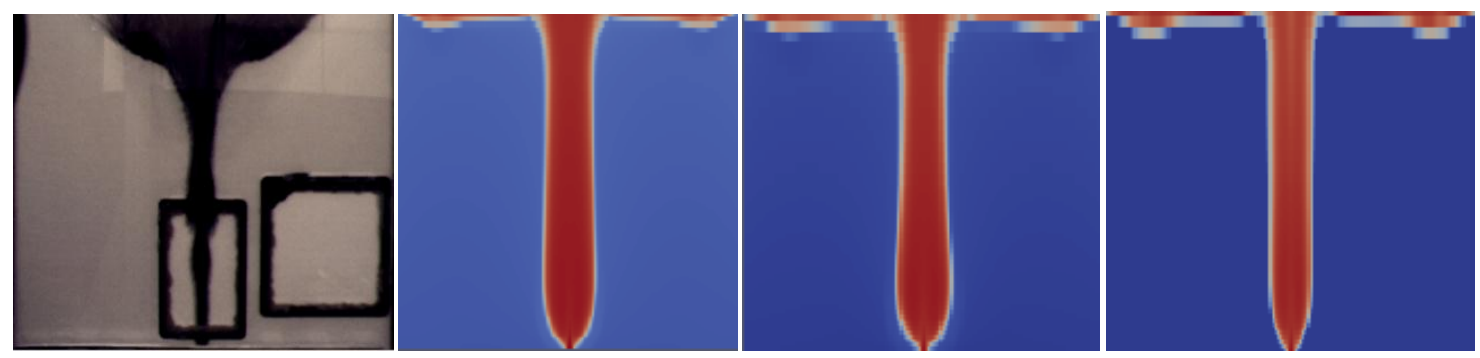

Figure 62: The bulk plume width estimated from photograph, compared to those estimated from concentration profiles. From left to right: experiment $=20 \mathrm{~mm}$; standard mesh $2 \mathrm{D}=70 \mathrm{~mm}$; coarse mesh $2 \mathrm{D}=70 \mathrm{~mm}$; coarse mesh $3 \mathrm{D}=50 \mathrm{~mm}$. 


\section{Conclusions}

A detailed experimental study of a jet penetrating a fluidized bed was conducted after a robust LDV technique to measure gas and particle velocities was developed. The mean and fluctuating, gas and particle velocity profiles inside the jet plume region have been reported and analyzed. The effect of fluidizing air on the mean and fluctuating profiles has been analyzed as well. The uncertainties associated with the experimental measurements have been studied.

Computational studies to investigate the effect of wall confinement on single-phase jets and fluidized beds have been conducted in order to enable a more accurate comparison of our experimental data with the widely studied two-dimensional cases. The sensitivity of minimum fluidization prediction to Eulerian frictional models employed has also been investigated. Additionally, the performance of some empirical, non-spherical minimum fluidization correlations has been studied.

The key findings of the project are summarized below.

(1) A procedure has been developed to simultaneously measure gas and particulate phase velocities based on LDV burst intensity and coincidence subranging. This technique has been implemented to obtain mean and fluctuating velocity profiles in a gas jet in a bubbling fluidized bed. In order to eliminate problematic Doppler signals due to frequency mixing, the LDV system must be optically configured to minimize the laser beam intensity fluctuations and the measurement volume oriented properly so that any remaining spurious signals can be easily filtered. Ice crystals were found to be a suitable tracer for high speed gas flows near viewing windows. These small gas tracers are on the order of the LDV fringe spacing in size and therefore produce low intensity bursts and can be readily differentiated from Doppler bursts produced by larger solid particles, which span several fringes and are on the order of the LDV measurement volume in size. The large solid particles require surface inclusions to produce Doppler signals; therefore the temporal coincidence criteria in a two-component system may be relaxed to increase the particulate phase burst count. The dynamic range of the photodector is adequate to capture the low intensity ice crystal gas tracer bursts as well as the high intensity solid particle bursts, yielding simultaneous gas and particulate phase velocity measurements.

(2) Gas and particulate phase velocity profiles in a gas jet plume in a bubbling 2D fluidized bed were obtained simultaneously via LDV burst intensity and coincidence subranging. The emulsion of Geldart Group B particles was fluidized approximately 15\% above minimum fluidization. The gas, particulate, and slip velocity profiles appear to be selfsimilar and Gaussian. When compared to the empty bed gas jet plume at the same inlet conditions, the gas phase velocity is significantly reduced though the plume width growth is similar. The particulate phase centerline velocity decreases downstream due to the entrainment of slow moving particles from the emulsion along the plume boundary. An average void fraction was calculated to be 95 to $96 \%$. The mass and momentum transport of the gas and particulate phases was calculated from the measured velocity profiles. The results reveal significant momentum transfer from the jet gas to the entrained particles. Mass flow calculations show considerable particle entrainment near the jet inlet while the 
amount of gas in the jet plume remains nearly constant at these bed conditions. Using the particulate and slip velocity profile data along with the particulate phase equation of motion, the particle drag coefficient was calculated and is found to be consistent with the established empirical value of 0.4. This indicates that high Reynolds number gas-particle drag is the dominant mechanism of momentum transfer and that particle-particle collisions are not significant in the dilute jet plume.

(3) Using an emulsion $838 \mu \mathrm{m}$ HDPE miropellets and maintaining the constant gas jet inlet conditions $\left(V_{j}=92 \mathrm{~m} / \mathrm{s}\right)$, the emulsion was fluidized at $V_{f l} / V_{m f}=0,0.7,1,1.15,1.3,1.5$. It was found that the maximum centerline velocity decreases and the velocity profile width increases for both phases with increasing fluidization. It was found that that void fraction increases with the fluidization state of the emulsion. The calculated gas phase mass flow rates suggest that that when the emulsion is fluidized below the minimum fluidization rate, gas originating from the jet inlet diffuses into the emulsion downstream to locally fluidize the particles as the gas phase mass flow decreases downstream. Above the minimum fluidization rate, interstitial gas and bubbles in the emulsion are entrained into the jet plume as the gas phase mass flow increases downstream. Likewise, as the fluidization rate increases, the gas phase momentum increases due to increased interstitial gas entrainment. The particulate phase mass flow and momentum rates decrease with increasing fluidization due to competition with the increased interstitial gas entrainment. It was noted that the ratio of the maximum velocities for the gas and particulate phases appeared to be independent of fluidization and an explanation for this behavior was offered.

(4) Using the same LDV technique, radial profiles of axial velocity fluctuations for different fluidized states of the emulsion were found. A qualitative insight on the role of emulsion fluidization in the turbulent flow by analyzing the variation in fluctuating velocities along the jet centerline with change in fluidization rate has been proposed. It is estimated that the gas flow within a packed bed causes additional entrainment of gas and particles from the emulsion phase into the jet plume at the cost of no variation in the jet spreading width. This results in a small decrease in velocity fluctuations in both phases on increasing distributor gas rate when below minimum fluidization. On the other hand, free mixing between the emulsion and the jet is achieved once minimum fluidization is reached. This widens the jet spreading width, thereby increasing velocity fluctuations with increase in distributor gas rate. It is expected that the fluctuations in the particle phase enhances gas turbulence, though further quantitative analysis is required to assess the importance of this mechanism.

(5) Some comparisons of minimum fluidization correlations were made with the experimentally obtained value for cylindrical polycarbonate particles. It was found that all the correlations overestimate the minimum fluidization velocity to an extent. Ergun's correlation matches closest to the experimental value and the predictions based on drag are highly sensitive to the projected area under consideration. 
(6) A CFD investigation revealed that spanwise confined single-phase jets exhibit a combination of free shear and wall shear characteristics. Free shear dominates at small distances downstream from the jet orifice, but wall shear becomes prominent as the jet half-width length scale becomes comparable to the spanwise width. Following this, the flow is characterized by a more gradual streamwise decay, less sharp spreading behavior and a drop in turbulent kinetic energy due to the influence of walls on the free shear. This transition point is not achieved within 70 jet diameters downstream when the spanwise width is greater than 16 jet diameters. For the spanwise width used in the experimental setup which is $\sim 2$ jet diameters, the wall effects come into play only at streamwise distances greater than 15 jet diameters, which is beyond our measurement region.

(7) It was found that the prediction of minimum fluidization obtained from simulations is highly sensitive to the frictional pressure expression but does not depend on the frictional viscosity equation. A value of $F r=0.05 \mathrm{~Pa}$ yields the best match of the minimum fluidization with the experimental value. Thus, the fluidization experiment can be used favorably to validate any frictional pressure model independent of the form of frictional viscosity being used.

(8) Finally, a CFD study on the sensitivity of frictional models in predicting the flow caused by a jet injection into a packed bed was conducted. While it was found that the frictional models differ primarily in the way the gas and particle half-plume widths and centerline velocities are captured as a function of downstream distance, the study was inconclusive as to which model performs best overall. However, numerical oscillations in the mean velocities were found in SRO, SS and Solid-strain models and were absent in Savage model suggesting that Savage is preferable. It was also found that the effect of bounding walls is to decrease the bulk plume size. 


\section{List of figures and tables}

Figure 1: Vertical gas jet in the laboratory 2D bubbling fluidized bed and corresponding sketch......

Figure 2: Velocity histogram for bed particles and gas tracer ice crystals measured in a jet plume before and after subranging

Figure 3: The simulation domain.

Figure 4: An example of the unphysical behavior observed when doing a 2D single-phase jet simulation using kepsilon model. The jet locks to one side of the domain.

Figure 5: Gas phase velocity profile

Figure 6: Gas velocity profile normalized by $\mathrm{x} /\left(\mathrm{y}-\mathrm{y}_{\mathrm{o}}\right)$

Figure 7: Normalized gas phase velocity profiles scaled with respect to the half-velocity points and compared to the Gaussian profile

Figure 8: Gas phase velocity profiles

Figure 9: Particulate phase velocity profiles.

Figure 10: Slip velocity profiles

Figure 11: Particle Reynolds number profiles

Figure 12: Normalized gas phase velocity profiles scaled with respect to the empty bed virtual origin

Figure 13: Normalized particle phase velocity profiles scaled with respect to the empty bed virtual origin

Figure 14: Half-velocity point values for the gas, particulate, and slip velocity profiles compared to the empty bed gas phase data

Figure 15: Maximum velocity values for the gas, particulate, and slip velocity profiles compared to the empty bed gas phase data.

Figure 16: Void fraction values determined from a momentum balance

Figure 17: Gas and particulate phase mass flow rates in the jet plume determined from the Gaussian profiles and calculated void fractions. The two-phase data is compared to the empty bed gas phase data.

Figure 18: Gas and particulate phase momentum rates in the jet plume determined from the Gaussian profiles and calculated void fractions. The empty bed gas phase momentum rate remains constant at the inlet value.

Figure 19: Maximum velocity values for the gas phase with varying fluidization velocity compared with the empty bed data. The momentum transfer from the gas to the particulate phase significantly reduces the maximum velocity values. 
Figure 20: Maximum velocity values for the gas phase with varying fluidization velocity. Increasing the fluidization velocity tends to decrease the maximum velocity values.

Figure 21: Maximum velocity values for the particulate phase with varying fluidization velocity. Increasing the fluidization velocity tends to decrease the maximum velocity values. .......

Figure 22: Ratio of the maximum velocity values for the gas and particulate phase with varying fluidization velocity. The ratio of maximum velocities appears to be independent of the fluidization velocity. . .24

Figure 23: Half-velocity point values for the gas phase with varying fluidization velocity compared with the empty bed data. The gas phase velocity profile width at minimum fluidization is comparable to the empty bed. Increasing the fluidization velocity tends to widen the velocity profile.

Figure 24: Half-velocity point values for the particulate phase with varying fluidization velocity. Increasing the fluidization velocity tends to widen the velocity profile.

Figure 25: Ratio of the half-velocity point values for the gas and particulate phases with varying fluidization velocity. Increasing the fluidization velocity tends to widen the gas velocity profile with respect to the particulate phase velocity profile as more interstitial gas is entrained.

Figure 26: Void fraction values with varying fluidization velocity. Increasing the fluidization velocity tends to increase the void fraction in the jet plume.

Figure 27: Mass flow rates for the gas phase with varying fluidization velocity compared with the empty bed data and jet inlet value.

Figure 28: Mass flow rates for the particulate phase with varying fluidization velocity. As the fluidization rate increases, the particulate phase mass flow decreases due to competition with the increased interstitial gas entrainment.

Figure 29: Momentum rates for the gas phase with varying fluidization velocity. As the fluidization rate increases, the gas phase momentum increases due to increased interstitial gas entrainment.

Figure 30: Momentum rates for the particulate phase with varying fluidization velocity. As the fluidization rate increases, the particulate phase momentum decreases due to competition with the increased interstitial gas entrainment.

Figure 31: Comparison of fluctuating velocity in the Empty bed, case 1, with planar, single-phase turbulent jet data from literature.

Figure 32: Radial variation in gas axial fluctuating velocity for different experimental cases at $y / \mathrm{D}_{\mathrm{j}}=7.61 \ldots \ldots \ldots \ldots . .32$

Figure 33: Radial variation in gas axial fluctuating velocity for different experimental cases at $y / \mathrm{D}_{\mathrm{j}}=10.87 \ldots \ldots \ldots \ldots .32$

Figure 34: Radial variation in gas axial fluctuating velocity for different experimental cases at $y / \mathrm{D}_{\mathrm{j}}=14.13 \ldots \ldots \ldots \ldots .33$

Figure 35: Radial variation in particle axial velocity fluctuations for different experimental cases at $y / D_{j}=7.61 \ldots . .33$

Figure 36: Radial variation in particle axial velocity fluctuations for different experimental cases at $y / D_{j}=10.87 \ldots .34$ 
Figure 37: Radial variation in particle axial velocity fluctuations for different experimental cases at $y / D_{j}=14.13 \ldots .34$

Figure 38: Axial gas fluctuating velocity along the centerline for different experimental cases ................................35

Figure 39: Axial particle fluctuating velocity along the centerline for different experimental cases .........................35

Figure 40: Variation in the ratio of gas half plume width to maximum axial velocity for different experimental cases

Figure 41: Change in ratio of particle half plume width to maximum axial velocity for different experimental cases

Figure 42: LDV gas and particulate phase velocity measurements at

Figure 43: Evolution of fluctuation statistics for gas tracer (a) and bed particles (b), at $y=70 \mathrm{~mm}$ and $\mathrm{x}=1.5 \mathrm{~mm}$ $\left(\mathrm{y} / \mathrm{D}_{\mathrm{j}}=7.61\right.$ and $\left.\mathrm{x} / \mathrm{x}_{1 / 2}=0.237\right)$ for case 2 , Spouted Bed..

Figure 44: Gas phase velocity profiles at $\mathrm{y}=100 \mathrm{~mm}$

Figure 45: Particulate phase velocity profiles at $\mathrm{y}=100 \mathrm{~mm}$

Figure 46: Repeatability in the measurement of fluctuating intensities of particle and gas phases at $y / D_{j}=10.87$ for case $5, \mathrm{~V}_{\mathrm{fl}} / \mathrm{V}_{\mathrm{mf}}=1.15$.

Figure 47: Steamwise centerline mean velocity decay in a single-phase jet ........................................................46

Figure 48: Streamwise variation in centerline turbulent kinetic energy in a single-phase jet...................................46

Figure 49: Streamwise variation in jet half-width in a single-phase jet...............................................................4

Figure 50: Non-normalized streamwise turbulent viscosity profiles in a single-phase jet.........................................47

Figure 51: Fluidization curve in the confined and non-confined simulations.........................................................48

Figure 52: Fluidization curve for SRO and Savage frictional models as function of Fr (in Pa) ................................50

Figure 53: Fluidization curve for $\mathrm{Fr}=0.05 \mathrm{~Pa}$ as a function of frictional viscosity expression .................................50

Figure 54: Concentration profiles (voidage) at $\mathrm{t}=1.5 \mathrm{~s}$ for different frictional models .............................................51

Figure 55: Evolution of centerline gas and particle phase velocity with time for different frictional models .............52

Figure 56: Non-dimensional gas phase profile for different frictional models .........................................................53

Figure 57: Non-dimensional particle phase profile for different frictional models .................................................53

Figure 58: Centerline gas phase velocity decay for different frictional models ......................................................54

Figure 59: Gas phase plume half-width increase for different frictional models.......................................................54

Figure 60: Centerline particle phase velocity decay for different frictional models .................................................55 
Figure 61: Particle phase plume half-width increase for different frictional models

Figure 62: The bulk plume width estimated from photograph, compared to those estimated from concentration profiles.

Table 1: LDV parameters. The system was optimized for maximum laser beam power and minimal laser beam intensity fluctuation complications.

Table 2: Summary of the continuum approach employed (www.mfix.netl.doe.gov) .......................................... 8

Table 3: Momentum rates in the jet plume determined from the Gaussian profiles. .............................................13

Table 4: Particle drag coefficients calculated from equation..........................................................................21

Table 5: Particle drag coefficients. The values were determined in the same manner as described earlier, using the Gaussian particulate phase and slip velocity profiles along with the calculated void fraction values.

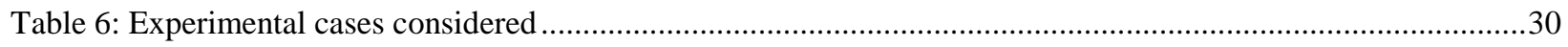

Table 7: Minimum fluidization correlations for non-spherical particles ....................................................43

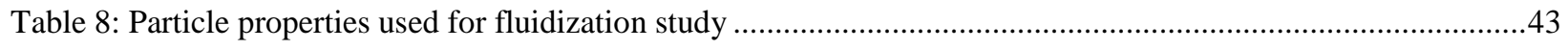

Table 9: Results of minimum fluidization prediction for cylindrical particles ................................................44

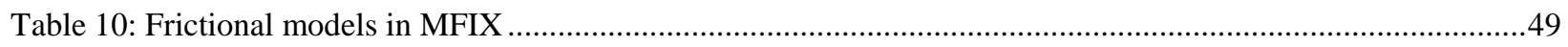




\section{References}

Akhtar, K., "Numerical Investigation using RANS Equations of Two-dimensional Turbulent Jets and Bubbly Mixing Layers," Virginia Polytechnic Institute, Master's Thesis (2010).

Alnahhal, M., and Panidis, T.H., "The effect of sidewalls on rectangular jets," Experimental Thermal and Fluid Science, 33 (2009) 838.

Anderson, T.B. and Jackson, R., "A fluid mechanical description of fluidized beds," Ind. Eng. Chem. Fundam., 6 (1967) 527.

Chien, S.F., "Settling velocity of irregular shaped particles," SPE Drilling and Completion, 9 (1994) 281.

Chitester, D.C., Kornosky, R.M., Fan, L.S., and Danko, J.P., "Characteristics of fluidization at high pressure," Chem. Eng. Sci., 39 (1984) 253.

Deo, R.C., Mi, J., and Nathan, G.J., "The influence of nozzle aspect ratio on planar jets," Experimental Thermal and Fluid Science, 31 (2007) 825.

Ergun, S., "Flow through packed columns," Chem. Eng. Prog., 48 (1952) 89.

Filla, M., Massimilla, L., and Vaccaro, S., "Gas jets in fluidized beds and spouts: A comparison of experimental behavior and models," Can. J. Chem. Eng., 61 (1983) 370 .

Flemmer, R.L.C., Picket, J., and Clark, N. N., "An experimental study on the effect of particle shape on fluidization behavior," Powder Technol., 77 (1993) 123.

Ganser, G.H., "A rational approach to drag prediction of spherical and nonspherical particles," Powder Technol., 77 (1993) 143.

Gutmark, E., and Wygnanski, I., “The planar turbulent jet,” J. Fluid Mech., 73 (1976) 465.

Haider, A., and Levenspiel, O., "Drag coefficient and the terminal velocity of spherical and nonspherical particles," Powder Technol., 58 (1989) 70.

Johnson, P.C., and Jackson, R., "Frictional-collisional constitutive relations for granular materials with application to plane shearing," J. Fluid Mech., 176 (1987) 67.

Khan, A.R., and Richardson, J.F., "Fluid particle interactions and flow characteristics of fluidized beds and settling suspensions of spherical particles," Chem. Eng. Comm., 78 (1989) 111.

Kuipers, J.A.M, "A two-fluid micro balance model of fluidized beds," PhD Thesis, Univ. of Twente, The Netherlands (1990). 
Lippens, B.C., and Mulder, J., "Prediction of the minimum fluidization velocity," Powder Technol., 75 (1993) 67.

Lun, C., Savage, S., Jeffrey, D. and Chepurniy, N., "Kinetic Theories for Granular Flow Inelastic Particles in Couette Flow and Slightly Inelastic Particles in a General Flow Field", $J$. Fluid Mech., 140 (1984) 223.

Merry, J.M.D., "Penetration of a horizontal gas jet into a fluidized bed," Trans. Instn. Chem. Engrs., 49 (1971) 189.

Merry, J.M.D., "Penetration of vertical jets into fluidized beds," AIChE J., 21 (1975) 507.

Miller, D.R., and Comings, E.W., "Static pressure distribution in the free turbulent jet," J. Fluid Mech., 3 (1957) 1.

Mychkovsky, A.G., "LDV measurements and analysis of gas and particulate phase velocity profiles in a vertical jet plume in a 2D bubbling fluidized bed," University of Michigan, Doctoral Dissertation.

Mychkovsky, A.G., and Ceccio, S.L., "The effect of emulsion fluidization on the gas and particulate transport of a high-speed jet plume in a two-dimensional bubbling bed," Powder Technol., submitted (2010).

Mychkovsky, A.G., Chang, N.A., and Ceccio, S.L., "Bragg cell laser intensity modulation: effect on laser Doppler velocimetry measurements," Appl. Opt., 48 (2009) 3468.

Mychkovsky, A.G., Rangarajan, D., and Ceccio, S.L., "An LDV technique for simultaneous measurements of gas and particulate phase velocity profiles in a high-speed jet plume in a 2D bubbling fluidized bed," Powder Technol., submitted (2010).

Ounnar, A., Arrar, J. and Bentahar, F., "Hydrodynamic behaviour of upflowing jet in fluidized bed: velocity profiles of sand particles," Chem. Eng. Process, 48 (2009) 617.

Rhodes, M., "An introduction to particle technology," Wiley, 2008, Second Edition

Richardson, J.F., and Zaki, W.N., "Sedimentation and Fluidisation: Part I," Trans. Inst. Chem. Eng., 32 (1954) 35.

Roach, P.E., "The penetration of jets into fluidized beds," Fluid Dyn. Res., 11 (1993) 197.

Savage, S.B., "Analysis of slow high-concentration flows on granular materials," J. Fluid Mech., 377 (1998) 1.

Srivastava, A., and Sundaresan, S., "Analysis of a frictional-kinetic model for gas-particle flow," Powder Technol., 129 (2003) 72. 
Symlal, M., Rogers, W. and O' Brien, T.J., "MFIX documentation: Theory Guide," U.S. Department of Energy, https://mfix.netl.doe.gov/documentation/Theory.pdf.

Wen, C.Y., and Yu, Y.H., "A generalized method for predicting the minimum fluidization velocity,” AIChE J., 12 (1966) 610.

White, F.M., “Viscous Fluid Flow,” McGraw-Hill, (2006).

Xuereb, C., Laguerie, C., and Baron, T., "Etude du comportement de jets continues horizontaux ou inclines introduits dans un lit fluidise par un gaz I: Morphologie des jets," Powder Tech., 67 (1991) 46.

Xuereb, C., Laguerie, C., and Baron, T., "Etude du comportement de jets continues horizontaux ou inclines introduits dans un lit fluidise par un gaz Deuxieme partie: profiles de vitesse du gaz dans les jets horizontaux," Powder Tech., 64 (1991) 271.

Xuereb, C., Laguerie, C., and Baron, T., "Etude du comportement de jets continues horizontaux ou inclines introduits dans un lit fluidise par un gaz III: modelisation de la zone d'ecoulement developpe du jet," Powder Tech., 72 (1992) 7. 


\section{Nomenclature}

\begin{tabular}{|c|c|}
\hline$A r$ & Archimedes' Number \\
\hline$C_{D}$ & Particle drag coefficient \\
\hline$D$ & Diameter \\
\hline$e$ & Coefficient of restitution between particles \\
\hline$e_{w}$ & Coefficient of restitution between particle and wall \\
\hline$F_{r}, r, s$ & Constants in the frictional pressure equation \\
\hline$F_{D}$ & Drag term in the Eulerian equations \\
\hline$g$ & Acceleration due to gravity \\
\hline$H$ & Height of emulsion with respect to fluidization distributor surface \\
\hline$\dot{j}$ & Momentum rate \\
\hline$\dot{m}$ & Mass flow rate \\
\hline$\dot{m}_{o}$ & Mass flow rate of gas that originates at the jet inlet orifice \\
\hline$P$ & Pressure \\
\hline$P_{c}$ & Critical state pressure \\
\hline$p$ & Pressure \\
\hline$\dot{Q}$ & Volumetric flow rate \\
\hline $\operatorname{Re}$ & Reynolds number \\
\hline$T$ & Temperature \\
\hline$v$ & Vertical component of velocity \\
\hline$V$ & Spatially averaged, vertical component of velocity \\
\hline$w$ & Width of the bed gap \\
\hline$x$ & Transverse (horizontal) coordinate \\
\hline$x_{1 / 2}$ & Half-velocity point \\
\hline$y$ & Axial (vertical) coordinate \\
\hline$y_{o}$ & Virtual origin location \\
\hline$z$ & $3^{\text {rd }}$ dimension coordinate across the bed gap \\
\hline
\end{tabular}




\section{Greek Letters}

$\varepsilon$

$\rho$

$\mu$

$\sigma_{\mathrm{s}}$

$\tau_{\mathrm{g}}$

$\phi$

v

\section{Subscripts}

$f$

$g$

j

$f l$

m

$m f$

$p$

S

sv

v

Acronyms

HDPE

LDV

2D

3D
Volumetric void fraction

Density

Viscosity

Solid-phase stress comprising the frictional stress $\left(\sigma_{\mathrm{f}}\right)$ and kinetic stress $\left(\sigma_{\mathrm{k}}\right)$

Gas-phase shear stress comprising the viscous $\left(\tau_{\text {vis }}\right)$ and turbulent $\left(\tau_{\text {tur }}\right)$ stresses

Specularity coefficient

Solids fraction

Frictional

Gas phase

Jet inlet value

Fluidization

Maximum transverse value at a given axial distance

Minimum fluidization

Particulate phase

Slip

Based on surface area to volume ratio

Based on volume

High density polyethylene

Laser Doppler velocimetry

Two dimensional

Three dimensional 


\section{Final Budget}

\begin{tabular}{|c|c|c|c|c|c|c|c|}
\hline $\begin{array}{l}\text { Project Grant \#: } \\
\text { Title: } \\
\text { Project Director: } \\
\text { Sponsor: } \\
\text { Project Period: } \\
\text { Budget Period: } \\
\text { Fund: } \\
\text { Program: } \\
\text { IC Rate: } \\
\end{array}$ & $\begin{array}{l}\text { FOO227383 } \\
\text { AStudy of Hor } \\
\text { Steven L. Cecc } \\
\text { DOE } \\
1 / 1 / 09-1 / 18 / 201 \\
1 / 1 / 09-1 / 18 / 201 \\
20000 \\
10000 \\
52 \% \\
\end{array}$ & $\begin{array}{l}\text { izontal Gas Jets } \\
\text { io } \\
1 \\
1\end{array}$ & $\begin{array}{l}\text { DRDA\#: } \\
\text { Payment Type: } \\
\text { FDP: }\end{array}$ & \begin{tabular}{|l|}
$08-5666$ \\
Cost Reimbursement \\
Yes \\
\end{tabular} & $\begin{array}{l}\text { DeptID: } \\
\text { iClass: } \\
\text { Reconciled as of : }\end{array}$ & $\begin{array}{c}222500 \\
22000 \\
1 / 31 / 11 \\
\\
\text { nt Fringe Rate: }\end{array}$ & \\
\hline Budget Category & $\begin{array}{c}\text { Budget } \\
\text { Account }\end{array}$ & $\begin{array}{c}\text { Authorized } \\
\text { Budget }\end{array}$ & $\begin{array}{l}\text { Project to Date } \\
\text { Expenditures }\end{array}$ & Project Balance & Encumbrances & $\begin{array}{l}\text { \%of Budget } \\
\text { Expended }\end{array}$ & $\begin{array}{c}\text { Available } \\
\text { Balance }\end{array}$ \\
\hline Research Salanies & 971000 & 51.170 .00 & $30,542.41$ & $20,567.59$ & $(1,851.73)$ & $36 \%$ & $22,419.32$ \\
\hline Adm. Salaries (A-21 Monitored) & 911100 & & - & - & - & & - \\
\hline $\begin{array}{l}\text { Clerical Sal. (A-21 Monitored) } \\
\text { SRO Salaries }\end{array}$ & $\begin{array}{l}911200 \\
911250\end{array}$ & & - & - & - & & - \\
\hline Fringe Benefits & 911300 & $15,334.00$ & $5,838.78$ & $9,495.22$ & (133.73) & $37 \%$ & 8,628.95 \\
\hline Tuition Waiver & 911400 & $37,056.00$ & $12,555.00$ & $24,501.00$ & - & $34 \%$ & $24,501.00$ \\
\hline Consultants & 911500 & & - & - & - & & - \\
\hline Respondents/Subjects & 911550 & & 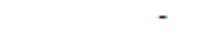 & - & - & & - \\
\hline Stipende & 911600 & & - & - & - & & - \\
\hline Student Aid & 911650 & & - & - & - & & - \\
\hline Patient Care & 911700 & & - & - & - & & - \\
\hline $\begin{array}{l}\text { Gen. Supplies (A-21 Monitored) } \\
\text { Research Supplies \& Sevices }\end{array}$ & $\begin{array}{l}911800 \\
911900\end{array}$ & $\begin{array}{l}4,300.00 \\
5,60000\end{array}$ & $\begin{array}{r}154.31 \\
77.229 .53\end{array}$ & $\begin{array}{r}4.145 .69 \\
(71,629.53)\end{array}$ & $(4,259.05)$ & $\begin{array}{c}4 \% \\
1303 \%\end{array}$ & $\begin{array}{r}4,145.69 \\
(87,370.48)\end{array}$ \\
\hline Data Processing & 911250 & $5,6000.00$ & $17,228.33$ & $(7,028-23)$ & $(4,200,05)$ & $1303 \%$ & $(67,3 / 0.48)$ \\
\hline Postage (A-21 Monitored) & 812000 & & - & - & - & & - \\
\hline Telephone (A-21 Monitored) & 912100 & & - & - & - & & - \\
\hline Pass Through Un & 912200 & & - & - & - & & - \\
\hline Pass Through Over \$25K & 912300 & & - & - & - & & - \\
\hline Alterations and Renovations & 912400 & & 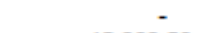 & - & - & & \\
\hline Travel Domestic & 912500 & $6,000.00$ & $10,363.56$ & $(4,363.56)$ & - & $173 \%$ & $(4,363.56)$ \\
\hline Travel-Foreign & 912550 & & 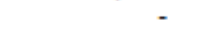 & 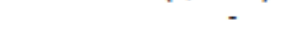 & - & & - \\
\hline Hosting (A-21 Monitored) & 912590 & & - & - & - & & - \\
\hline Equip & 912600 & $12,000.00$ & $60,559.90$ & $(48,559.90)$ & $(78,559.90)$ & $-150 \%$ & $30,000.00$ \\
\hline Transfers & 912700 & & 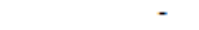 & - & - & & \\
\hline Computing Center & 912800 & & - & - & - & & - \\
\hline ory Animal Medicine & 912900 & & - & - & - & & - \\
\hline Serv non-MTDC & 913000 & & - & - & - & & - \\
\hline Budget To Be Allocated & 999998 & - & - & - & - & & - \\
\hline Unallocated & 999999 & & 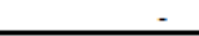 & - & 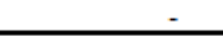 & & - \\
\hline \multicolumn{2}{|c|}{ Total Direct Cost } & $131,400.00$ & $197,243.49$ & $(65,843.49)$ & $(84,804.41)$ & $86 \%$ & $18,960.92$ \\
\hline Indirect Cost & 813400 & $42,812.00$ & $64,546.86$ & $(21,727.86)$ & $(3,247.15)$ & $143 \%$ & $(18,480.71)$ \\
\hline Total for $\mathrm{k}$ & & $174,219.00$ & $261,790.35$ & (87,571.35) & (88,051.56) & $100 \%$ & 480.21 \\
\hline
\end{tabular}




\section{Milestones}

\begin{tabular}{|c|c|c|c|c|c|c|c|c|c|c|c|c|c|c|}
\hline \multirow{3}{*}{$\begin{array}{c}\text { Task } \\
\#\end{array}$} & \multirow{3}{*}{$\begin{array}{l}\text { Project Milestone } \\
\text { Description }\end{array}$} & \multicolumn{8}{|c|}{ Start:1/1/09 End: 12/30/10 } & \multirow{3}{*}{$\begin{array}{l}\text { Planned } \\
\text { Start Date }\end{array}$} & \multirow{3}{*}{$\begin{array}{l}\text { Planned } \\
\text { End Date }\end{array}$} & \multirow{3}{*}{$\begin{array}{l}\text { Actual } \\
\text { Start Date }\end{array}$} & \multirow{3}{*}{$\begin{array}{l}\text { Actual End } \\
\text { Date }\end{array}$} & \multirow{3}{*}{$\begin{array}{l}\text { Comments (explanation of } \\
\text { deviation from plan) }\end{array}$} \\
\hline & & \multicolumn{4}{|c|}{ Project Year 1} & \multicolumn{4}{|c|}{ Project Year 2} & & & & & \\
\hline & & Q1 & Q2 & Q3 & Q4 & Q5 & Q6 & Q7 & Q8 & & & & & \\
\hline 1 & $\begin{array}{l}\text { Revise and maintain } \\
\text { PMP }\end{array}$ & $\mathrm{x}$ & & & & & & & & $1 / 1 / 2009$ & $12 / 30 / 2010$ & $1 / 1 / 2009$ & $12 / 30 / 2010$ & completed \\
\hline 2.1 & $\begin{array}{l}\text { Setup and Calibrate } \\
\text { LDV }\end{array}$ & $\mathrm{x}$ & $\mathrm{x}$ & & & & & & & $1 / 1 / 2009$ & $2 / 15 / 2009$ & $1 / 1 / 2009$ & $7 / 10 / 2009$ & $\begin{array}{c}\text { Issues with LDV measurements } \\
\text { have been reported and are of } \\
\text { technical interest }\end{array}$ \\
\hline \multirow[t]{2}{*}{2.2} & $\begin{array}{l}\text { Obtain LDV } \\
\text { measurements in 2D } \\
\text { bed }\end{array}$ & & & $\mathrm{x}$ & $\mathrm{x}$ & & & & & $3 / 1 / 2009$ & $5 / 1 / 2009$ & $5 / 10 / 2009$ & $9 / 15 / 2009$ & $\begin{array}{l}\text { Vertical jet has been fully tested } \\
\text { and characterized }\end{array}$ \\
\hline & $\begin{array}{l}\text { Learn MFIX code } \\
\text { and capabilities }\end{array}$ & $\mathrm{x}$ & $\mathrm{x}$ & & & & & & & $1 / 9 / 2009$ & $4 / 1 / 2009$ & $1 / 9 / 2009$ & $4 / 1 / 2009$ & completed \\
\hline 2.3 & $\begin{array}{l}\text { MFIX simulation of } \\
\text { 2D bubbling bed } \\
\text { with spherical } \\
\text { particles }\end{array}$ & & & & $\mathrm{x}$ & & & & & $3 / 1 / 2009$ & $6 / 30 / 2009$ & $9 / 1 / 2009$ & $12 / 1 / 2009$ & $\begin{array}{l}\text { This task has been delayed } 1 \\
\text { quarter in favor of non-spherical } \\
\text { particle constitutive modeling }\end{array}$ \\
\hline 3 & $\begin{array}{l}\text { Fiber Optic Probe } \\
\text { phase concentration } \\
\text { measurements }\end{array}$ & & & & & $\mathrm{x}$ & & & & $5 / 1 / 2009$ & $9 / 1 / 2009$ & $10 / 1 / 2009$ & $11 / 1 / 2009$ & $\begin{array}{c}\text { The focus remains on } \\
\text { simultaneous gas and particulate } \\
\text { phase LDV velocity } \\
\text { measurements }\end{array}$ \\
\hline $4.1 \mathrm{a}$ & $\begin{array}{l}\text { Developed new } \\
\text { constitutive models } \\
\text { for the } \\
\text { particle-phase stress } \\
\text { associated with non- } \\
\text { spherical particles }\end{array}$ & & & $\mathrm{x}$ & & & & & & $3 / 1 / 2010$ & $9 / 1 / 2010$ & $8 / 1 / 2009$ & 9/30/2009 & $\begin{array}{l}\text { All constitutive models have been } \\
\text { developed prior to bed simulation }\end{array}$ \\
\hline $4.1 \mathrm{~b}$ & $\begin{array}{l}\text { Design and Develop } \\
\text { an Imaging } \\
\text { Borescope }\end{array}$ & & & & & & & & & $10 / 1 / 2009$ & $7 / 1 / 2010$ & & & $\begin{array}{c}\text { The focus remains on } \\
\text { simultaneous gas and particulate } \\
\text { phase LDV velocity } \\
\text { measurements }\end{array}$ \\
\hline 4.2 & $\begin{array}{c}\text { Non-Spherical } \\
\text { Particle } \\
\text { Characterization in a } \\
\text { Gas Jet of a 2D } \\
\text { Bubbling Bed } \\
\end{array}$ & & & & $\mathrm{x}$ & & & & & $10 / 1 / 2009$ & $12 / 31 / 2010$ & $10 / 1 / 2009$ & & \\
\hline 3.4 & $\begin{array}{l}\text { MFIX validation } \\
\text { with experimental } \\
\text { results- } 2 \mathrm{~d} \text { and } 3 \mathrm{~d} \\
\text { cases }\end{array}$ & & & & & & $\mathrm{x}$ & $\mathrm{x}$ & & $3 / 1 / 2010$ & $9 / 1 / 2010$ & $3 / 1 / 2010$ & & $\begin{array}{l}\text { Good agreement between } \\
\text { simulation and experiment for } \\
\text { single phase }\end{array}$ \\
\hline 4.4 & $\begin{array}{l}\text { Fluidization } \\
\text { experiments with } \\
\text { non-spherical } \\
\text { particles }\end{array}$ & & & & & & $\mathrm{x}$ & & & $3 / 1 / 2010$ & $9 / 1 / 2010$ & $3 / 1 / 2010$ & & $\begin{array}{l}\text { Different non-spherical drag } \\
\text { models compared }\end{array}$ \\
\hline 2.4 & $\begin{array}{l}\text { LDV turbulence } \\
\text { measurements }\end{array}$ & & & & & & & $\mathrm{x}$ & & $3 / 1 / 2010$ & $9 / 31 / 2010$ & $3 / 1 / 2010$ & $9 / 31 / 2010$ & Completed and analyzed \\
\hline
\end{tabular}




\section{Publications}

\section{Published}

Mychkovsky, A.G., Chang, N.A., and Ceccio, S.L., "Bragg cell laser intensity modulation: effect on laser Doppler velocimetry measurements," Appl. Opt., 48 (2009) 3468.

\section{Submitted}

Mychkovsky, A.G., Rangarajan, D., and Ceccio, S.L., "An LDV technique for simultaneous measurements of gas and particulate phase velocity profiles in a high-speed jet plume in a 2D bubbling fluidized bed," Powder Technol., submitted (2010).

Mychkovsky, A.G., and Ceccio, S.L, "Gas and particulate phase velocity profiles of a high-speed gas jet into a two-dimensional bubbling fluidized bed," Powder Technol., submitted (2010).

Mychkovsky, A.G., and Ceccio, S.L., "The effect of emulsion fluidization on the gas and particulate transport of a high-speed jet plume in a two-dimensional bubbling bed," Powder Technol., submitted (2010).

\section{Being prepared}

Rangarajan, D., Mychkovsky, A.G., Curtis, J.S., and Ceccio, S.L., "Effect of emulsion fluidization state on the fluctuations in gas and particle velocities inside the plume of a gas jet penetrating a fluidized bed".

Rangarajan, D., and Curtis, J.S., "Effect of spanwise confinement on single-phase turbulent jets".

Acknowledgement: "This material is based upon work supported by

the Department of Energy [National Nuclear Security Administration] under Award Number DE-NT0007649." 